\title{
Assessment of cancer-associated biomarkers by positron emission tomography: Advances and challenges
}

\author{
T. Lee Collier ${ }^{\mathrm{a}}$, Roger Lecomte ${ }^{\mathrm{c}}$, Timothy J. McCarthy ${ }^{\mathrm{e}}$, Steve Meikle ${ }^{\mathrm{f}}$, Thomas J. Ruth ${ }^{\mathrm{d}}$, \\ Francesco Scopinaro ${ }^{\mathrm{g}}$, Alberto Signore ${ }^{\mathrm{g}}$, Henry VanBrocklin ${ }^{\mathrm{h}}$, Christophe Van de Wiele ${ }^{\mathrm{i}}$ and \\ Rikki N. Waterhouse ${ }^{\mathrm{b}, *}$ \\ ${ }^{\text {a }}$ PETNET Pharmaceuticals, North Wales, PA, USA \\ ${ }^{\mathrm{b}}$ Department of Psychiatry, Columbia University, New York, NY, USA \\ ${ }^{\mathrm{c}}$ Department of Nuclear Medicine and Radiobiology, Université de Sherbrooke, Québec, Canada \\ ${ }^{\mathrm{d}}$ UBC/TRIUMF PET Program, University of British Columbia, Canada \\ e Pharmacia, Peapack, NJ, USA \\ ${ }^{\mathrm{f}}$ Department of PET and Nuclear Medicine, Royal Prince Alfred Hospital, Sydney, Australia \\ ${ }^{g}$ Department of Nuclear Medicine, University "La Sapienza," Roma, Italy \\ ${ }^{\mathrm{h}}$ Department of Nuclear Medicine and Functional Imaging, Lawrence Berkeley National Laboratory, Berkeley CA, \\ USA \\ iDivision of Nuclear Medicine, University Hospital Ghent, Ghent, Belgium
}

\begin{abstract}
Positron emission tomography (PET) provides a powerful means to non-invasively image and quantify protein expression and biochemical changes in living subjects at nano- and picomolar levels. As the field of molecular imaging develops, and as advances in the biochemistry, pharmacology, therapeutics, and molecular biology of disease are made, there is a corresponding increase in the number of clinically relevant, novel disease-associated biomarkers that are brought to the attention of those developing imaging probes for PET. In addition, due to the high specificity of the PET radiotracers being developed, there is a demand for PET cameras with higher sensitivity and resolution. This manuscript reviews advances over the past five years in clinical and pre-clinical PET instrumentation and in new PET probes and imaging methods associated with the latest trends in the molecular imaging of cancer. Included in the PET tracer review is a description of new radioligands for steroid receptors, growth factor receptors, receptor tyrosine kinases, sigma receptors, tumor-associated enzymes, gene reporter probes, markers for tumor hypoxia and metabolism, and sites associated with angiogenesis and cellular proliferation. The use of PET imaging in drug development, including the monitoring of cancer chemotherapy, also is discussed.
\end{abstract}

\section{Introduction}

With respect to other imaging modalities, positron emission tomography (PET) provides a most sensitive

* Corresponding author: Rikki N. Waterhouse, Ph.D., Departmen of Psychiatry, New York State Psychiatric Institute (NYSPI) and Columbia University, 1051 Riverside Drive, Box 126, New York, NY 10032, USA. Tel.: +1 212543 6630; Fax: +1 212543 5854; E-mail: rnw7@columbia.edu. and powerful means to quantify protein expression and biochemical changes non-invasively in living subjects at nano- and picomolar concentrations. The entities evaluated by PET include, but are not limited to, receptors, enzymes, transporters, ion channels, mRNA, and specific substrate-associated sites such as $\beta$-amyloid plaques found in Alzheimer's disease. As the field of molecular imaging develops, and as advances in the biochemistry, pharmacology, therapeutics, and molecular biology of disease are made, there is a correspond- 
ing increase in the number of clinically relevant, novel disease-associated biomarkers that are brought to the attention of those developing imaging probes for PET. In addition, due to the high specificity of the PET radiotracers being developed, there is a demand for PET cameras with higher sensitivity and resolution. This manuscript reviews advances over the past five years in clinical and pre-clinical PET instrumentation and in new PET probes and imaging methods associated with the latest trends in the molecular imaging of cancer. Included in the PET tracer review is a description of new site-specific radioligands targeted to steroid receptors, sigma receptors, tumor-associated enzymes, receptor tyrosine kinases, growth factor receptors, gene reporter probes, markers of tumor hypoxia and metabolism, and sites associated with angiogenesis and cellular proliferation. The use of PET imaging in drug development, including the monitoring of cancer chemotherapy, also is discussed. While the text mainly is focused on technical advances in the field of tumor imaging by PET, specific examples of clinical studies also are provided where a significant point can be proven.

\section{Technical advances in small-animal and human PET scanners}

\subsection{Pre-clinical applications and small-animal imaging}

\subsubsection{Current state of the art}

Since the development of the first PET scanners about three decades ago, there have been dramatic advances in detector technology and imaging methodology that now make it possible to obtain threedimensional (3D) images of the time course and distribution of radiolabeled probes in vivo. Biomedical research studies in animal models can be conducted using clinical PET scanners designed for human use. Although some useful biological data can be collected in rats using these instruments, most studies are restricted to larger animals such as non-human primates (brain) and dogs or pigs (heart), and sometimes rabbits or cats, due to limitations in spatial resolution and sensitivity. The most recent breed of high-resolution research tomographs (HRRT) dedicated to brain imaging, which achieves a spatial resolution below $2.5 \mathrm{~mm}$, meets some of the challenges raised by imaging small laboratory animals such as rats. However, the limited accessibility and inadequate environment of clinical settings for animal experiments prevent widespread utilization of hu- man PET devices for pre-clinical studies. These limitations have brought several groups of researchers worldwide to develop PET scanners and establish facilities designed specifically for small-animal imaging.

Initial attempts to develop dedicated animal scanners were based on the block detector technologies currently employed in clinical PET cameras. Scanners developed by Hamamatsu in Japan [1], at the University of California, Los Angeles (UCLA) [2], and at Indiana University [3] offered relatively large axial and transaxial fields of view (FOV), which were sufficient to accommodate the brain of non-human primates or the chest of dogs. These systems achieved a transaxial resolution in the range of $2.6-3.8 \mathrm{~mm}$. The development of a smaller size system targeted specifically for rodent imaging at Hammersmith Hospital made it possible to reach a resolution of $2.4 \mathrm{~mm}$ [4]. Successful basic and pre-clinical research programs have been developed around these instruments, demonstrating for the first time the potential utility of small dedicated PET scanners for biomedical research. However, due to the asymmetric shape of individual crystal elements in the block detectors, the axial resolution was significantly worse, resulting in volumetric resolutions (transaxial resolution $^{2} \times$ axial resolution) of $\sim 25 \mu$ l or more. Due to the large depth of the crystals, the smaller diameter systems designed to enhance sensitivity also suffered from a non-uniform resolution that degrades rapidly away from the center of the FOV.

These pioneering works triggered a large number of innovative ideas focused on developing more appropriate detector technologies and scanner configurations for imaging rats and mice, the preferred animals for biomedical research. The challenge was to find ways to improve spatial resolution to the level required to resolve organs in these small animals, while achieving an adequate sensitivity for receptor imaging, and count-rate capabilities suitable for dynamic imaging of radiotracer biodistribution in pharmacokinetic studies. The cost of the scanners also needed to be low enough to remain competitive with other emerging imaging modalities for small-animal research [5-8].

Taking advantage of the capability of new positionsensitive and multi-channel photomultiplier tubes (PMTs), several novel detector schemes have been explored. These include thin continuous plates of sodium iodide $(\mathrm{NaI}(\mathrm{Tl}))$ or lutetium oxyorthosilicate (LSO) scintillators, 2D arrays of bismuth germanate (BGO) and LSO crystals, and linear arrays of 1-mm wide LSO coupled to position-sensitive PMTs, which allowed a spatial resolution down to less than $2 \mathrm{~mm}$ to be achieved 
over a reduced FOV. A system implementing the measurement of the depth-of-interaction (DOI) using dualcrystal LSO/gadolinium orthosilicate (GSO) phoswich detectors to improve resolution uniformity across the FOV recently was built at the National Institutes of Health (NIH) [9]. Two systems have been built based on yttrium aluminum perovskite (YAP), a very bright but low-density scintillator $[10,11]$. Using arrays of $2 \times$ $2 \mathrm{~mm}$ cross-section crystals coupled to large positionsensitive PMTs, an isotropic spatial resolution of close to $2 \mathrm{~mm}(\sim 9 \mu \mathrm{l})$ was achieved. Interestingly, a very low energy threshold was advocated to accept the first Compton interaction events in order to compensate for the poor detection efficiency of YAP without sacrificing spatial resolution [12]. All of the above systems, consisting of opposite banks of detectors mounted on gantries that allow variable separation to accommodate animals of different sizes, are very flexible, relatively inexpensive, and achieve a high spatial resolution suitable for tumor imaging in rat models. Unfortunately, this is obtained at the expense of a poor sensitivity and serious limitations for fast dynamic studies due to the incomplete ring configuration that requires the detectors (or the imaged subject) to be rotated to acquire complete tomographic data sets.

The physical size of presently available PMTs, with their bulky glass or metal envelope, actually prevents implementation of the continuous (or quasicontinuous) cylindrical configuration required to provide simultaneous acquisition of tomographic data over all incidence angles. Alternative detector technologies had to be sought in order to allow full angular coverage while satisfying the other requirements of small-animal PET imaging. The solution retained by researchers at UCLA to uncouple the scintillation crystals from the bulky PMTs was to use optical fibers to transport the scintillation light from individual $2 \times 2 \mathrm{~mm}$ LSO scintillators in a compact $8 \times 8$ crystal array to a distant photodetector [13]. In addition to allowing the detectors to be arranged in a continuous ring, the oneto-one coupling between crystals and individual channels of a 64-channel PMT was one significant improvement of this design, which avoided the inherent loss of spatial resolution resulting from the previous lightsharing schemes. An isotropic-reconstructed resolution of $1.8 \mathrm{~mm}$, or $\sim 6 \mu \mathrm{l}$ volumetric resolution, is obtained at the center of the FOV [14]. The positioning algorithm still makes use of charge-sharing on the resistive anode of the multi-channel PMT to identify the crystal of interaction, which restricts the achievable resolution to almost twice the crystal geometric resolu- tion and limits the maximum count-rate of the detector. Another limitation is the fair energy resolution resulting from loss of scintillation light in the optical fibers. Nonetheless, this has been the most successful animal PET scanner design yet, and Concorde Microsystems (Knoxville, TN) has commercialized it under the name microPET [15].

Other approaches that avoid the use of bulky PMTs have been investigated. These include the use of a photosensitive gas detector to read out the ultraviolet (UV) scintillation light from arrays of barium fluoride $\left(\mathrm{BaF}_{2}\right)$ scintillators [16] and the use of semiconductor photodetectors. Solid-state photon detectors have several inherent advantages over PMTs: high quantum efficiency, compact and flexible shape that can be adapted to individual crystals, ruggedness, and potentially inexpensive mass production. Standard unity-gain photodiodes currently do not achieve the required signalto-noise ratio to perform coincidence detection with scintillators in PET. They must be used in conjunction with another fast photodetector [17], or devices with an internal gain must be used [18]. The animal PET scanner developed at Université de Sherbrooke was the first imaging system to use silicon avalanche photodiodes (APD) to independently read out small discrete scintillation crystals [19].

This system is shown in Fig. 1. Since crystal identification can be performed unambiguously without having recourse to light or charge sharing, a reconstructed resolution of $2.1 \times 3.1 \mathrm{~mm}$ (transaxial $\times$ axial), or $14 \mu \mathrm{l}$ volumetric, is reached with this individual readout scheme even using fairly large $3 \times 5 \mathrm{~mm}$ BGO crystals [20]. Due to the low light output and slow decay time of BGO, the APDs had to be operated at high gain in conjunction with fast low-noise preamplifiers to achieve suitable coincidence time resolution $(\sim 15 \mathrm{~ns}$ full width at half-maximum peak height, FWHM), which in turn required tight regulation of APD bias voltage and temperature [21]. These drawbacks can be avoided almost completely by using the newer scintillator LSO, which is about seven times faster and three times more luminous than BGO, and several animal PET projects based on APD and LSO currently are under development.

Another original animal PET system marketed by Oxford Positron Systems (United Kingdom) is based on the multi-wire gas proportional chamber (MWPC) detector technology [22] combined with lead conversion plates to detect the $511 \mathrm{keV}$ annihilation radiation [23]. Although the High Density Avalanche Chamber (HIDAC) detectors have some inherent drawbacks (low detection efficiency, poor coincidence time res- 


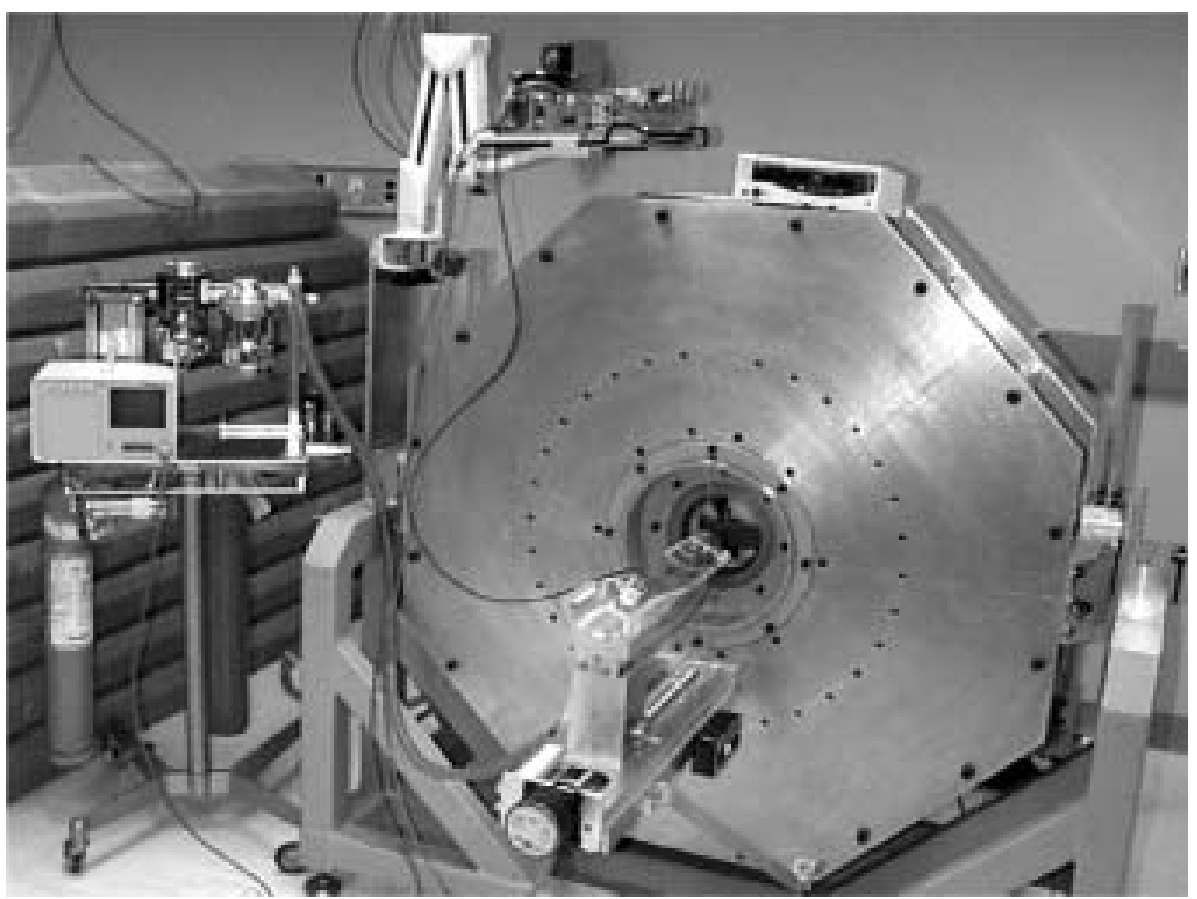

Fig. 1. Sherbrooke Small-Animal PET Scanner.

olution, no energy resolution), large area multi-layer stacks of lead converters can be manufactured at a very low cost to compensate for the low detection efficiency. The unique 3D detection capability of the HIDAC system provides the best spatial resolution in PET at the present time, reaching sub-millimeter resolution in the reconstructed image with advanced $3 \mathrm{D}$ iterative reconstruction techniques [24].

\subsubsection{Limitations}

One distinct feature of PET is its ability to provide quantitative information on biochemical processes in vivo. As in human PET studies, precise quantification of the tissue radioactivity concentration in small animals is dependent on the accuracy of corrections applied for photon attenuation and scattering in the subject and on partial volume effects. While the corrections for attenuation and scatter, which amount to only a few tens of percent overall at the most, are relatively easy to compensate for using standard methods without significantly affecting accuracy, partial volume potentially can be a significant source of error in quantification. This can be particularly serious in follow-up studies of tumor progression/regression in response to therapy, where the tumor metabolic activity may be underestimated severely when the size of the lesion approaches the resolution of the scanner. Similarly, identification and estimation of the radioactivity concentration in tumors or metastases may be altered due to spillover from high activity in adjacent structures. Methods involving resolution recovery or spectral analysis techniques have been proposed to compensate for partial volume and spillover effects. Ideally, an independent measurement of the size and shape of the object, by visual inspection or high-resolution anatomical imaging, would be required to apply appropriate corrections. Clearly, higher spatial resolution in PET would be helpful.

With the current PET detector technology, the resolution and quantitative accuracy achieved with dedicated small-animal imagers in the rat are grossly equivalent to what can be achieved in humans with state-ofthe-art clinical PET scanners. Achieving the same level of definition in the mouse is a challenging undertaking due to the limits imposed by physical (positron range, photon non-colinearity), chemical (specific activity), and biological (injected mass) constraints. However, millimeter resolution already has been demonstrated in in vivo images [24], and an isotropic resolution close to $1 \mathrm{~mm}(1 \mu \mathrm{l})$ probably will be achieved with the next generation microPET using $1 \times 1 \mathrm{~mm}$ needle crystals [25]. Several other detector designs that presently are being investigated will very likely allow the $\mathrm{mm}$ resolution barrier to be broken in PET in the near future (see below). 
In spite of improved spatial resolution, a complementary non-invasive high-resolution anatomical imaging modality often will be mandatory to overcome one adverse feature of PET images deriving from the major strength of PET imaging. The extremely high specificity with which new molecular probes are being tailored to be directed toward one particular membrane receptor or cellular target may result in PET images lacking proper anatomical landmarks to identify and localize uptake tissues. Suitable methods for coregistrating and fusing images from other micro-imaging modalities are required, or better multi-modality scanners combining magnetic resonance imaging (MRI) or computed tomography (CT) to PET would be desirable.

Other methodological issues must be addressed concurrently with the scanner characteristics if smallanimal PET imaging is to become a viable research tool in the biomedical sciences. Contrary to other non-invasive imaging modalities that provide information on anatomy and tissue composition, PET opens a unique window on the biochemistry, physiology, and function of living organisms at the molecular level. Not only is it necessary to immobilize the animal during the imaging procedure, the physiological conditions of the subject (depth of anesthesia, body temperature, glycemia, blood pressure and gas, ventilation, heart rate, etc.), which often will have an indirect effect on the biological parameters under investigation, must be controlled carefully throughout the imaging period and beyond. This is mandatory to ensure the reliability and reproducibility of the PET data in challenge studies where the same subject is used as its own control, but also in longitudinal studies where the same animal must be preserved to be scanned repeatedly over days, weeks, or even months.

Likewise, pharmacokinetic modeling of radiotracer distribution and metabolism requires that the blood input function, and sometimes the plasma concentration of labeled metabolites, be known. Repeated manual blood sampling in small animals, especially mice, requires sophisticated arterial cannulation techniques and is hazardous due to the limited blood volume that can be drawn safely. Automated, continuous microvolumetric blood sampling has been demonstrated [26] but remains a difficult task that requires skillful personnel. Dynamic, whole-body imaging using a large solid-angle scanner provides an alternative means to obtain the input function from the left ventricular blood pool, large vessels, or another reference tissue.

\subsubsection{Future research directions}

With proposed micro-crystal detector designs and innovative detector technologies achieving sub-millimeter intrinsic accuracy in the laboratory [25,27,28], the race to break the $\mathrm{mm}$ resolution barrier (or $\mu 1$ volumetric resolution) in PET is well underway. The several projects currently in progress that are based on photodiode and APD detector designs likely will provide the technological basis for further developments in this area.

Progress must be made in intrinsic detection efficiency and system sensitivity concurrently with resolution, however, in order to obtain the full benefit of the higher resolution in extracting information from images in real animal studies. Smaller systems with more efficient geometry and larger solid angles (up to $4 \pi$ [29]) must be considered. The measurement of the exact $3 \mathrm{D}$ coordinates of the position of detection (that is, region of interest, ROI) in addition to the identification of the crystal of interaction) in these compact detector systems becomes essential for uniform resolution across the FOV. Although the scintillation performance of crystals is crucial in micro-crystal detector designs, the intrinsic detection efficiency of the detector material also becomes a critical issue. Since the photoelectric interaction probability of currently available detectors is limited to $43 \%$ (BGO) or less, which means less than $20 \%$ photoelectric detection probability in coincidence, some consideration should be given to other detection paradigms, such as first interaction detection [30] and Compton imaging of positron emitters [31].

The necessity of collecting anatomical information in conjunction with the metabolic and functional data provided by PET has been recognized rapidly in clinical oncology. The same obviously applies for research in oncology using small-animal imaging, and researchers already are addressing this problem. The possibility of fully integrating PET and CT detectors into a single scanner system also is being investigated [32-34].

The availability of small-size position-sensitive PMTs and APD arrays, compact integrated electronics, and advanced position-tracking techniques now makes it possible to envision miniature, portable, or handheld PET cameras that can be used to image unanesthetized, unrestrained, free-moving animals. While these technological advances open the way to a wide range of research applications in living animals, significant progress remains to be made in merging this technology with current research practices in animal models.

Recent, more extensive reviews of PET-scanner technology dedicated to small-animal imaging and PET 
methodology for pre-clinical imaging studies can be found in [35-38].

\subsection{Current state-of-the-art in clinical PET instrumentation}

\subsubsection{Detector technologies}

\subsubsection{Inorganic scintillators used for PET}

BGO has been the scintillation material of choice in PET for the past 20 years, mainly due to its high effective $\mathrm{Z}$ and high density, which result in very good stopping power [39]. With BGO, $94 \%$ of all $511 \mathrm{keV}$ photons interact within a 30-mm thick detector, compared to only $36 \%$ for a $30-\mathrm{mm}$ thick $\mathrm{NaI}(\mathrm{Tl})$ detector. The light yield, however, is fairly low compared to $\mathrm{NaI}(\mathrm{Tl})$ (15-20\%), which results in a relatively poor but adequate energy resolution. The relatively long scintillation decay time constants of both BGO (300 ns) and $\mathrm{NaI}(\mathrm{Tl})$ (230 ns) limit the count-rate capabilities of systems using these scintillation materials and increase the acceptance of unwanted random coincidences relative to true coincidences. One other drawback of $\mathrm{NaI}(\mathrm{Tl})$ is that it is hygroscopic; i.e., it absorbs moisture from the environment and, therefore, must be hermetically sealed to prevent discoloration and reduced light output.

LSO and GSO are inorganic scintillators that were developed more recently that have several advantageous properties for use in PET [40,41]. Both have high effective $\mathrm{Z}$, high density, high light yield (75\% for LSO relative to $\mathrm{NaI}(\mathrm{Tl})$ and $30 \%$ for GSO), and short scintillation decay time (40 ns and $60 \mathrm{~ns}$, respectively). The higher light yield than BGO provides potentially improved energy resolution and better detector identification in arrays of small crystals, which should lead to better spatial resolution. The shorter scintillation decay time allows for a shorter coincidence time window, which reduces the acceptance of random coincidences, and shorter signal integration times should lead to improved count-rate performance compared with BGO systems. The performance of the first human research tomographs to employ LSO [42] and GSO [43] recently was described, and the first clinical scanners recently became available commercially.

\subsubsection{Detector designs}

Most current-generation BGO and LSO PET scanners are based on the block detector design [44]. In this design, grooves are cut in a block of scintillator material, creating a matrix of typically $8 \times 8$ detector elements whose light output is shared by four photo- multiplier tubes. Using current crystal-cutting technology, the individual detector elements reliably can be made as small as $4 \times 4 \mathrm{~mm}$, which can be identified uniquely by the position-encoding scheme, particularly in the case of bright scintillators such as LSO. The count-rate capability of ring systems is maintained because of the large number of detector blocks $(>200$ in a current-generation PET scanner), each of which has its own dedicated circuitry for performing signal integration and encoding of energy, position, and timing information.

A variation on the block design called quadrant sharing uses larger photomultiplier tubes, with each tube being centered over a corner of the block. Thus, each tube "sees" four adjacent blocks. As in the block detector, localized Anger logic is used to determine the crystal of interaction. In this design, many blocks can be abutted to each other to form a large flat panel detector, requiring approximately four times fewer photomultiplier tubes than an equivalent panel based on block detectors.

An alternative detector design is one in which many discrete crystals are coupled to an array of photomultiplier tubes via a continuous optical light guide [45]. The position of interaction is determined by a local centroid calculation involving a cluster of seven neighboring photomultiplier tubes centered on the tube with maximal signal amplitude. This design results in more or less even light distribution among all crystals, whereas the block design results in less light collection from edge crystals than from center crystals.

While block detectors can be made from $\mathrm{NaI}(\mathrm{Tl})$ crystal material, PET scanners using this scintillator tend to be based on a large-area detector design. In this design, the light output from the crystal slab is shared by several photomultiplier tubes, and positioning is determined by Anger logic as in a gamma camera. Because of the higher light output of $\mathrm{Na}(\mathrm{Tl})$ compared with BGO, positioning accuracy is very good, resulting in spatial resolution approaching that achieved in a full-ring PET scanner. However, generally there is a much higher degree of multiplexing (number of photomultiplier tubes per detector element) in such systems, resulting in inferior count-rate capability. Two example state of the art clinical PET scanners are provided in Figs 2 and 3.

\subsubsection{Dedicated PET systems}

\subsubsection{Ring detector tomographs}

The most common type of dedicated PET system comprises one or more complete rings of BGO or LSO 


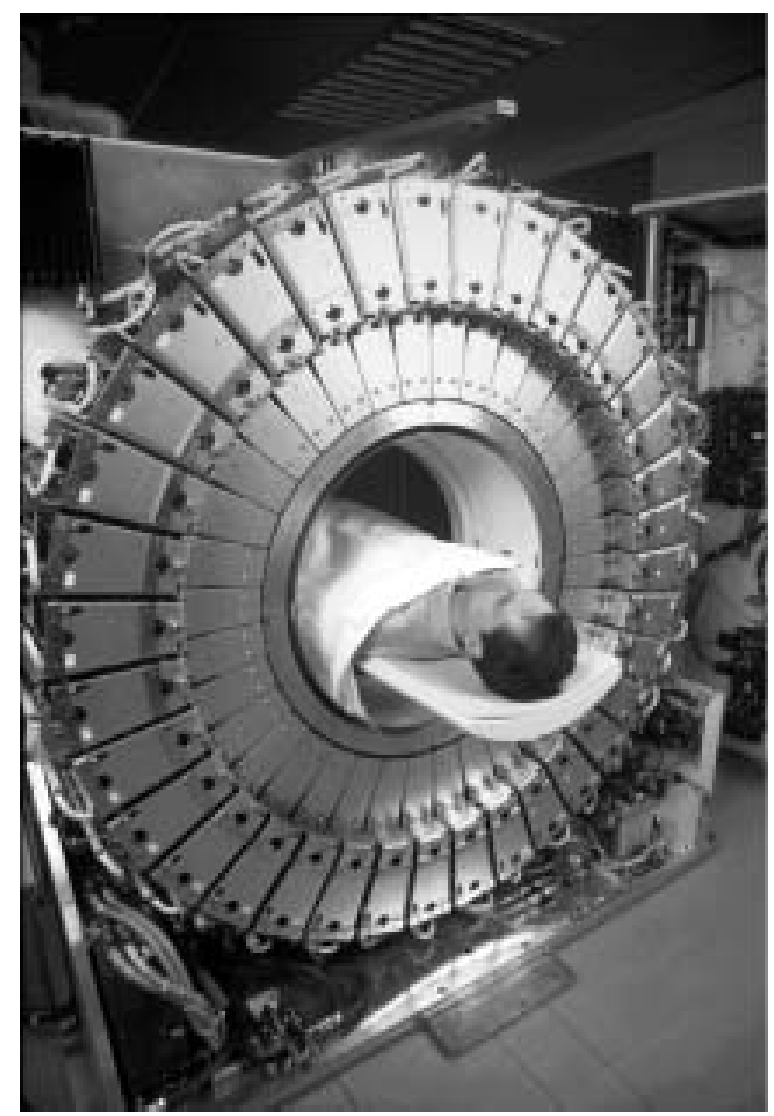

Fig. 2. A full-ring PET scanner based on the block-detector design. This image is reproduced with permission from Dale Bailey and CTI PET Systems.

block detectors surrounding the subject. Because data are recorded simultaneously from all projections surrounding the subject and because of the relatively high count-rate capability of the block detector design, such tomographs are well suited to a wide range of clinical studies employing steady-state protocols as well as kinetic studies. Clinical scanners usually are constructed with a ring diameter that is suitable for both brain and whole-body imaging (approximately $80 \mathrm{~cm}$ ), although dedicated brain units also are available. The axial FOV depends on the number of rings but typically is $10-20 \mathrm{~cm}$.

Another ring detector design is based on the continuous light guide and discrete GSO crystals [43]. In these tomographs, the continuous light guides are curved sectors which, when coupled together at their edges, form a complete ring with the crystal array on its inner surface and the photomultiplier tube on its outer surface. Such tomographs have been designed for brain and wholebody scanning with performance similar or better than other commercially available ring tomographs [43].

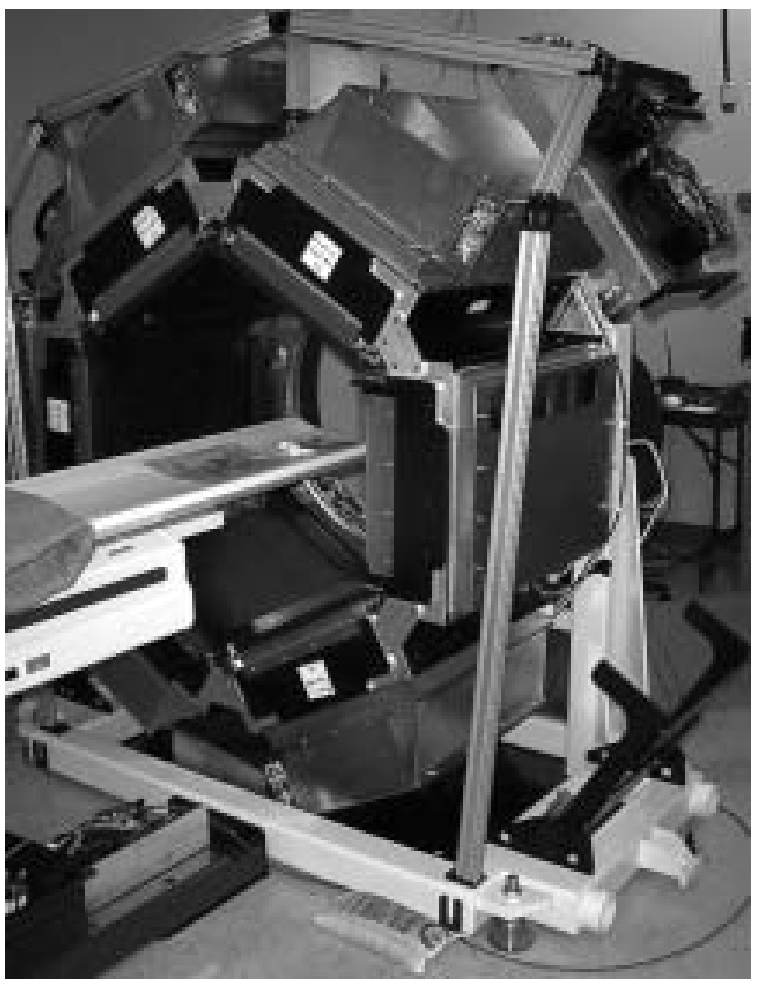

Fig. 3. A partial-ring rotating PET scanner based on the flat panel LSO detector design. This image is reproduced with permission from Dale Bailey and CTI PET Systems.

\subsubsection{Large area detector tomographs}

A low-cost alternative to ring detector tomographs is found in $\mathrm{NaI}(\mathrm{Tl}) \mathrm{PET}$ systems [46,47]. Although the properties of $\mathrm{NaI}(\mathrm{Tl})$ are better suited to single photon emission computed tomography (SPECT) than to PET, a number of adaptations can be made that result in a system that is viable for clinical PET studies. First, $\mathrm{NaI}(\mathrm{Tl})$ detectors used in PET typically are thicker (approx. $25 \mathrm{~mm}$ ) than are those used in SPECT (approx $9 \mathrm{~mm}$ ) because of the higher energy of the photons. Large area crystals are employed rather than a block configuration, and six such crystals surround the subject in a hexagonal arrangement. While the light-decay time of $\mathrm{NaI}(\mathrm{Tl})$ is shorter than that of BGO, the small number of detectors compared to the large number of block detectors $(>200)$ typical of BGO and LSO systems means that the count rate per detector is substantially higher for the $\mathrm{NaI}(\mathrm{Tl})$ system for a given source strength. The relatively high light output of $\mathrm{NaI}(\mathrm{Tl})$ allows the integration time to be shortened to reduce dead time with only small deterioration in positioning accuracy and energy resolution [48]. Dead time is reduced further by using only photomultiplier tubes in the 
local neighborhood of a scintillation event to determine its position in the crystal, effectively partitioning the single detector into multiple detector zones (typically 3-4 zones per detector). Recently, the use of curved $\mathrm{NaI}(\mathrm{Tl})$ detectors has been introduced, which results in more uniform spatial resolution throughout the field of view [49].

\subsubsection{Partial-ring rotating tomographs}

To reduce the cost of dedicated PET scanners, partial-ring rotating tomographs were developed [4,50, 51]. These scanners contain about $45 \%$ by volume of the scintillator material (the main cost component) of the corresponding full-ring tomograph but employ 3D acquisition and reconstruction to compensate for the loss of efficiency. The partial ring of detectors typically rotates at 30 revolutions/minute on a slip-ring gantry to acquire a full set of projections. The axial FOV is $16 \mathrm{~cm}$, and efficiency and spatial resolution are similar to an equivalent full-ring system operated in 2D acquisition mode.

Partial-ring rotating tomographs that use three or five flat-panel LSO detectors also are under development [52] and soon will be available commercially. These systems have no interplane septa and operate in 3D mode only. In this design, there is no reduction in the total volume of scintillator. Instead, the lack of a full ring is compensated by using a large axial FOV $(50 \mathrm{~cm})$ to improve $3 \mathrm{D}$ sensitivity. The speed of LSO and associated electronics allows a relatively short coincidence time window to be used to minimize the impact of randoms and dead time on count-rate performance.

\subsubsection{4. $3 D$ versus $2 D$ systems}

In a full-ring PET scanner, lead or tungsten septa normally are used to separate adjacent rings of detectors and prevent photons that are detected in one imaging plane from being in coincidence with photons detected in other imaging planes. This is referred to as $2 \mathrm{D}$ acquisition mode. Current-generation PET scanners have the capability to retract the interplane septa from the FOV and acquire coincidence data at all possible angles in three dimensions. This is referred to as 3D acquisition mode and results in a substantial increase in detection efficiency [53]. Volume-imaging PET scanners, such as the GSO ring system [43], hexagonal $\mathrm{NaI}(\mathrm{Tl})$ systems [47], and flat-panel LSO systems [52], do not have any interplane septa and are, therefore, inherently 3D. Such systems require specially developed $3 \mathrm{D}$ image-reconstruction algorithms [47,54,55].

\subsubsection{Transmission systems}

A transmission scan is required to correct the PET data for absorption of annihilation photons in the body that otherwise would degrade image quality and the ability to quantify radiotracer uptake. Attenuation correction factors typically are measured in ring-detector systems by rotating a transmission source around the subject and comparing the attenuated transmission counts to non-attenuated transmission counts obtained without a subject in the scanner. The source usually is a long-lived positron emitter (e.g., ${ }^{68} \mathrm{Ge} /{ }^{68} \mathrm{Ga}$ ) and is detected in coincidence. Techniques have been developed to minimize and correct for cross-contamination from emission photons, thus allowing simultaneous emission/transmission or post-injection transmission studies to be carried out [56-59]. At present, however, simultaneous scanning normally is not performed for oncology studies and the transmission scan can account for a large part of the imaging session, making subject movement a possible source of error.

Due to count-rate limitations, coincidence transmission scanning is difficult or impractical to implement on 3D-only systems. Instead, attenuation measurements based on singles transmission are employed [60]. To separate emission from transmission counts, an isotope with different energy is used (e.g., ${ }^{137} \mathrm{Cs}$, with an energy of $662 \mathrm{keV}$ ). Singles transmission measurements require careful correction for differences in attenuation properties at the differing transmission and emission energies, correction for higher level of scatter in singles transmission, and correction for crosscontamination from emission data to achieve accurate attenuation correction. However, singles transmission systems can provide relatively low-noise transmission data in a comparably short time.

An alternative approach for 3D-only systems is to use dedicated fast detectors for transmission measurements [61-63]. This currently is being implemented in a commercial LSO-based tomograph and is likely to make simultaneous emission/transmission scanning routine in the near future. It also is possible to derive attenuation correction factors from spatially coregistered X-ray CT data when available. This approach is discussed below in the context of dual modality systems.

\subsubsection{Dual modality PET/CT systems}

Scanners that are capable of acquiring PET and CT data during the same imaging session recently have become available [64]. These systems typically comprise a full-ring PET gantry abutted to a single- or multi-slice 
spiral CT gantry with a common subject couch and aperture and an integrated computer system. Because the studies are performed sequentially and the subject is not moved between studies, the system is capable of producing spatially co-registered PET and CT image volumes. The software typically displays the two sets of tomographic images as orthogonal volumes with linked crosshairs and/or as a fused display where the PET images (in pseudo color) are overlayed on the CT images (in greyscale).

The potential benefits of a dual modality system include: the ability to accurately localize radiotracer uptake using CT as the anatomical reference; shorter scan times because a whole-body CT scan can be acquired in under two minutes, compared with a conventional transmission scan that takes up to 20 minutes to acquire; and the capability to perform radiotherapy treatment planning using the co-registered anatomical and functional imaging data for potentially more accurate target volume definition.

There are some issues to address to ensure that accurate attenuation-correction factors can be derived from CT data [65]. For example, linear attenuation coefficients $(m)$ do not scale linearly from the low energy of x-rays (approximately $60 \mathrm{keV}$ ) to the relatively high energy of annihilation photons $(511 \mathrm{keV})$, an issue that may be complicated further when contrast agents are used as an adjunct to the CT study. This usually is addressed by segmenting the CT images into a discrete set of tissue types. Then, each discrete tissue type can be treated separately by applying an empirical scale factor that scales the corresponding voxels to an $m$ value appropriate for $511 \mathrm{keV}$ imaging. A further problem arises when imaging the thorax, because $\mathrm{CT}$ provides a snapshot that may represent any part of the respiratory cycle, whereas PET produces a time-averaged image. Without due care, this can lead to substantial artifacts in the reconstructed images [66]. These problems mostly have been addressed, and combined PET/CT appear to offer unique benefits in oncologic imaging.

\section{Advances in PET radiotracer development}

\subsection{Growth factor receptor imaging}

Over the last decade, a number of cancer cell surface receptor families, namely growth factor receptors, have been identified. Many of these receptors sit at the head of complex signaling pathways. Ligand binding to the extracellular domain triggers a cascade of downstream events that culminates in a variety of processes including cell division, differentiation, motility, adhesion, angiogenesis, and apoptosis. These receptors and the associated signaling pathways provide fertile ground for the development of imaging agents. Many of these receptors are the target of active pharmaceutical development programs [67]. The receptor families that have been the focus of many studies include the epidermal growth factor (EGF), platelet-derived growth factor (PDGF), fibroblast growth factor (FGF), and vascular endothelial growth factor (VEGF).

The growth factor receptor tyrosine kinases share structural and functional similarities, most notably, an intracellular tyrosine kinase domain. Ligand binding to the extracellular domain promotes receptor dimerization followed by autophosphorylation of tyrosine residues on adjacent receptors. The phosphorylated receptor recruits proteins and enzymes, thus initiating the intracellular signal cascade [68]. Two regions of the receptor, the extracellular ligand binding domain and the intracellular tyrosine kinase domain, are therapeutic targets and also are suitable for labeled imaging probes. Developing probes for these targets may present opportunities to integrate imaging studies into the drug development schema.

The epidermal growth factor receptor (EGFR, ErbB1) was one of the first oncogenes [69] discovered and the first member of the ErbB family of receptor tyrosine kinases to be identified. The ErbB family, which also includes ErbB2 (HER2), ErbB3, and ErbB4, is over-expressed in a variety of cancers, including head and neck tumors; gliomas; non-small cell lung cancer; and tumors of the breast, ovaries, cervix, esophagus, bladder, prostate, and kidney [70]. Herceptin ${ }^{\circledR}$ (trastuzumab), the first clinically approved ErbB-targeting agent for breast cancer, is an antibody that blocks the ErbB2 receptor [71,72]. A number of antibodies and small molecule tyrosine kinase inhibitors targeting the EGFR (ErbB1) are at various stages in the pharmaceutical pipeline (see Fig. 4) [67].

EGF, the 53 amino acid, $6 \mathrm{kDa}$, natural ligand, binds to the EGFR with a $\mathrm{Kd}$ of 0.1-1.0 nM [73] and has been labeled directly with iodine-123, iodine-125, and iodine-131 as well as indium-111 and technetium-99m bifunctional chelates [50,74-79]. EGF has been labeled with the positron-emitting bromine-76 and was found to accumulate in EGFR-expressing tumors in the rat [80]. No human studies have been performed with this tracer.

Monoclonal antibodies (MAbs) against EGFR are being developed as therapeutic anti-tumor agents. A 


\section{EGFR tyrosine kinase Inhibitors}
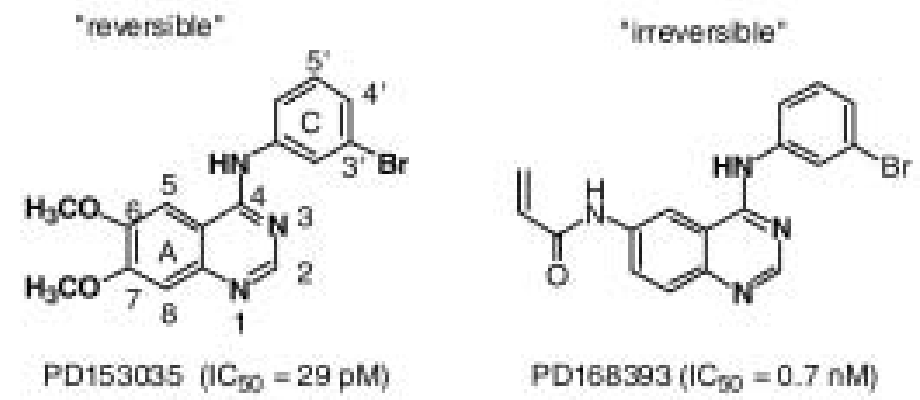

\section{VEGFR tyrosine kinase Inhibitors}
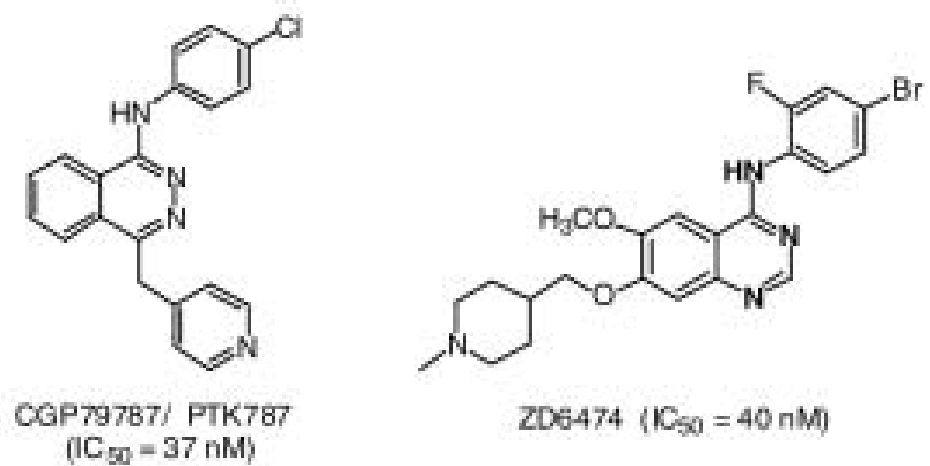

Fig. 4. Chemical structures of selected EGFR and VEGF tyrosine-kinase inhibitors.

few selective MAbs have been labeled with indium111 and technetium-99m and evaluated as imaging agents [81-85]. Generally, the MAbs appear to have better imaging characteristics than do the labeled EGF analogs. The anti-EGFR MAbs have not been labeled with positron-emitting isotopes. A copper-64-labeled antibody or antibody fragment would be the logical choice.

To date, no small organic molecules have been identified with affinity for the extracellular domain of the EGFR; however, a number of small molecules have been shown to be potent (nM to $\mathrm{pM}$ ) inhibitors of the EGFR tyrosine kinase at the intracellular adenosine triphosphate (ATP) binding site. A reversible-binding and irreversible-binding anilinoquinazoline is shown in Fig. 4 [86,87]. Tryphostins, dianilinopthalimides and pyrrolo-pyrimidines also are classes of small molecules that inhibit the EGFR tyrosine kinase-mediated autophosphorylation [88-90].

A number of positron-radiolabeled analogs of PD153035 have been reported. The compounds incorporate labeled substituents on the A- or C- rings (see Fig. 4) of the anilino- or benzylaminoquinazoline. The C-ring-substituted analogs include 4-(3'-[ ${ }^{125}$ I]iodoanilino [91,92], 4-(3'- $\left[{ }^{18}\right.$ F $]$ fluoro-5' trifluoromethylanilino)- [93,94], 4-(3',4'-dichloro-6'$\left[{ }^{18} \mathrm{~F}\right]$ fluoroanilino)- [93,94], 4-(3' -chloro-4' - $\left[{ }^{18}\right.$ F $]$ fluoroanilino)- $[95,96], 4-\left(4^{\prime}-\left[{ }^{18} \mathrm{~F}\right]\right.$ fluorobenzylamino $)$ dimethoxyquinazolines [97], and 4-(4'-[ ${ }^{18}$ F]fluorobenzylamino)diethoxyquinazoline [98]. The 7-[ $\left.{ }^{18} \mathrm{~F}\right]$ fluoroethoxy [99] and the 6- or 7-[ $\left.{ }^{11} \mathrm{C}\right]$ methoxy derivatives constitute the A-ring-labeled analogs $[99,100]$. A study of the carbon-11 methoxy derivative demonstrated some uptake in human neuroblastoma xenografts in mice [101,102]; however, the half-life of the carbon11 (half-life $=20 \mathrm{~min}$ ) may not allow adequate time for the development of adequate signal-to-background signal contrast. Recently, the 4-[3',4'-dichloro6'-fluoroanilino]-6-acryylamido-quinazoline, an irreversible EGFR tyrosine kinase inhibitor (see Fig. 4), has been reported labeled with carbon-11 in the acrylamide group [103,104]. To date, a radioprobe with desirable imaging characteristics, including receptormediated uptake, has not been identified. Optimization and validation of several analogs is in progress. 

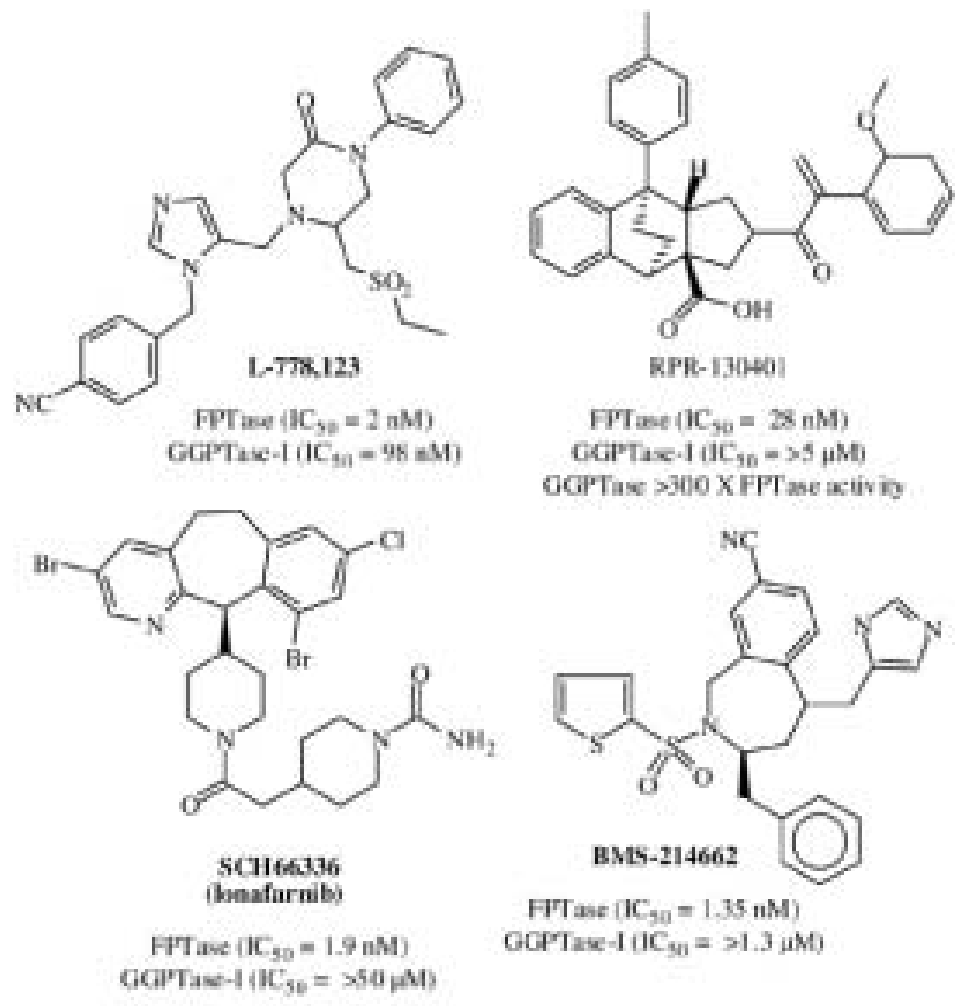<smiles></smiles>

R. 115777

Tipifarnits

FPTase $\left[\mathrm{IC}_{30}=1.35 \mathrm{nM}\right)$ GCPTaw $-1\left(\mathrm{CC}_{\mathrm{sin}}=>1.3 \mu \mathrm{MO}\right.$<smiles>CSCC[C@H](C(=O)O)N(C)C(=O)c1ccc(N([Tl])CC(N)CS)cc1-c1ccccc1</smiles>

Fig. 5. Structures of selected farnasyl-transferase inhibitors.

Angiogenesis, the process of new blood vessel formation, plays an essential role in tumor growth [105]. VEGF promotes new blood-vessel growth through the VEGF receptor (VEGFR) signaling. The VEGFR family is comprised of three members, VEGF R1 (Flt-1), VEGF R2 (KDR or Flk-1), and VEGF R3 (Flt-4) [106]. VEGFR, like EGFR, is a receptor tyrosine kinase that dimerizes and phosphorylates the tyrosine residues of the adjacent receptor upon VEGF binding to the extracellular ligand-binding domain.

VEGFR is a target for anti-cancer therapeutic development with anti-VEGFR antibodies being produced to block the extracellular receptor domain and smallmolecule inhibitors being evaluated to inactivate the tyrosine-kinase signaling. Additionally, anti-VEGF antibodies that reduce circulating VEGF and prevent its interaction with the receptor are being analyzed.

To date, only one labeled probe directly targeting the VEGFR has been reported in the literature. The synthesis and initial evaluation of [ $\left.{ }^{123} \mathrm{I}\right]$-VEGF recently was described [107]. The bulk of imaging related to angiogenesis has targeted indirect measures of bloodvessel formation, including tissue hypoxia, blood flow, and cell permeability [108].

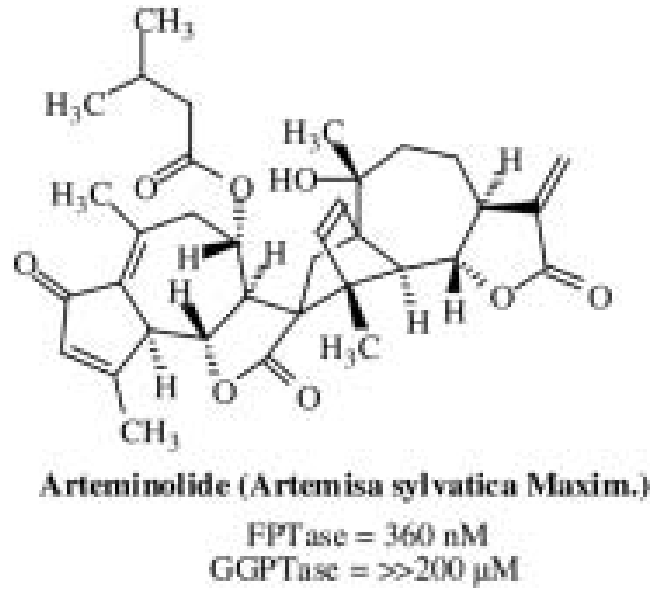

Fig. 6. Structure of arteminolide.

Several small-molecule inhibitors of the intracellular tyrosine kinase have been synthesized and evaluated as tumor therapeutics. Two classes of compounds that exhibit potent inhibition of the enzyme are shown in Fig. 4 [109-111]. The aminoquinazoline compound (ZD6474) is a structural analog of the EGFR tyrosine kinase inhibitors. Following the labeling paradigm for 
the EGFR imaging agents also may lead to PET probes to measure VEGFR density.

Growth factors are produced in many types of cancer and promote tumor growth and proliferation. Growthfactor receptors are important mediators of cellular activity in response to growth-factor activation, and their over-expression in a variety of tumor types is associated with poor prognosis and survival. Development of anti-neoplastic therapeutics based on growth-factor expression in tumors is an active area of current research in the pharmaceutical and biotech industries. Thus, the design of growth-factor radioprobes may complement these efforts and be efficacious in subject selection, monitoring therapeutic response, and drug development.

\subsection{Enzyme imaging}

Over the last two decades, several major advances in molecular and cellular biology have led to the identification of a number of genes that are intimately involved in cancer initiation, progression, invasion, and angiogenesis. Mutations in ras have been identified in about $30 \%$ of all human cancers. Mutations of K-ras commonly are found in human malignancies, whereas $\mathrm{N}$ - and H-ras are found less often. K-ras mutations are found most often in solid malignancies and predominate in pancreatic, colorectal, and non-small cell lung cancer, whereas breast cancer and gliomas have a low occurrence of ras mutations. The demonstration that Ras requires prenylation for its cancer-causing activity led several groups of investigators to an intense search for farnesyltransferase and geranylgeranyltransferase (GGT) inhibitors as potential anticancer drugs (Figs 57) [112]. This prenylation involves the transfer of a 15carbon farnesyl group from farnesyl diphosphate to a Cterminal tetrapeptide sequence of the Ras protein. This causes the protein to become more hydrophobic; this farnesylated protein readily associates with the lipid bilayer of the cell membrane, enabling it to cycle from the inactive Ras-guanosine 5'-diphosphate to the activated Ras-guanosine 5'-triphosphate. The function of inhibitors in this prenylation is to inhibit the transduction of proliferative cancer signals. The related GGT also can catalyze the attachment of prenyl groups to several proteins. This potential for cross-prenylation of K-Ras by GGT indicates that, even with the blockade of farnesyltransferase by a suitable inhibitor, the function of the Ras protein may be restored by prenylation using GGT. The fact that both farnesyltransfease and GGT inhibitors are required for inhibition of oncogenic K-
Ras prenylation (but each alone is able to suppress human tumor growth in mouse models [113]), along with a low toxicological profile, has fueled the development of new inhibitors.

\subsubsection{Farnesyltransferase}

Farnesyltransferase inhibitors represent a new class of agents that target signal transduction pathways responsible for the proliferation and survival of diverse malignant cell types. These agents have shown some success in a number of conditions, including breast [114,115], head and neck [116,117], ovarian [114], and non-small cell lung cancers [116]. A number of questions remain to be answered to evaluate the effectiveness of farnesyltransferase inhibitors [118, 119]. Due to the presence of endogenous inhibitors and because farnesyltransferase inhibitors are reversible inhibitors, the direct measurement of farnesyltransferase activity as a marker of drug effect has proven difficult. This is a potential role that PET can play in the development of effective imaging agents to determine the level of farnesyltransferase inhibition in vivo.

\subsubsection{Geranylgeranyltransferase inhibitors}

It has been shown that GGTase-I inhibitors arrest cells in G0/G1 and induce accumulation of p21WAF in a p53-independent manner and that FTase inhibitors can interfere with cell cycle events by a mechanism that involves neither p21WAF nor p27KIP [120]. The results also point to the potential of GGTase-I inhibitors as agents capable of restoring growth arrest in cells lacking functional p53. Studies indicated that treatment of NIH3T3 cells with GGTI-298 (GGT-I inhibitor) or lovastatin, which inhibits both protein farnesylation and geranylgeranylation, arrested cells in G0/G1; whereas cells treated with FTI-277 (farnesyltransferase inhibitor) progressed normally through the cell cycle [121] and protein geranylgeranylation is critical for the control of programmed cell death [122]. PET studies can play a key role in the evaluation of the function of both farnesyltransferase and GGT in vivo.

\subsubsection{Fatty acid synthase}

Abnormal fatty acid synthesis is among the most prevalent features of human cancer. In comparison to normal or benign hyperplastic glandular structures, all of which were negative for fatty acid synthase (FAS) staining, an immunohistochemical signal was evident in $24 / 25$ low-grade prostatic epithelial neoplasia (PIN) lesions, in 26/26 high-grade PIN lesions, and in 82/87 invasive carcinomas. Staining intensity for fatty acid 


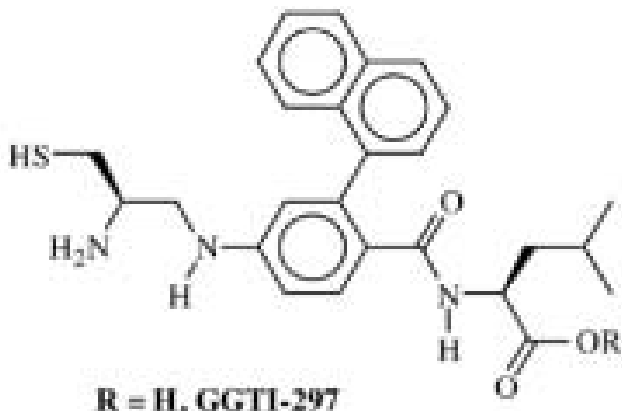

GGPTase-1 ( $\left(\mathrm{CC}_{50}=50 \mathrm{nM}\right)$
FTase $\left(1 \mathrm{C}_{50}=250 \mathrm{nM}\right)$

$\mathbf{R}=\mathbf{M e}, \mathbf{G G T H}-\mathbf{2 9 8}$

\section{Completely blocked RaplA processing without affecting H-Ras}

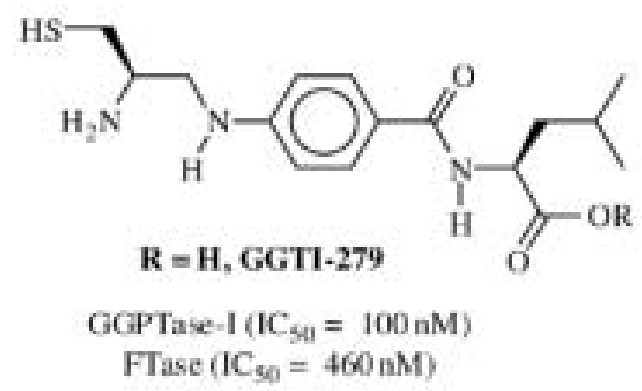

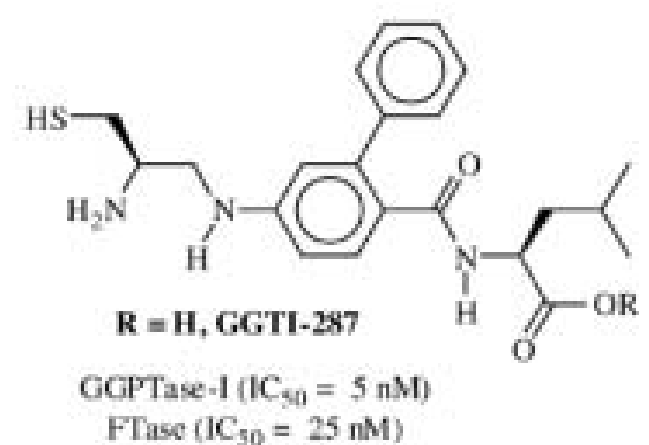

$\mathrm{R}=\mathrm{Me}, \mathbf{G G T 1}-2 \mathrm{2} 6$

GGPTase-I (IC $s 0=2 \mathrm{nM})$

FTase $\left(1 C_{50}=30 n \mathrm{M}\right)$

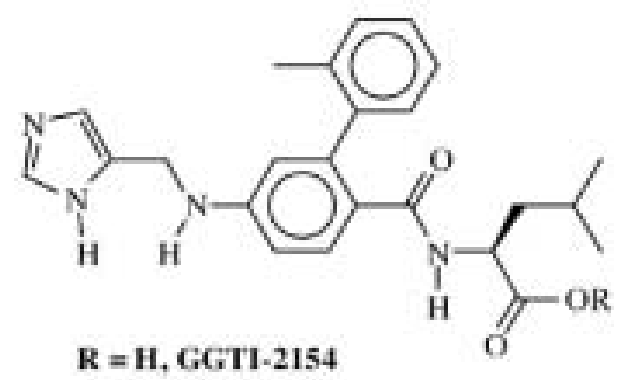

GGPTase-I ( $\left.\mathrm{IC}_{\mathrm{S0}}=21 \mathrm{nM}\right)$

FTase $\left(\mathrm{IC}_{50}=5600 \mathrm{nM}\right)$

$\mathrm{R}=\mathrm{Me}$, GG'TI-2166

GGPTase-I $\left(\mathrm{IC}_{30}=300 \mathrm{nM}\right)$

FTase $\left(\mathrm{IC}_{30}=>30 \mu \mathrm{M}\right)$

Fig. 7. Structures of selected geranylgeranyltranserase inhibitors.

synthase was found to increase from low grade to high grade PIN in invasive carcinoma, and cancers with a high FAS expression had an overall high proliferative index [123]. These findings indicate that increased FAS expression is one of the earliest and most common events in the development of prostate cancer, suggesting that FAS may be used as a general prostate cancer marker and that anti-neoplastic therapy based on FAS inhibition may be an option for chemoprevention or curative treatment for nearly all prostate cancers. Increased FAS has been seen in numerous cancers, such as those of the prostate [123], ovary [124,125], and breast [126-131]. The development of imaging agents to determine the level of fatty acid synthase in vivo could be useful in the determination of cancer grade.

\subsection{Steroid receptor imaging}

The use of PET to delineate steroid-receptor-positive tissue in tumors has been an interesting target for many years [132]. The primary goal of these efforts has been to develop diagnostic tools that would be capable of determining the presence or absence of a key steroid receptor that would then impact the therapeutic strategy for treatment of the disease. PET radiopharmaceuticals have been developed for a number of steroid receptors; this review will focus on the estrogen, androgen, and progestin receptors.

\subsubsection{Estrogen receptor}

In the mid-1980s, Welch and Katzenellenbogen developed a positron-radiolabeled estrogen ligand, $\left[{ }^{18} \mathrm{~F}\right]-$ 
16 $\alpha$-18-fluoroestradiol-17 $\beta$ ([ $\left.{ }^{18} \mathrm{~F}\right] \mathrm{FES}$, Fig. 8). This tracer [133] demonstrated excellent in vitro and in vivo characteristics in pre-clinical models; subsequently, excellent delineation of estrogen-receptor (ER)-positive breast tumors was observed in humans [134-136].

In clinical studies, $\left[{ }^{18} \mathrm{~F}\right] \mathrm{FES}$ has been studied most extensively as a radiopharmaceutical for breast carcinoma imaging. Mintun et al. found a correlation coefficient of $0.96(p<0.001)$ between non-specific binding and partial volume effect corrected in vivo breast tumor uptake of $\left[{ }^{18} \mathrm{~F}\right] \mathrm{FES}$ expressed as percentage of the dose injected per $\mathrm{mL} \times 10^{-4}$ and ER concentration (fmol/ $\mathrm{mg}$ protein) in nine ER-documented patients suffering from primary breast carcinoma. In a subsequent study in the same group of 16 patients with clinical or radiographic evidence of metastatic disease, metastatic lesions within the regions imaged on PET studies were identified by other imaging studies in 14 out of 16 patients. The pre-therapy PET images with $\left[{ }^{18} \mathrm{~F}\right]$ FES demonstrated accumulation of the radiopharmaceutical in the lesion or lesions of 11 of these 14 patients (79\%) and in 53 of 57 lesions (93\%). Based on available data in a small subgroup of seven patients, the correlation between pre-therapy $\% \mathrm{ID} / \mathrm{mL}$ uptake vs. ER status ( $r=0.36, p=0.43)$, however, was much poorer when compared to the results obtained in primary tumors. Dehdashti et al., in a series of 53 patients (32 patients with primary breast tumours and 21 with clinical or radiological evidence of distant metastases or disease recurrence), found a good overall agreement [88\% (35/40)] between in vitro ER assays and $\left[{ }^{18} \mathrm{~F}\right] \mathrm{FES}$ PET \% ID/ml [137]. Of interest, all five cases of disagreement were positive on in vitro ER but negative on $\left[{ }^{18} \mathrm{~F}\right] \mathrm{FES}$ PET (standard uptake values [SUVs] $<$ 1.0). Only one of these patients was treated with hormonal therapy, and she did not respond. Mortimer et al. assessed the value of $\left[{ }^{18} \mathrm{~F}\right] \mathrm{FES}$ in women with breast cancer for predicting response to systemic therapy [138]. Results of $\left[{ }^{18} \mathrm{~F}\right]$ FES PET were related to ER status. Cancers were considered functionally hormone sensitive if the standardized uptake value of the lesion on $\left[{ }^{18} \mathrm{~F}\right]$ FES PET was $>1.0$ and hormone resistant if FES SUV was $<1.0$. In this series, all $20 \mathrm{ER}$ - tumors did not accumulate $\left[{ }^{18} \mathrm{~F}\right] \mathrm{FES}$. However, of the $21 \mathrm{ER}+$ tumors, 16 took up $\left[{ }^{18} \mathrm{~F}\right] \mathrm{FES}$ and five did not. Thirteen patients were treated with hormone therapy, and eight $(61 \%)$ responded to that therapy. Only one of the five patients whose tumors were ER+ and did not take up $\left[{ }^{18} \mathrm{~F}\right] \mathrm{FES}$ received hormone therapy, and this treatment resulted only in disease stabilization. When compared with the in vitro assays of ER status, $\left[{ }^{18} \mathrm{~F}\right] \mathrm{FES}$ PET had a sensitivity of $76 \%$ and specificity of $100 \%$.<smiles>Oc1ccc2c(c1)CCC1C2CCC2C1CC(F)[C@H]2O</smiles><smiles>CC[C@H]1CC2C3CCC4=CC(=O)CC[C@H]4C3CC[C@]2(C)[C@H]1C(=O)C[18F]</smiles><smiles>[2H]C(O[C@H]1CC2C3CCC4=CC(=O)CC[C@H]4C3CC[C@]2(C)[C@]1(C)C(=O)C[18F])c1ccco1</smiles><smiles>C[C@]12CCC(=O)C[C@H]1CCC1C3CC(F)[C@@H](O)C3CCC12</smiles><smiles>C[C@]12CCC(=O)C[C@H]1C[C@H](F)C1C[C@@H](O)CCC12</smiles>

Fig. 8. Structures of selected steroid-based PET radiotracers. From top: $\left[{ }^{18} \mathrm{~F}\right] \mathrm{FES},\left[{ }^{18} \mathrm{~F}\right]$ FENP, $\left[{ }^{18} \mathrm{~F}\right]$ FFNP, $\left[{ }^{18} \mathrm{~F}\right]$ FDHT, $\left[{ }^{18} \mathrm{~F}\right] 7$ (FDHT).

Dehdashti et al. reported on the potential usefulness of consecutive $\left[{ }^{18} \mathrm{~F}\right] \mathrm{FES}$ imaging to predict responsiveness to anti-estrogen therapy in patients with ER+ metastatic breast cancer [137]. Eleven post- 
menopausal women were included and underwent $\left[{ }^{18} \mathrm{~F}\right]$ FES PET before and seven to 10 days after initiation of tamoxifen therapy. There were seven responders and four non-responders on clinical follow-up (3-24 months). Responders had higher baseline SUVs when compared to non-responders ( $>2.2$ vs. $<1.7$ ), and the degree of ER blockade by tamoxifen was greater in responders (mean SUV decrease $2.7+1.7$ ) than in non-responders (mean decrease $0.8+0.5$ ).

The general utilization of this radiotracer in the clinic has been disappointing, however; this is due, in part, to the realization that this approach is unlikely to replace tumor biopsy as a technique for determining the estrogenic nature of a tumor. Therefore, it has limited utility as a diagnostic agent. However, it could be that this radiotracer has great application for monitoring target modulation or disease progression for estrogen-targeted therapy. In fact, PET has proven useful in imaging the "metabolic flare" response that occurs after initiation of tamoxifen therapy $[139,140]$. In these studies, both the findings of a flare response by $\left[{ }^{18} \mathrm{~F}\right]$ FDG-PET and the degree of ER blockade by $\left[{ }^{18} \mathrm{~F}\right] \mathrm{FES}$ PET appear to predict the responsiveness of anti-estrogen therapy in patients with ER+ breast cancer.

\subsubsection{Progestin receptor}

Attempts to delineate the progestin receptor (PR) in humans have been less successful than for the ER. A number of derivatives have been suggested [141-143], but have had only limited evaluation in humans. One ligand, $\quad\left[{ }^{18} \mathrm{~F}\right]$ fluoro-16 $\alpha$-ethynyl-19-norprogesterone ([18 F]FENP, Fig. 8), an analog of the potent progestin ORG 2058, demonstrated highly selective uterine uptake and excellent uterus-to-blood and uterus-tomuscle ratios in pre-clinical models [142,144]. Unfortunately, this specificity was not reproduced in patients with primary breast cancer, and it was concluded that $\left[{ }^{18} \mathrm{~F}\right]$ FENP was not a suitable radiotracer for the delineation of PRs in humans [134,135].

Another radiotracer for the PR has been reported $[145,146]$, the endo isomer of $21-\left[{ }^{18} \mathrm{~F}\right]$ fluoro$16 \alpha, 17 \alpha-[(R)-(1$ '- $\alpha$-furylmethylidene)-19-norpregn-4 -ene-3,20-dione ([ $\left.\left.{ }^{18} \mathrm{~F}\right] \mathrm{FFNP}\right)$. This radiotracer was designed to be more resistant to reduction of the C-20 ketone, a feature that was blamed for the failure of $\left[{ }^{18} \mathrm{~F}\right] \mathrm{FENP}$ in humans. In addition, it is hoped that the structural changes in $\left[{ }^{18} \mathrm{~F}\right] \mathrm{FFNP}$ will make this candidate less susceptible to in vivo defluorination; unfortunately, no clinical evaluation of this tracer has been reported to date.

\subsubsection{Androgens}

Radiopharmaceuticals targeting the androgen receptor (AR) may have potential as a method to monitor the pathophysiology of metastatic prostate cancer. A number of potential candidates have been identified and one ligand, $16 \mathrm{a}-\left[{ }^{18} \mathrm{~F}\right]$ fluoro- $5 \alpha$ dihydrotestosterone ( $\left.\left[{ }^{18} \mathrm{~F}\right] \mathrm{FDHT}\right)$, was chosen by nonhuman primate imaging [147] to be the best radiotracer for evaluation in humans. Clinical data concerning this ligand has been presented at scientific meetings, and publication of this data is anticipated soon. Another androgen ligand that has promise is a $7 \alpha$-fluoro derivative of dihydrotestosterone; an interesting pre-clinical assessment of this ligand has been published [148], but no clinical evaluation has been reported to date.

\subsection{Sigma receptor radiotracers}

The two currently accepted sigma receptor subtypes (termed sigma-1 and sigma-2) have been targets of interest for PET and SPECT radiotracer development for many years [149-159]. Both subtypes are over-expressed in many human malignancies, including those of the breast, lung, colon, brain, and prostate [160,161]. Human, rodent, and guinea pig sigma-1 receptors have been cloned. Sigma-1 receptors are not homologous to any known mammalian protein but are highly homologous to yeast sterol isomerase [162,163]. These receptors are expressed on the cell membrane and within the endoplasmic reticulum where they are co-localized with sterol isomerase enzymes. It is thought that sigma- 1 receptors are involved in cellular proliferation processes, and antagonism at sigma-1 sites causes cell death. It recently has been shown in malignant human breast tumor biopsies that sigma-1 receptor densities correlate positively with Bcl-2 expression and inversely with progesterone expression, indicating their potential use as prognostic markers for breast cancer [164].

Several PET and SPECT radioligands have been synthesized and tested in vivo over the past decade. PET sigma-1 receptor tracers have been labeled with carbon11 and fluorine-18, and examples are shown in Fig. 9. Most PET tracers have been evaluated especially for imaging sigma- 1 receptors in the CNS. One sigma1 receptor PET radiotracer that has shown promise as a tumor imaging agent is $\left[{ }^{18}\right.$ F]FPS $[149,158,165]$. $\left[{ }^{18} \mathrm{~F}\right] \mathrm{FPS}$ has been fully characterized through preclinical models and has proven suitable for imaging sigma-1 receptors in the primate CNS as well as those expressed in tumors. In mouse models of melanoma 
<smiles>CCN(CC)CCc1ccc(OC)c(OCCc2ccccc2)c1</smiles>

NE-100

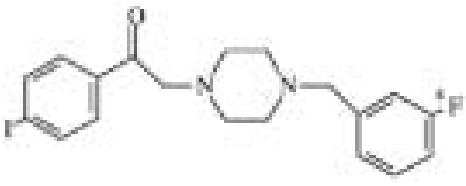

$2 \cdot[18$ Thenramides.

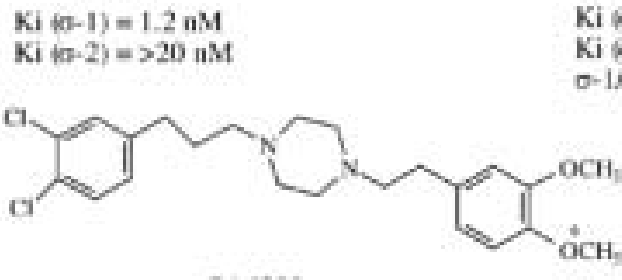

SA6298

$\mathrm{Ki}(\mathrm{s}-1)=0.38 \mathrm{nM}$ $\mathrm{Ki}(\sigma-2)=20.3 \mathrm{nM}$ $0-1,6-2=53$

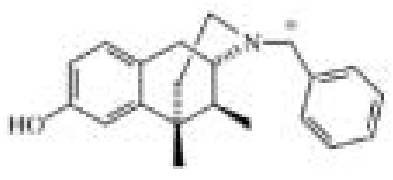

(+)-cis-N-Benzylomrnetazincine

Ki $($ n -1$)=0.67$ nM

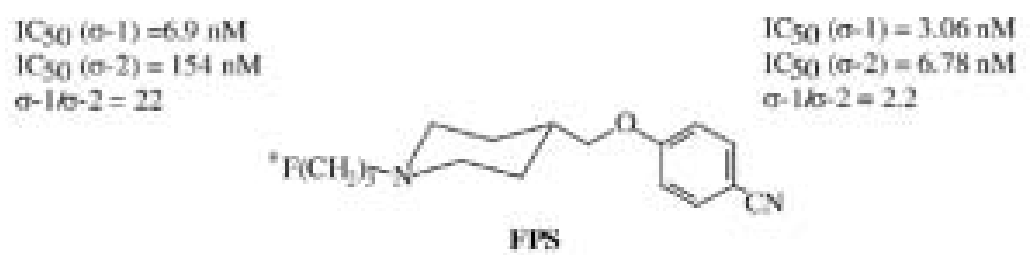

HIS

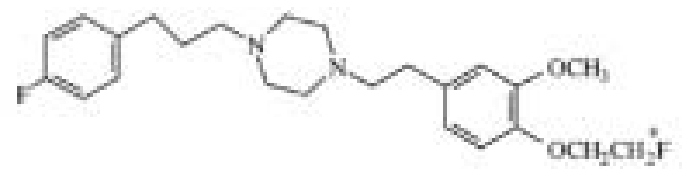

FE-SAS845

$$
\begin{aligned}
& \mathrm{Ki}(0 \cdot 1)=1.0 \mathrm{nM} \\
& \mathrm{Ki}(0 \cdot 2)=144 \mathrm{nM} \\
& \log \mathrm{P}_{7.5}=2.80
\end{aligned}
$$

Fig. 9. Structures of sigma-receptor PET radioligands. Asterisks (*) denote positions in which a radiolabel has been placed.

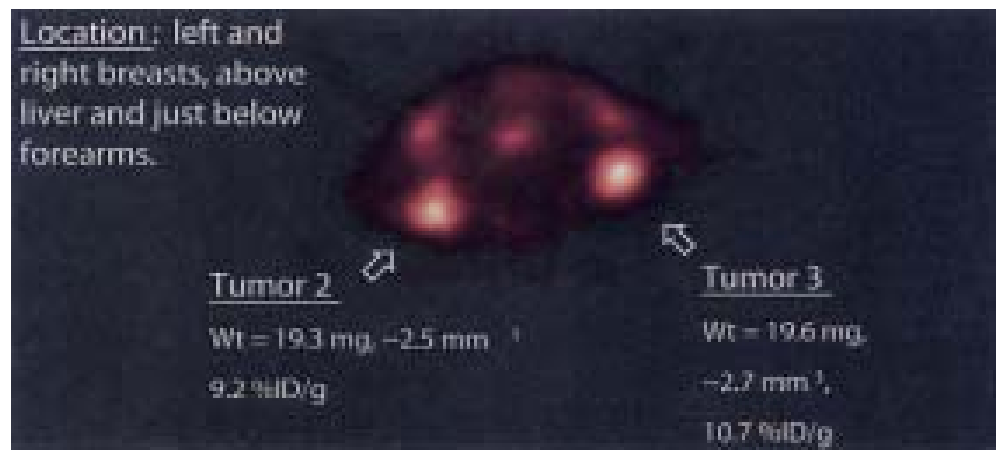

Fig. 10. Transaxial microPET image obtained at four hours post injection with $\left[{ }^{18} \mathrm{~F}\right] \mathrm{FPS}$ in a transgenic MMTV mouse that developed breast tumors.

and breast cancer, high $\left[{ }^{18} \mathrm{~F}\right] \mathrm{FPS}$ uptake and excellent tumor-to-normal tissue ratios consistently have been demonstrated in several in vivo tumor models, including the transgenic MMTV mouse model of breast cancer (Fig. 10). In all models examined thus far, including the MMTV breast cancer model, the binding of this tracer to sigma receptors in vivo in the CNS and in tumors has been demonstrated to be $>90 \%$ specific.

Another interesting study was the assessment of a mixed sigma-1 and sigma-2 receptor radiotracer as a reporter of proliferation status by Mach et al. In this study,

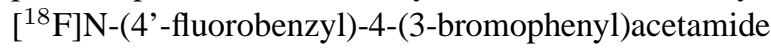
was studied in nude mice bearing tumor xenografts of the mouse mammary adenocarcinoma and compared with the metabolic imaging agent $\left[{ }^{18} \mathrm{~F}\right] \mathrm{FDG}$ and a radiolabeled DNA precursor, $\left[{ }^{125} \mathrm{I}\right] \mathrm{IUdR}$. Both $\left[{ }^{18} \mathrm{~F}\right] \mathrm{FDG}$ and $\left[{ }^{125} \mathrm{I}\right] \mathrm{IUdR}$ have been proposed as agents to report on the proliferative status of solid tumors. When the 
sigma-1 receptor binding of $\left[{ }^{18} \mathrm{~F}\right] \mathrm{N}$-(4'-fluorobenzyl)4-(3-bromophenyl)acetamid was blocked, the results of the distribution studies suggested that imaging with a sigma-2 selective tracer might provide advantages in overall tumor/tissue ratios and correlation with proliferative status. However, these studies are very preliminary and further work is required to support these hypotheses.

Sigma-2 receptors are not as well characterized as are sigma- 1 sites, and endogenous ligands are yet to be identified. However, expression of sigma-2 receptors has been shown to be increased during the $\mathrm{S}$ phase in cancer cells. Therefore, these sites could provide an important marker of cellular proliferation rates. Very few attempts to prepare PET and SPECT radioligands for sigma-2 receptors have been reported. Progress in this area currently lags behind that of sigma-1 tracer development due to the lack of highly selective sigma-2 binding compounds. No PET radiotracers with clear potential have been reported to date. However, regardless of the subtype targeted, the development of sigma receptor imaging agents for tumor visualization still remains a promising and active area of research.

\subsection{Tumor hypoxia imaging}

Several clinical trials have confirmed that hypoxia may be a cure-limiting factor in radiotherapy. These trials include studies showing that improvements in local control can be achieved by the use of hypoxic cell radiosensitizers or hyperbaric oxygen and that reduced hemoglobin levels and low tumor $\mathrm{PO}_{2}$ are associated with higher treatment failure rates. As such, identification and quantification of tumor hypoxia may predict outcome and may identify patients who might benefit from concomitant radiosensitizing therapy to overcome the hypoxia effect [166-170].

For the purpose of hypoxia imaging by means of PET, imidazole and non-imidazole- containing imaging agents have been developed. The 2-nitro-imidazole moiety present in $\left[{ }^{18} \mathrm{~F}\right]$ misonidazole $\left(\left[{ }^{18} \mathrm{~F}\right] \mathrm{MISO}\right)$ acts as a bioreductive molecule, accepting a single electron and producing a free-radical anion that, after further reduction, is then incorporated into cell constituents under hypoxic conditions. In contrast, in [ $\left.{ }^{62} \mathrm{Cu}\right]$ diacetylbis(N-4-methylthiosemicarbazone) $\left(\left[{ }^{62} \mathrm{Cu}\right] \mathrm{ATSM}\right)$ the radiolabelled complex is believed to be bioreducible by itself.

\subsection{1. $\left[{ }^{18} \mathrm{~F}\right] \mathrm{MISO}$}

\subsubsection{Pre-clinical data}

$\left[{ }^{18} \mathrm{~F}\right] \mathrm{MISO}$ was shown to bind selectively to hypoxic cells both in vitro and in vivo at radiobiologically significant oxygen levels [171].

\subsubsection{Clinical data}

Koh et al. evaluated $\left[{ }^{18} \mathrm{~F}\right] \mathrm{MISO}$ tumor uptake in eight patients with selected cancers, five of whom suffered from primary head and neck carcinoma [162, 163]. All patients were imaged prior to primary radiotherapy and three returned for follow-up scans, resulting in a total of 11 imaging studies. Six of eight pre-radiotherapy studies revealed $\left[{ }^{18} \mathrm{~F}\right]$ MISO retention exceeding a tumor-to-plasma concentration ratio of 1.4 by $2 \mathrm{hr}$. pi. According to this criterion, all five patients with head and neck carcinoma had positive scans. Toward the end of a course of fractionated radiotherapy, the three repeat studies performed in patients with initially positive scans showed no tumor accumulation of drug above the threshold ratio of 1.4, which suggests that reoxygenation had occurred. On the other hand, in a group of seven locally advanced non-small cell lung cancer patients undergoing sequential $\left[{ }^{18} \mathrm{~F}\right] \mathrm{MISO}$ imaging during fractionated radiotherapy, measuring changes in oxygenation proved difficult to predict [172, 173]. Rasey et al. studied 37 patients suffering from a variety of tumors, 36 of whom showed $\left[{ }^{18}\right.$ F]MISO uptake [171]. The extent of uptake varied markedly between tumors in the same site or of the same histology.

\subsection{2. $\left[{ }^{62} \mathrm{Cu}\right] \mathrm{ASTM}$}

3.5.2.1. Pre-clinical data

$\left[{ }^{62} \mathrm{Cu}\right]$ ASTM uptake in EMT6 tumors grown in $\mathrm{BALB} / \mathrm{c}$ mice occurred preferentially in hypoxic tumor tissue [174].

\subsubsection{Clinical data}

PET studies performed in four normal subjects and in six patients with lung cancer showed rapid clearance from blood and intense tumor uptake in all six patients. A negative correlation was observed between blood flow and flow-normalized $\left[{ }^{62} \mathrm{Cu}\right] \mathrm{ASTM}$ uptake, which suggests an enhancement of retention of $\left[{ }^{62} \mathrm{Cu}\right]$ ASTM by low flow. 


\subsection{Visualizing cellular proliferation}

Both radiolabelled thymidines, respectively $2-\left[{ }^{11} \mathrm{C}\right]$ thymidine, [methyl- $\left.{ }^{11} \mathrm{C}\right]$ thymidine, and $\left[{ }^{18} \mathrm{~F}\right]$ fluorothymine, as well as halogenated deoxyuridines, respectively ${ }^{76} \mathrm{Br}$-deoxyuridine, ${ }^{124} \mathrm{I}$-deoxyuridine and $\left[{ }^{18} \mathrm{~F}\right]$ fluorodeoxyuridine, have been developed for imaging tumor proliferation [132,175-198].

$2-\left[{ }^{11} \mathrm{C}\right]$ thymidine and methyl $\left[{ }^{11} \mathrm{C}\right]$ thymidine were shown to be taken up by a wide variety of human tumor tissues, including lymphoma, small cell lung carcinoma and sarcoma, head and neck carcinoma, brain tumors, and renal carcinoma. In contrast, clinical studies on halogenated deoxyuridines are limited to patients suffering from brain carcinoma. In general, for both radiolabelled thymidines as well as deoxyuridines, different uptake levels were reported in a large proportion of patients, indicating that different information was being obtained. Firm proof that the degree of tumor uptake of these radiopharmaceuticals relates to differences in the human tumor proliferation rate has not been provided so far. Additionally, both 2$\left[{ }^{11} \mathrm{C}\right]$ thymidine and methyl $\left[{ }^{11} \mathrm{C}\right]$ thymidine, as well as $\left[{ }^{76} \mathrm{Br}\right]$ deoxyuridine and $\left[{ }^{124} \mathrm{I}\right]$ deoxyuridine, are rapidly metabolized, resulting in high background activity and low tumor uptake. Contrariwise, $\left[{ }^{18} \mathrm{~F}\right]$ fluorothymidine is much more resistant to in vivo degradation and is more avidly taken up by tumor tissues. Initial clinical results suggest that $\left[{ }^{18} \mathrm{~F}\right]$ fluorothymidine tumor uptake values correlate significantly with tumor proliferative status. Whether, however, $\left[{ }^{18} \mathrm{~F}\right]$ fluorothymidine can be used as a proliferation marker after therapeutic interventions currently is unknown. Accordingly, studies that address the biological interpretation of accumulation early after therapeutic intervention are warranted.

\subsection{Cell metabolism imaging: Fluoredeoxyglucose PET}

$\left[{ }^{18} \mathrm{~F}\right]$ fluorodeoxyglucose $\left(\left[{ }^{18} \mathrm{~F}\right] \mathrm{FDG}\right)$, a glucose ana$\log$, is transported by facilitated diffusion into the cell, where it is phosphorylated by hexokinase. [ $\left.{ }^{18} \mathrm{~F}\right] \mathrm{FDG}-$ 6-phosphate is effectively "trapped," as it is not a substrate for the subsequent enzymatically driven pathways for glucose metabolism, and the rate of dephosphorylation is slow in tissue with low levels of glucose6-phosphatase. As early as 1925, Warburg and colleagues showed that tumor cells have high glucolytic rates of metabolism, which explains why enhancement of $\left[{ }^{18} \mathrm{~F}\right] \mathrm{FDG}$ uptake is ubiquitous in malignant tumors. It remains unclear, however, what specifically medi- ates tumor $\left[{ }^{18} \mathrm{~F}\right] \mathrm{FDG}$ uptake. It has been documented that uptake depends on the expression of glucose transporters on the tumor cell membrane, on the presence of hexokinase, and on the level of glucos- 6 phosphatase; but it appears that no single factor may be responsible universally [199-201]. In fact, different tumors may have different mechanisms to account for their uptake of $\left[{ }^{18} \mathrm{~F}\right] \mathrm{FDG}$, and a combination of factors may exist in the same tumor. Activated macrophages avidly take up $\left[{ }^{18} \mathrm{~F}\right] \mathrm{FDG}$, and their infiltration into tumors also has been implicated in increased $\left[{ }^{18} \mathrm{~F}\right] \mathrm{FDG}$ accumulation. For previously untreated breast cancer, however, uptake mainly is in tumor cells.

\subsubsection{Lung carcinoma}

\subsubsection{Staging of solitary lung nodules}

Identification of the underlying benign or malignant nature of solitary lung nodules is achieved mainly through bronchoscopy and/or transthoracic puncture. For proximal lesions, the diagnostic yield of bronchoscopy varies from 20-80\%. Similarly, for lesions located in the periphery, when performed under CTguidance, the diagnostic yield of transthoracic puncture approximates $80 \%$. When, however, both techniques either are inconclusive or unfeasible due to increased risk of pneumothorax or damage to vital organs, $\left[{ }^{18} \mathrm{~F}\right]$ FDG PET is of interest. Several studies have addressed the potential of $\left[{ }^{18} \mathrm{~F}\right] \mathrm{FDG}$ PET to discriminate benign from malignant solitary pulmonary lesions. These studies recently have been the subject of a meta-analysis that demonstrated an overall sensitivity of $94 \%$ and a specificity of $73 \%$ for this indication. Importantly, by using $\left[{ }^{18} \mathrm{~F}\right] \mathrm{FDG}$ PET for this indication, the number of surgical diagnostic biopsies can be reduced by $20 \%$ [202-204].

\subsubsection{Mediastinal staging of non-small cell lung carcinoma}

The only curative treatment for patients suffering from non-small cell lung carcinoma is surgery. The decision to perform surgery relies mainly upon the extent of invasion of the mediastinum; only patients with lymph-node involvement that is limited or equal to an N2 stage are good candidates for surgery. Although mediastinoscopy is the most performed technique for staging of the mediastinum, it is invasive and is associated with a $2-3 \%$ morbidity. Accordingly, noninvasive techniques are desirable. During the past 10 years, the cornerstone of non-invasive mediastinal staging has been the $\mathrm{CT}$ scan, with reported sensitivities and specificities respectively varying from 48-91\% and 53- 
99\% when compared to mediastinoscopy. The criterion used most often to differentiate benign from malignant lymph nodes is their size; in general, lesions larger than $10 \mathrm{~mm}$ in size are considered malignant. In the past few years, $\left[{ }^{18} \mathrm{~F}\right]$ FDG PET also has been studied for its potential to non-invasively stage the mediastinal status in patients suffering from non-small cell lung carcinoma. As illustrated by the meta-analysis by Dwamena et al., it appears that the performance of $\left[{ }^{18} \mathrm{~F}\right] \mathrm{FDG}$ PET for this indication varies depending upon the results obtained by CT [205]. If the CT scan is negative, sensitivity and specificity are $74 \%$ and $96 \%$, respectively. If, on the other hand, the CT scan is positive, the sensitivity increases to $95 \%$; however, specificity drops to $76 \%$. Of interest, in a study by Van Steenkiste et al., implementation of $\left[{ }^{18} \mathrm{~F}\right]$ FDG PET resulted in a $25 \%$ reduction in surgical biopsies and/or medistinoscopy [206,207]. Meta-analysis concluded that PET is superior to CT for mediastinal staging of non-small cell lung cancer, independent of performance index or clinical context of PET imaging [205]. Marom et al. also demonstrated that whole-body PET analysis is more accurate than are thoracic CT, bone scintigraphy, and brain CT or MR imaging in staging bronchogenic carcinoma [208]. Finally, Peiterman et al. reported that PET improves the rate of detection of local and distant metastases in patients with non-small cell lung cancer [209].

\subsubsection{Extra-thoracic staging}

Available studies on the potential of $\left[{ }^{18} \mathrm{~F}\right] \mathrm{FDG}$ PET for extra-thoracic staging, although limited in number, suggest that the technique is superior to conventional staging techniques. More specifically, it appears that $\left[{ }^{18} \mathrm{~F}\right]$ FDG PET can reduce the number of false-positive surrenal gland localizations and bone metastases suggested respectively on CT scan and bone scan [210].

\subsubsection{Breast carcinoma}

\subsubsection{Diagnosis of primary breast carcinoma}

The overall reported sensitivity and specificity of $\left[{ }^{18} \mathrm{~F}\right]$ FDG PET for the diagnosis of primary breast carcinoma varies from $67-100 \%$ and from $75-100 \%$, respectively, with the highest sensitivity and specificity being obtained when clinically palpable lesions or lesions superior to $1.5 \mathrm{~cm}$ in size were studied. In contrast, when dealing with non-palpable tumors, the reported sensitivity and specificity is significantly lower, although still acceptable, ranging respectively from 70$95 \%$ and $70-90 \%$. For lesions smaller than or equal to $10 \mathrm{~mm}$, the sensitivity is poor, relating to the physical detection limits of the PET camera and to the poor glucose utilization of small lesions. For the purpose of diagnosing primary breast carcinoma, the technique should be reserved for patients with breast prosthesis, dense breasts, or structurally modified breast tissue (e.g., due to previous radiotherapy), in whom mammography and echography are suboptimal. Importantly, as with any morphological imaging technique, it does not replace biopsy [210-213].

\subsubsection{Staging of the axilla}

Reported sensitivity and specificity of $\left[{ }^{18} \mathrm{~F}\right] \mathrm{FDG}$ PET for staging the axilla in patients suffering from breast carcinoma range from $60-100 \%$ and $70-100 \%$, respectively. The results of these studies should be placed against those obtained by the sentinel-node procedure performed by means of lymphoscintigraphy and handheld gamma probes. The choice of one of the two techniques is likely to vary from one center to another and will depend upon availability, expertise, surgical opportunities, and adopted oncological strategies [211213].

\subsubsection{Detection of tumor recurrence}

$\left[{ }^{18} \mathrm{~F}\right]$ FDG PET is essential when a recurrence of breast carcinoma is suspected either clinically or biochemically. Reported sensitivities and specificities of $\left[{ }^{18} \mathrm{~F}\right]$ FDG PET for this indication range from $84-100 \%$ and 55-100\%, respectively. By virtue of its wholebody imaging capacity, the technique can substitute for many other diagnostic assessments aimed at uncovering the site of recurrence [211-213].

\subsubsection{Monitoring response to treatment}

Initial reports on $\left[{ }^{18} \mathrm{~F}\right] \mathrm{FDG} \mathrm{PET}$ as a tool for prediction or early assessment of response to chemotherapy based on tumor response at the biochemical level in patients suffering from breast carcinoma are promising but need to be explored more extensively. Specifically for $\left[{ }^{18} \mathrm{~F}\right] \mathrm{FDG}$ PET, additional studies to determine the optimal percentage SUV decrease following the first course of chemotherapy when compared to baseline values in terms of accuracy are warranted. This cut-off value should target $100 \%$ sensitivity as, from a clinical point of view, it would be unethical to discontinue any effective chemotherapeutic treatment. When adopting such criterion, available data suggest that $90 \%$ of breast carcinoma patients who receive neoadjuvant chemotherapy could accurately be defined as responders or non-responders as early as two to three weeks following treatment instigation. In the palliative setting, a lower accuracy of $\left[{ }^{18} \mathrm{~F}\right] \mathrm{FDG}$ PET is to 
be expected, given the potential influence of previous treatment and the related more substantial infiltration of inflammatory cells [214].

\subsection{Choline}

Choline, an important natural substrate for a variety of biochemical pathways, is utilized in every cell in the body, including membrane synthesis and cholinergic neurotransmission. There is a growing body of evidence that suggests that the tumoral uptake of choline and conversion to phosphatidyl choline is coupled with tumor proliferation. Early work with $\left[{ }^{3} \mathrm{H}\right]$ choline and neuroblastoma cell lines demonstrated the rapid influx and conversion to phosphorylcholine [215]. Brain magnetic resonance spectroscopy (MRS) showed an enhanced signal in the tumor relative to normal [216218], and this signal has been used to differentiate tumor recurrence from radiation necrosis. Proton MRS studies of the prostate also have shown an increase in choline and decreased citrate in tumors. Methyl protons are visible in the in vivo spectra from normal and tumor tissue of the brain and prostate [219,220].

Carbon-11-labeled choline first was produced at Lawrence Berkeley National Laboratory in the early 1980s [221,222] to study brain uptake and conversion to acetylcholine. It was observed that $\left[{ }^{11} \mathrm{C}\right]$ choline was not readily taken up in the normal brain tissue and that its distribution mimicked that of $\left[{ }^{14} \mathrm{C}\right]$ phosphorylcholine. Indeed, $\left[{ }^{3} \mathrm{H}\right]$ choline studies demonstrated that the radiolabel in the brain and other organs was not associated with acetylcholine but rather phosphorylcholine [223]. It was not until the late 1990s that the first studies of $\left[{ }^{11} \mathrm{C}\right]$ choline as a tumor-imaging agent emerged.

The first reports of $\left[{ }^{11} \mathrm{C}\right]$ choline imaging prospects in cancer were in brain tumors where accumulation of the label was high compared to the surrounding normal brain tissue, which provided excellent tumor/brain contrast [224,225]. It also was found that $\left[{ }^{11} \mathrm{C}\right]$ choline cleared the blood faster than did FDG, and it offered tumor-to-normal-tissue ratios greater than did $\left[{ }^{11} \mathrm{C}\right]$ methionine [224]. Given that the urinary excretion of $\left[{ }^{11} \mathrm{C}\right]$ choline was minimal, prostate tumors were discernable easily [226]. Additionally, $\left[{ }^{11} \mathrm{C}\right]$ choline PET was more sensitive at detecting bone metastases than was bone scintigraphy. Thus, $\left[{ }^{11} \mathrm{C}\right]$ choline is a suitable PET tracer for primary and metastatic tumors of the brain, prostate, and other regions of the body [227].
Given the success of the $\left[{ }^{11} \mathrm{C}\right]$ choline for imaging a spectrum of tumors, a fluorine-18-labeled choline was sought. The advantages of a fluorine-18 tracer are longer half-life, which translates into widespread availability and shorter positron range, and provides improved image quality. Several choline analogs that contain fluorine were examined and yielded two candidates for further study: $\left[{ }^{18} \mathrm{~F}\right]$ fluoromethyl-dimethyl-2hydroxyethyl-ammonium (fluorocholine) and 2-[ $\left.{ }^{18} \mathrm{~F}\right] \mathrm{f}-$ luoroethyl-dimethyl-2-hydroxyethyl-ammonium(fluoroethylcholine) [228,229]. Both tracers have been evaluated in vitro and in patient tumor-imaging studies. The two agents were rapidly taken up by tumors; however, both exhibited increased excretion through the kidneys and bladder relative to $\left[{ }^{11} \mathrm{C}\right]$ choline $[229,230]$. While these agents may not be superior to FDG for delineating abdominal tumors or metastases, they have very favorable properties for brain tumor imaging and for improving our knowledge of choline metabolism in a variety of tumor types.

\subsection{PET imaging of infection and inflammation}

Radiological techniques such as MRI and spiral computerized tomography can identify in vivo small focal abnormalities. However, these methods rely on morphological changes and are not accurate enough in detecting inflammation or infection. They do not provide information on the state of activity of the process. For these reasons, nuclear-medicine-based imaging modalities have been used successfully in the last decades to study inflammation/infection in vivo [231,232,234]. In particular, a radiopharmaceutical designed for imaging infection and inflammation accumulates in the lesion due to the locally changed physiological condition such as enhanced blood flow, enhanced vascular permeability, and presence of metabolically active white blood cells. Thus, scintigraphic images largely do not depend on morphological changes. In the last years, to increase the specificity of scintigraphic imaging, new receptor-targeted radiopharmaceuticals also have been synthethized. These can provide useful biochemical information for diagnosis and therapy decisionmaking.

Nevertheless, the superior image quality, better resolution, and attenuation correction of positron-emitting radionuclides recently has suggested the use of PET scintigraphy in the study of inflammation/infection. As a result of its favorable physical characteristics, fluorine-18 appears to be the best candidate for labelling bioactive peptides $[235,236]$. Indeed, with the exception of ${ }^{18} \mathrm{~F}$-labelled- and ${ }^{66} \mathrm{Ga}$-labelled or ${ }^{68} \mathrm{Ga}-$ 
labelled somatostatin analogs, no peptides have been labelled yet for PET use in inflammation/infection imaging [237-239]. The autoradiographic finding that intratumoral $\left[{ }^{18} \mathrm{~F}\right] \mathrm{FDG}$ distribution in certain tumors is highest in the reactive inflammatory tissue (i.e., the activated macrophages and leukocytes surrounding the neoplastic cells) has provided the rationale for using $\left[{ }^{18} \mathrm{~F}\right] \mathrm{FDG}$ in inflammatory lesions [240,241].

In an experimental rat model of turpentine-induced inflammation, Yamada et al. showed that $\left[{ }^{18} \mathrm{~F}\right] \mathrm{FDG}$ uptake is high in inflammatory tissue and that uptake is higher in chronic than in acute inflammation [242]. In another rat model of Escherichia coli infection, it was demonstrated that $\left[{ }^{18} \mathrm{~F}\right] \mathrm{FDG}$ uptake is higher than that of other radiotracers such as 67-gallium, radiolabelled thymidine, methionine, and human serum albumin, particularly in areas rich in inflammatory cells and in surrounding necrotic regions [243]. Several other reports have confirmed the potential of $\left[{ }^{18} \mathrm{~F}\right]$ FDG PET imaging in different types of infection and inflammation [244-249]. Nevertheless, the routine introduction of $\left[{ }^{18} \mathrm{~F}\right]$ FDG PET in the field of clinical infectious imaging is justified only if an added value compared to more available techniques can be shown; i.e., if patient management can be altered and if cost-effectiveness can be demonstrated. Furthermore, it must be well considered that the specificity of $\left[{ }^{18} \mathrm{~F}\right] \mathrm{FDG}$ PET can be limited by the fact that $\left[{ }^{18} \mathrm{~F}\right] \mathrm{FDG}$ accumulates in sterile inflammatory lesions and tumors.

In conclusion, some indications are especially promising for $\left[{ }^{18} \mathrm{~F}\right]$ FDG PET [250]. These include (1) chronic osteomyelitis, especially in the central skeleton, where other imaging modalities have shown to be poorly accurate; (2) fever of unknown origin, where it seems to be cheaper and preferable over the combination of CT scan, gallium scan, and radiolabelled-WBC scan; and (3) AIDS patients, particularly for the differential diagnosis of CNS lesions and for the early detection of complications. Results obtained so far certainly are encouraging and will lead soon to the development of ${ }^{18} \mathrm{~F}$-labelled peptides tailored for specific and accurate imaging of inflammatory processes. Particular classes of peptides that are excellent candidates for specific receptor imaging in inflammation and infection include cytokines and chemokines [251]. Some of these have been labelled with iodine-123 or technetium-99m to produce a new class of radiopharmaceutical that, by highlighting in vivo the binding to specific receptors expressed on selected cell populations, allow the molecular and functional characterization of immune-mediated processes [232,251,252].
Cytokines and chemokines are soluble proteins produced by a large variety of activated cells that, via binding to specific receptors, play an important role in controlling cell function, motility, homing, neoplastic transformation, and metastasis [253]. Among the cytokines, chemokines are a large family of small proteins that, after binding with the receptors, are able to regulate several biological processes, including $\mathrm{T}$ celldifferentiation and trafficking, angiogenesis, extracellular matrix component production, hematopoiesis, and organogenesis [254,255].

Several groups have radiolabelled IL2 to target Tlymphocytes and monocytes in chronic, mononuclearcell-mediated, inflammatory processes, such as autoimmune diseases [256-262], kidney graft rejection [263], and melanoma characterized by over-expression of CD25 (interleukin-2 receptors) [264]. Clinical studies have demonstrated the efficacy of using scintigraphy to detect radiolabelled IL2 specifically targeted to activated lymphocytes, which correlates with the severity of tissue-lymphocytic infiltration and can be used to monitor the efficacy of therapies [260,261].

In animal models, $\left[{ }^{125} \mathrm{I}\right] \mathrm{IL} 12 \mathrm{p} 40$, a peptide derived from IL12, a Th1-specific cytokine, showed specific binding to tissue-infiltrating lymphocytes [265]. Also, radiolabelled IL1 and IL1 receptor antagonists (IL1ra) have been studied extensively in animal models of acute inflammation, where they showed specific binding to granulocytes, and in humans in rheumatoid arthritis [266-272]. [ $\left.{ }^{99} \mathrm{mTc}\right]$ labelled monocyte chemotactic peptide-1 (MCP-1) has been used recently for the specific imaging of macrophages in animal models of subacute inflammatory diseases [273], and interleukin-6 has been used for acute inflammation [274].

Among chemokine receptor ligands, several authors have investigated extensively the use of radiolabelled interleukin-8 (IL8) in the pre-clinical and clinical setting [275-281]. IL8 is a member of the CXC-family of chemokines, which bind with high affinity to the type I and II CXC-receptor that is expressed abundantly on neutrophils and monocytes.

The deeper knowledge of the pathology of the diseases clarifies mechanisms at the molecular levels that create the rationale for new applications in molecular nuclear medicine and, in the future, we will observe an increase in new radiolabelled peptides for imaging inflammation, infection, and tumors, both by SPECT and PET technology. One promising future development that deserves attention is the development of PET imaging agents for cytokine and chemokine receptors, to define processes of infection and inflammation and 
to distinguish such processes from malignant legions. Such a development would provide a powerful means to establish selectively the presence of cancer more effectively than does PET imaging with $\left[{ }^{18} \mathrm{~F}\right] \mathrm{FDG}$ alone.

\subsection{Imaging gene expression by PET}

A more recent advance in PET imaging involves the quantification of in vivo gene expression, although progress in all respects essentially is in the pre-clinical stage of development. Several recent, excellent reviews have been published that cover both PET and SPECT applications and include induced gene expression in many organs, such as the heart, brain, liver, lung, and malignant tumors [282-289]. The target gene can be one that occurs naturally in the organ or tissue of interest, where the aim of the study is to quantify the expression of the protein encoded for in that gene. In essence, all of the PET imaging and quantification of endogenous receptors, enzymes, and proteases really are measures of gene expression. Alternatively, reporter genes, through molecular biology manipulations, can be included downstream of a therapeutic gene as part of a synthetic construct. Successful transfection and expression of the therapeutic gene then is monitored by imaging the reported gene through radiotracer methods. Some of the new innovative reporter gene constructs that have proved effective in vivo include the herpes simplex virus 1 thymidine kinase (HSV1-TK) [289291], somatostatin receptor subtype 2 (SSTR2) [288], cytosine deaminase [291,292], and the dopamine D2 receptor [285,292]. All of these could be suitable for imaging gene promoter activation and repression, signal transduction pathways, and protein-protein interactions in vivo. One positive aspect of the reporter probe approach is that the reporter gene can be selected such that its product can be detected in vivo by a solidly validated PET probe. This is an advantage that eliminates problems of designing new, effective radiotracers for each gene of interest, since the same reporter probe can be used indirectly to report on the expression of many different primary target genes of interest for which no PET radioligand exists. The field of reporter gene imaging, whether the product is quantified by PET, SPECT, or non-nuclear-based imaging methods such as optical or MR imaging techniques, is in the very early years of development. The future should provide many novel, exciting, and clinically relevant applications of this new and emerging technology and, due to its high sensitivity and quantification potential, PET imaging is very likely to play a pivotal role.

\subsection{Positron-emitting metals used in tumor imaging}

Discussion of the use of radio-metallic nuclides should include mention of the coordination chemistry associated with incorporating these nuclides into biologically useful molecules. However, such a discussion is beyond the scope of this review, and the article by Anderson and colleagues [293] serves as an excellent starting point for the interested reader. Specific discussions of copper chemistry can be found in reports by Welch [294] and Ashfield [295]. Nevertheless, the specific positron-emitting metals that have been explored over the last five years are listed in Table 1, along with their modes of production and decay properties.

The imaging studies that make use of the metals can be characterized as those that involve measurements of blood flow, the hypoxic nature of the tissue in question, or the receptor status of tumors. Copper-62 (II) pyruvaldehyde bis-(N4-methyl)thiosemicarbazone ([ $\left.\left.{ }^{62} \mathrm{Cu}\right] \mathrm{PTSM}\right)$, known for its ability to measure blood flow in neurological and cardiac studies, has been used to study the feasibility of monitoring changes in tumor blood flow [296]. Using the same chemical characteristics, the copper isotopes 60, 62, and 64, combined with PTSM, have been proposed for identifying multi-drug resistant (MRD) tumors.

$\mathrm{Cu}$ (II)-diacetylbis(N4-methylthiosemicarbazone) ( $\mathrm{Cu}-\mathrm{ATSM})$ is reduced rapidly to the $\mathrm{Cu}(\mathrm{I})$ form in hypoxic tissue, causing it to be irreversibly trapped in this tissue. Chao et al. [297] labeled ATSM with ${ }^{60} \mathrm{Cu}$ and demonstrated the feasibility of using $\mathrm{Cu}$-ATSM to monitor hypoxic tissue in cooperation with image-guided radiation therapy.

In an illustration of how modifying the structure of the ligand can impact the biological qualities of a tracer, the compound 1,4,8,11-tetraazacyclotetradecane-N,N', N",N"'-tetraacetic acid-Tyr3-octreotate (TETA-Y3-TATE) was synthesized and radiolabeled with ${ }^{64} \mathrm{Cu}$ and its receptor-binding properties were determined. The characteristics of TETA-Y3-TATE appear to be superior to the other octreotide analog, $\left[{ }^{64} \mathrm{Cu}\right] 1,4,8,11$ tetraazacyclotetradecane-N,N',N",N"'-tetraacetic acid -OC ([ $\left.{ }^{64} \mathrm{Cu}\right]$ TETA-OC [298].

Of the copper isotopes, ${ }^{64} \mathrm{Cu}$ appears to be the most promising in terms of high-resolution imaging, due to its low positron-emission energy, and in terms of widespread usage, because it has a half-life $(12.4 \mathrm{hr})$ suitable for production at a number of locations and shipping to distant sites. In this regard, it is much like ${ }^{123} \mathrm{I}$, which has a similar half-life. However, with the relatively short half-life, multiple production cen- 
Table 1

Positron-emitting metallic radionuclides

\begin{tabular}{|c|c|c|c|c|}
\hline Isotope & $\mathrm{T} 1 / 2(\mathrm{~h})$ & Methods of production & Decay mode & $\mathrm{E} \beta+_{-}(\mathrm{keV})$ \\
\hline${ }^{45} \mathrm{Ti}$ & 3.1 & ${ }^{\text {nat }} \mathrm{Sc}(\mathrm{p}, \mathrm{n}){ }^{45} \mathrm{Ti}$ & $\beta+(85 \%) \mathrm{EC}(15 \%)$ & 1.04 \\
\hline${ }^{60} \mathrm{Cu}$ & 0.4 & ${ }^{60} \mathrm{Ni}(\mathrm{p}, \mathrm{n}){ }^{60} \mathrm{Cu}$ & $\beta+(93 \%) \mathrm{EC}(7 \%)$ & $3920,3000,2000$ \\
\hline${ }^{62} \mathrm{Cu}$ & 0.16 & ${ }^{62} \mathrm{Zn} /{ }^{62} \mathrm{Cu}$ generator & $\beta+(98 \%) \mathrm{EC}(2 \%)$ & 2910 \\
\hline${ }^{64} \mathrm{Cu}$ & 12.7 & ${ }^{64} \mathrm{Ni}(\mathrm{p}, \mathrm{n}){ }^{64} \mathrm{Cu}$ & $\beta+(19 \%) \mathrm{EC}(41 \%) \beta+-(40 \%)$ & 656 \\
\hline${ }^{66} \mathrm{Ga}$ & 9.5 & $\left.{ }^{63} \mathrm{Cua}, \mathrm{n}\right){ }^{66} \mathrm{Ga}$ & $\beta+(56 \%) \mathrm{EC}(44 \%)$ & 4150,935 \\
\hline${ }^{68} \mathrm{Ga}$ & 1.1 & ${ }^{68} \mathrm{Ge} /{ }^{68} \mathrm{Ga}$ generator & $\beta+(90 \%)$ EC (10\%) & 1880,770 \\
\hline${ }^{86} \mathrm{Y}$ & 14.7 & ${ }^{86} \mathrm{Sr}(\mathrm{p}, \mathrm{n}){ }^{86} \mathrm{Y}$ & $\beta+(33 \%)$ EC $(66 \%)$ & 2335, 20191603,12481043 \\
\hline${ }^{94} \mathrm{mTc}$ & 0.88 & ${ }^{\text {nat }} \mathrm{Mo}(\mathrm{p}, \mathrm{n})^{94} \mathrm{mTc}$ & $\beta+(72 \%)$ EC (28\%) & 2470 \\
\hline${ }^{140} \mathrm{Pr}$ & 0.57 & ${ }^{141} \operatorname{Pr}(\mathrm{p}, 2 \mathrm{n}){ }^{140} \mathrm{Nd}$ & $\beta+(50 \%) \mathrm{EC}(50 \%)$ & \\
\hline
\end{tabular}

Table adapted from Reichert, Lewis, and Anderson (293). References to the production of the radionuclides can be found therein.

ters will be required to meet the needs for imaging and possibly therapy.

The relatively underutilized PET tracer ${ }^{45} \mathrm{Ti}$ has been attached to transferring and used to assess angiogenisis using rodent models of lung cancer and microPET [299].

While ${ }^{66} \mathrm{Ga}$ appears to be a suitable gallium isotope for use in studies requiring a long half-life, its highenergy positrons may limit its utility for PET imaging. Nevertheless, the somatostatin analogue DOT ATOC (DOTA-DPhe1-Tyr3-octreotide) has been labeled with ${ }^{66} \mathrm{Ga}$ and used to image receptor concentration in conjunction with the possibilities of using its high-energy betas for internal radiation therapy [265]. This same ligand also has been labeled with ${ }^{68} \mathrm{Ga}$ and shows better target to non-target ratios as compared to ${ }^{111} \operatorname{In}(7)$. $\mathrm{Ga}$ (III) complexes were tested for their ability to bind to the P-glycoprotein associated with multi-drug resistance (MDR). While ${ }^{67} \mathrm{Ga}$ was used in the studies, the result indicated that ${ }^{68} \mathrm{Ga}$ should be a suitable tracer for imaging the MRD1 P-glycoprotein [300].

In further experiments to assess the viability of using gallium isotopes, an investigation of the in vitro and in vivo performance of a ${ }^{67} \mathrm{Ga}$ complex with cis,cis-1,3,5triaminocyclohexane-N,N',N"-triacetic acid (tachta) as a potential ligand for use as a $\mathrm{Ga}(\mathrm{III})$ radiopharmaceutical for PET imaging was undertaken [301]. According to the authors, serum stability experiments demonstrated that at 5 hours $\left[{ }^{67} \mathrm{Ga}\right]($ tachta) exists in serum as a free complex; that at 24 hours, $30 \%$ of $\left[{ }^{67} \mathrm{Ga}\right]$ (tachta) is reversibly bound to transferrin-albumin fraction of serum; and that this percentage remains unchanged for a period of 4 days. The biodistribution data also appear favorable for the complex's usage as a PET tracer.

Tumor contrast enhancement has been obtained using a multi-step targeting approach consisting of the sequential administration of an antitumor/antihapten bispecific antibody (BS-MAb), a blocker to saturate the antihapten binding sites of the BS-MAb that remains in circulation, and a low-molecular-weight Ga chelate, labeled with the positron emitter ${ }^{68} \mathrm{Ga}$, which serves as the hapten [302]. Good tumor uptake was observed.

Two metals have been used as surrogate markers for their corresponding SPECT/therapy radionuclides. Tc-94m has been used to label an antibody agent as a means for quantifying its SPECT isotope, ${ }^{99} \mathrm{mTc}$, while ${ }^{86} \mathrm{Y}(11)$ has been used in place of ${ }^{90} \mathrm{Y}$, which has no imageable photons, to monitor bio-distributions [303, 304]. Pentolow et al. determined that the coincident photons associated with ${ }^{86} \mathrm{Y}$ decay obscure the image, making quantification difficult. However, this problem can be corrected with a simple sinogram subtraction routine.

The issue of supply always is a concern in developing either new applications of existing radioisotopes or the introduction of new tracers. In this regard, there are two radionuclides that are supplied from generators (see Table 1). While the ${ }^{62} \mathrm{Zn} /{ }^{62} \mathrm{Cu}$ generator has attractive chemical features, it suffers from the need to produce the parent ${ }^{62} \mathrm{Zn}$ on a daily basis with only regional access because of the short half-life of ${ }^{62} \mathrm{Zn}(9.3 \mathrm{hr})$.

The lanthanides offer a unique opportunity to study subtle chemical changes as the choice of chemical properties gradually changes in moving through the series. However, there only are a few radioisotopes in the lanthanide series that decay via positron emission. One of these is the short-lived ${ }^{140} \mathrm{Pr}$. While its half-life appears too short for most applications, its use has been enhanced by supplying it from an in vivo generator. Thus, the ${ }^{140} \mathrm{Nd} / \mathrm{Pr}$ pair is interesting in that the chemistry of the parent is of importance since it becomes the vehicle for delivery, while the imaging is achieved from the positron decay of ${ }^{140} \operatorname{Pr}$ [305]. In the reported work, the ${ }^{140} \mathrm{Pr}$ remained localized over a period of 120 hours. Further validation of this approach is required with a variety of chelating agents. The ${ }^{68} \mathrm{Ge} / \mathrm{Ga}$ 
generator has been around for more than 20 years, yet its incorporation into wide usage has been slow. Of all of the generator systems for PET radioisotopes, it holds the most promise because the half-life for ${ }^{68} \mathrm{Ge}$ is nearly a year and its production rate is sufficiently high to meet a wide distribution. The one deficiency is the short half-life of ${ }^{68} \mathrm{Ga}$ (68 minutes) that will limit its usage to those applications with rapid uptake/clearance kinetics.

\subsection{PET in drug research and development}

The application of imaging in drug development has been discussed for many years. The primary motivation for this strategy is to make more informed decisions, which may have immediate financial and strategic impacts for the company as a whole, earlier in a program. Biomarkers for these types of drug development questions can be divided broadly into three areas: (1) measurement of drug interactions or pharmacokinetics (PK) at the target site, (2) evidence of activity/modulation at the target site, and (3) evidence of clinical benefit.

PET radiopharmaceuticals, by virtue of their highly specific activities, are well positioned to address issues associated with areas (1) and (2) above. In the case of CNS drug development, knowledge of drug occupancy of a central compartment relative to the plasma PK is invaluable in terms of selecting dose and dose regimen to obtain the desired therapeutic benefit. This topic has been reviewed recently [306-315], and at least one society that is focused on the use of PET and other non-invasive imaging modalities in drug evaluation has evolved (see Society of Non-Invasive Imaging in Drug Development, SNIDD, at http://www.snidd.org).

To develop this concept further, we next consider the role of PET radiopharmaceuticals in two scenarios: (1) Assessment of Drug PKs and (2) Assessment of Response to Therapy.

\subsubsection{Assessment of drug pharmacokinetics}

By radiolabeling an oncologic agent with positronemitting radionuclides, one can assess, non-invasively, tissue and tumor PK distinct from plasma PK that is measured through blood sampling. These concepts have been reviewed and a number of interesting articles have been published [310,314,316-319]. A good example is 5-Fluorouracil, a cytotoxic agent that has been in clinical use for more than 30 years. Its mechanism of action requires anabolism to nucleosides and nucleotides that inhibit RNA processing and DNA syn- thesis. Unfortunately, almost $80 \%$ of systematically administered 5-FU is degraded through catabolism to $\alpha$-fluoro- $\beta$-alanine (FBAL). PET imaging studies with 5 - $\left[{ }^{18} \mathrm{~F}\right] \mathrm{FU}$ have demonstrated [314-319] that timeactivity curves over the liver are representative of the catabolism to FBAL. This strategy was used to noninvasively assess the ability of eniluracil (an inactivator of dihydropyrimidine dehydrogenase) to modulate the tissue PK of 5FU. Decreased liver uptake and increased tumor half-life of the radiotracer accompanied increased plasma uracil levels following treatment with eniluracil (20 mg, twice daily for 4 days), suggestive of increased exposure of the tumor to $5-\left[{ }^{18} \mathrm{~F}\right] \mathrm{FU}$ and its anabolites.

Another key application of radiotracers is confirmation that a drug is interacting with the desired target. A recent application [320] involved the use of anti-VEGF humanized monocloncal antibodies (HuMV833) as antiangiogenic agents in a phase 1 trial. A component of the study utilized HuMV833 radiolabeled with the positron nuclide iodine-124 (half-life 4.2 days). The $\left[{ }^{124} \mathrm{I}\right] \mathrm{HuMV} 833$ was co-administered with varying doses of the therapeutic agent, and PET imaging was used to assess the distribution and clearance of the radiotracer from tissues. MRI was used to measure vascular permeability, and as such, assess the antiangiogenic effects of the drug. The study determined that there was a wide variation in clearance from tumors but homogenous PK in other tissues. There was no clear relationship between plasma PK and the PETdetermined clearance of HuMV833 from tumors. Not surprisingly, the measurements of permeability change (and as such biological activity) also were very mixed. Combined, these results demonstrate that assessment of novel angiogenic therapies is complex but that imaging markers of PK can help in understanding pharmacodynamic variability.

As with CNS-targeted drugs, a good anti-cancer agent ideally localizes well in tumor tissues, clears readily from normal organs, and interacts with a target site to elicit a biological response. Anti-cancer drug behavior in vivo typically is monitored indirectly by assessing plasma drug levels over time and by the classical pharmacokinetic measurements (adsorption, distribution, metabolism, and elimination, or ADME). While PET radiotracer methods can serve to visualize such parameters if the drug is labeled directly with a positron-emitting isotope, a potentially more important contribution stems from the use of tracer methods to monitor downstream biochemical responses of tumorassociated cells to drug treatment to report on drug effi- 
cacy. While the use of PET in CNS drug development is increasing rapidly, such methods for the evaluation of anti-cancer drugs are not as mature. Factors that contribute to the slower application of PET in monitoring tumor therapy include the known heterogeneous cellular composition and unpredictable blood flow of tumors, which leads to difficulties in tracer kinetic modeling. Another such factor is the need to assess many key target receptors, enzymes, or second messenger systems involved in tumor processes, including angiogenesis, apoptosis, proliferation, invasion, and up-regulated genes for which no effective PET tracers currently exist.

\subsubsection{Assessment of response to therapy}

The biological response of a tumor to therapeutic intervention can be assessed in a number of ways using PET, and there are a number of PET radiopharmaceuticals that have been studied as tools to monitor these phenomenon. The most widely used PET radiopharmaceutical is $\left[{ }^{18} \mathrm{~F}\right]$ fluordeoxyglucose; uptake of this is enhanced in most malignant tumors. A number of small clinical trials have indicated that quantification of the change in tumor $\left[{ }^{18} \mathrm{~F}\right] \mathrm{FDG}$ uptake may provide an early, sensitive, pharmacodynamic marker of the tumoricidal effect of anti-cancer drugs [198]. A recent example is illustrated in the work by Van den Abbeele and colleagues [321] in looking at the effects of Gleevec in patients with gastrointestinal stromal tumors (GIST). In a study of 64 patients, a decrease in SUV to $\leqslant 2.0$ on or prior to 21-40 days was predictive of long-term clinical response, while SUV > 2.0 was suggestive of poor clinical response/progression.

Other examples of studies in which PET has facilitated anti-tumor drug evaluation include mainly the monitoring of radiolabeled drug to assess tumor uptake and PK, the use of FDG to monitor tumor size and metabolic status, administration of $\left[{ }^{11} \mathrm{C}\right]$ thymidine or radiolabeled amino acids to monitor cellular proliferation rates, and radiolabed substrates of multi-drug resistance (MDR)-associated pumps to monitor drug efflux potential in tumors [322-328]. Future direction of research will involve the development of radiolabeled probes to monitor some of the biochemical markers associated with a desired chemotherapeutic effect rather than imaging the target receptor directly. Such targets might include proliferation-associated proteins including Bcl2, cell-invasion-associated proteases such as Cathepsins B and K, and angiogenic markers including endoglin and tie-2.

Monitoring of tumor-associated, MDR-associated proteins in cancer patients by PET is worthy of further comment. MDR is a kind of resistance of cancer cells to the effects of many structurally and mechanistically unrelated classes of chemotherapic drugs. Classical MDR involves an altered membrane cell transport that results in lower intra-cellular concentrations of therapeutic drug. This is due to the over-expression of a variety of proteins that act as ATP-dependent extrusion pumps. P-glycoprotein (Pgp) and MDR protein (MRP1) are the main members of the family of socalled ABC transporters. It is apparent that, aside from their role in cancer cell resistance, these proteins have multiple physiological functions, since they also are expressed in many normal tissues. Since the presence of such pumps in malignant lesions constitutes resistance to therapy, non-invasive detection of the presence of efflux pumps in tumors can be highly important in determining whether a particular course of treatment will be effective. Such detection is performed by monitoring low uptake of PGP- or MDR-protein-targeted radiotracers in a particular lesion, while significant uptake and good retention of such radiotracers indicates an absense of such efflux mechanisms. Currently, there are a few effective SPECT PGP and MDR radiotracers, including [ $\left.{ }^{99} \mathrm{mTc}\right]$ sestimibi and [ $\left.{ }^{99} \mathrm{mTc}\right]$ tetrofosmin [329-333]. Only a handful of PET tracers, including Gallium (III) lipophilic cation substrates, and carbon-11 labeled PGP substrates, such as verapamil and daunorubicin, have been reported for these sites, all of which currently are in the preliminary stages of development [300,332, 334-336]. It has been hypothesized that developing of PET PGP tracers would provide a more effective way to quantify these sites in tumors as compared to corresponding evaluations carried out by SPECT imaging. This provides the impetus for the development of PET analogs for the assessment of PGP and MDR efflux pumps. It remains to be demonstrated whether PET provides an advantage over SPECT in regard to quantification of active PGP and MDR proteins in the clinical setting. Several reviews on the use of imagingMDR-associated efflux pumps by PET and SPECT methods have been published [332,337-339].

\section{References}

[1] M. Watanabe, H. Okada, K. Shimizu, T. Omura, E. Yoshikawa, T. Kosugi, S. Mori and T. Yamashita, A high resolution animal PET scanner using compact PS-PMT detectors, IEEE Trans Nucl Sci 44(3/2) (1997), 1277-1282.

[2] P.D. Cutler, S.R. Cherry, E.J. Hoffman, W.M. Digby and M.E. Phelps, Design features and performance of a PET system for animal research, J Nucl Med 33 (1992), 595-604. 
[3] N.C. Rouze, W. Winkle and G.D. Hutchins, IndyPET - $a$ high-resolution, high-sensitivity dedicated research scanner, in IEEE Nuclear Science Symposium and Medical Imaging Conference Record 1999, pp. M10-36.

[4] D.L. Bailey, H.E. Young, P.M. Bloomfield, S.R. Meikle, D.E Glass, M.J. Myers, T.J. Spinks, C.C. Watson, P. Luk, A.M. Peters and T. Jones, ECAT ART - A continuously rotating PET camera: performance characteristics, comparison with a full ring system, initial clinical studies, and installation considerations in a nuclear medicine department, Eur J Nucl Med 24(1) (1997), 6-15.

[5] C. Bremer and R. Weissleder, In vivo imaging of gene expression: MR and optical technologies, Acad Radiol 8 (2001), 15-23.

[6] A. Jacobs, J.G. Tjuvajev, M. Dubrovin, T. Akhurst, J. Balatoni, B. Beattie, R. Joshi, R. Finn, S.M. Larson, U. Herrlinger, P.A. Pechan, E.A. Chiocca, X.O. Breakefield and R.G. Blasberg, Positron emission tomography-based imaging of transgene expression mediated by replication-conditional, oncolytic herpes simplex virus type 1 mutant vectors in vivo, Cancer Res 61(7) (2001), 2983-2995.

[7] M.J. Paulus, S.S. Gleason, M.E. Easterly and C.J. Foltz, A Review of high-resolution X-ray computed tomography and other imaging modalities for small animal research, Lab Anim 30 (2001), 36-45.

[8] D.W. Townsend and S.R. Cherry, Combining anatomy and function: the path to true image fusion, Eur Radiol 11 (2001), 1968-1974.

[9] J. Seidel, J.J. Vaquero and M.V. Green, Resolution uniformity and sensitivity of the NIH ATLAS small animal PET scanner: comparison to simulated LSO scanners without depth-ofinteraction capability, in IEEE Nuclear Science Symposium Conference Record, 2001, pp. M9A-5.

[10] G. Di Domenico, A. Motta, G. Zavattini, A. Del Guerra, C. Damiani, V. Bettinardi and M.C. Gilardi, Characterization of the Ferrara animal PET scanner, Nucl Instrum Meth 477(1-3) (2002), 505-508.

[11] S. Weber and C.C. COLLABORATION, The ClearPET project: development of a 2nd generation high performance small animal PET scanner. HiRes2001: High Resolution Imaging In Small Animals: Instrumentation, Applications And Animal Handling, Rockville, MD, September 9-11, 2001.

[12] A. Del Guerra, G. Di Domenico, M. Scandola and G. Zavattini, High spatial resolution small animal YAP-PET, $\mathrm{Nucl}$ Instrum Meth A 409 (1998), 508-510.

[13] S.R. Cherry, Y. Shao and S.e.a. Siegel, Optical fiber readout of scintillator arrays using a multi-channel PMT: a high resolution PET detector for animal imaging, IEEE Trans Nucl Sci 43 (1996), 1932-1937.

[14] A.F. Chatziioannou, S.R. Cherry, Y. Shao, R.W. Silverman, K. Meadors, T.H. Farquhar, M. Pedarsani and M.E. Phelps, Performance evaluation of microPET: a high resolution lutetium oxyorthosilicate PET scanner for animal imaging, J Nucl Med 40(7) (1999), 1164-1175.

[15] Y.C. Tai, A. Chatziioannou, S. Siegel, J. Young, D. Newport, R.N. Goble, R.E. Nutt and S.R. Cherry, Performance evaluation of the microPET P4: a PET system dedicated to animal imaging, Phys Med Biol 46(7) (2001), 1845-1862.

[16] P. Bruyndonckx, X. Liu, S. Tavernier and S. Zhang, Performance study of a 3D small animal PET scanner based on $\mathrm{BaF} 2$ crystals and a photo sensitive wire chamber, $\mathrm{Nucl}$ Instrum Meth A 392(1-3) (1997), 407-413.
[17] J.S. Huber, W.W. Moses and S.E.e.a. Derenzo, Characterization of a 64 channel PET detector using photodiodes for crystal identification, IEEE Trans Nucl Sci 44 (1997), 11971201.

[18] R. Lecomte, C. Martel and C. Carrier, Status of BGOavalanche photodiode detectors for spectroscopic and timing applications, Nucl Instrum Meth A 278 (1989).

[19] R. Lecomte, J. Cadorette, P. Richard, S. Rodrigue and D. Rouleau, Design and engineering aspects of a high resolution positron tomograph for small animal imaging, IEEE Trans Nucl Sci 41 (1994), 1446-1452.

[20] R. Lecomte, J. Cadorette, S. Rodrigue, D. Lapointe, D. Rouleau, M. Bentourkia, R. Yao and P. Msaki, Initial results from the Sherbrooke avalanche photodiode positron tomography, IEEE Trans Nucl Sci 43 (1996), 1952-1957.

[21] J. Cadorette, S. Rodrigue and R. Lecomte, Tuning of avalanche photodiode PET camera, in: Conf Rec, 1992 IEEE Nuclear Science Symposium and Medical Imaging Conference, IEEE Catalog 92CH3232-6 2 (1992), 870-872.

[22] G. Charpak, Electronic imaging of ionizing radiation with limited avalanche in gases, Rev Mod Phys 65(3) (1993).

[23] A.P. Jeavons, R.A. Chandler and C.A.R. Dettmar, A 3D HIDAC-PET camera with sub-millimetre resolution for imaging small animals, IEEE Trans Nucl Sci 46 (1999), 468478.

[24] R.J. Walledge, R. Manavaki, A.J. Reader, A.P. Jeavons, P.J. Julyan, S. Zhao, D.L. Hastings and J. Zweit, Quad-HIDAC PET: comparison of four image reconstruction techniques for high resolution imaging, in IEEE Nuclear Science Symposium Conference Report, 2001, pp. M9C-26.

[25] A. Chatziioannou, Y.C. Tai, N. Doshi and S.R. Cherry, Detector development for microPET II: a $1 \mu \mathrm{l}$ resolution PET scanner for small animal imaging, Phys Med Biol 46 (2001), 2899-2910

[26] D. Lapointe, J. Cadorette, S. Rodrigue, D. Rouleau and R. Lecomte, A microvolumetric blood counter/sampler for metabolic PET studies in small animals, IEEE Trans Nucl Sci 45 (1998), 2195-2199.

[27] J.A. Correia, C.A. Burnham, D. Kaufman and A.J. Fischman, Development of a small animal PET imaging device with resolution approaching $1 \mathrm{~mm}$, IEEE Trans Nucl Sci 46 (1999), 631-635.

[28] S. Park, L. Han, S.J. Wilderman, P. Sukovic, A. Czermak, P. Jalocha, B. Sowicki, M. Kowal, W. Dulinski, G. Maehlum, E. Nygard, K. Yoshioka, J. Fuster, C. Lacasta, M. Mikuz, S. Roe, J. Weilhammer, D. Meier, W.L. Rogers and N.H. Clinthorne, Experimental setup for very high resolution animal PET based on solid state detector, in IEEE Nuclear Science Symposium Conference Record, 2001, pp. M3-1.

[29] J.S. Huber and W.W. Moses, Conceptual design of a high sensitivity small animal PET camera with $4 \pi$ coverage, IEEE Trans Nucl Sci 46 (1999).

[30] G. Zavattini, A. Del Guerra, G. Di Domenico, M. Gambaccini and N. Sabba, High Z and medium Z scintillators in ultra high resolution small animal PET, in 2002 IEEE Nuclear Science Symposium Conference Record CD, 2002, pp. M3-11.

[31] J.W. LeBlanc, N.H. Clinthorne, E. Hua, C.-H. Nygard, W.L. Rogers, D.K. Wehe, P. Weilhammer and S.J. Wilderman, CSPRINT: a prototype Compton camera system for low energy gamma ray imaging, IEEE Trans Nucl Sci 45(3) (1998), 943949.

[32] M. Khodaverdi, F. Pauly, S. Weber, G. Schroder, K. Ziemons, R. Sievering and H. Halling, Preliminary studies of a microCT for a combined small animal PET/CT scanner, in 2001 
IEEE Nuclear Science Symposium Conference Record 3, 2001, pp. 1605-1606.

[33] A. Saoudi and R. Lecomte, A novel APD-based detector module for multi-modality PET/SPECT/CT scanners, IEEE Trans Nucl Sci 46(3) (1999), 479-484.

[34] A. Seidel, J.J. Vaquero, J. Pascau, M. Desco, C.A. Johnson and M.V. Green, Features of the NIH ATLAS small animal PET scanner and its use with a coaxial small animal volume CT scanner, in Proceedings of the 2002 IEEE International Symposium on Biomedical Imaging, 2002, pp. 545-548.

[35] A.F. Chatziioannou, PET scanners dedicated to molecular imaging of small animal models, Molecular Imaging and Biology 4(1) (2002), 47-63.

[36] S.R. Cherry and S.S. Gambhir, Use of positron emission tomography in animal research, ILAR Journal 42(3) (2001), 219-232.

[37] S.R. Meikle, S. Eberl and H. Iida, Instrumentation and methodology for quantitative pre-clinical imaging studies, Curr Pharm Des 7(18) (2001), 1945-1966.

[38] R. Myers, The biological application of small animal PET imaging, Nucl Med Biol 28 (2001), 585-593.

[39] Z.H. Cho and M.R. Farukhi, Bismuth germanate as a potential scintillation detector in positron cameras, J Nucl Med $\mathbf{1 8}$ (1977), 840-844.

[40] M. Ishii, M. Kobayashi, H. Ishibashi, S. Akiyama and C.L. Melcher, Research and development of Ce-doped GSO scintillation crystals, Proc SPIE 2305 (1994), 68-79.

[41] C.L. Melcher and J.S. Schweitzer, Cerium-doped lutetium oxyorthosilicate: a fast, efficient new scintillator, IEEE Trans Nucl Sci NS-39(4) (1992), 502-505.

[42] K. Wienhard, M. Schmand, M.E. Casey, K. Baker, J. Bao, L. Eriksson, W.F. Jones, C. Knoess, M. Lenox, M. Lercher, P. Luk, C. Michel, J.H. Reed, N. Richerzhagen, J. Treffert, S. Vollmar, J.W. Young, W.D. Heiss and R. Nutt, The ECAT HRRT: performance and first clinical application of the new high resolution research tomograph, IEEE Trans Nucl Sci 49(1) (2002), 104-110.

[43] S. Surti, J.S. Karp, L.E. Adam and G. Muehllehner, Performance measurements for the GSO-based brain PET camera $(G-P E T)$, in IEEE Nuclear Science Symposium Conference Record, 2001.

[44] M.E. Casey and R. Nutt, A multicrystal two dimensional BGO detector system for PET, IEEE Trans Nucl Sci 33(1) (1986), 460-463.

[45] S. Surti, J.S. Karp, R. Freifelder and F. Liu, Optimizing the performance of a PET detector using discrete GSO crystals on a continuous lightguide, IEEE Trans Nucl Sci 47(3) (2000), 1030-1036.

[46] J.S. Karp, P.E. Kinahan, G. Muehllehner and P. Countryman, Effect of increased axial field-of-view on the performance of a volume imaging PET scanner, IEEE Trans Med Imag 12 (1993), 299-306.

[47] J.S. Karp, G. Muehllehner, D.A. Mankoff, C.E. Ordonez, J.M. Ollinger, M.E. Daube-Witherspoon, A. Haigh and D. Beerbohm, Continuous-slice PENN-PET: a positron tomograph with volume imaging capability, J Nucl Med 31 (1990), 617-627.

[48] J.A. Wear, J.S. Karp, R. Freifelder, D.A. Mankoff and G. Muehllehner, A model of the high count rate performance of NaI(Tl)-based PET detectors, IEEE Trans Nucl Sci $\mathbf{4 5}$ (1998), 1231-1237.

[49] L.E. Adam, J.S. Karp, M.E. Daube-Witherspoon and R.J. Smith, Performance of a whole-body PET scanner using curve-plate $\mathrm{NaI}(\mathrm{Tl})$ detectors, J Nucl Med 42(12) (2001), 1821-1830.

[50] J. Capala, R.F. Barth, M.Q. Bailey, R.A. Fenstermaker, M.J. Marek and B.A. Rhodes, Radiolabeling of epidermal growth factor with $99 \mathrm{mTc}$ and in vivo localization following intracerebral injection into normal and glioma-bearing rats, Bioconj Chem 8(3) (1997), 289-295.

[51] D.W. Townsend, M. Wensveen, L.G. Byars, A. Geissbuhler, H.J. Tochon-Danguy, A. Christin, M. Defrise, D.L. Bailey, S. Grootoonk, A. Donath and R. Nutt, A rotating PET scanner using BGO block detectors: design, performance and applications, J Nucl Med 34 (1993), 1367-1376.

[52] C. Nahmias, R. Nutt, R.D. Hichwa, J. Czernin, C. Melcher, M. Schmand, M.S. Andreaco, L. Eriksson, M.E. Casey, J.C. Moyers, C. Michel, T. Bruckbauer, M. Conti, B. Bendriem and J. Hamill, PET tomograph designed for five minute routine whole body studies, J Nucl Med 43(5) (2002), 11P (abstract).

[53] B. Bendriem and D.W. Townsend, The theory and practice of 3D PET, Vol. 32, Dordrecht: Kluwer Academic Publishers, 1998 , pp. 167.

[54] M. Defrise, P.E. Kinahan, D.W. Townsend, C. Michel, M. Sibomana and D.F. Newport, Exact and approximate rebinning algorithms for 3-D PET data, IEEE Trans Med Imaging 16(2) (1997), 145-158.

[55] P.E. Kinahan and J.G. Rogers, Analytic 3-D image reconstruction using all detected events, IEEE Trans Nucl Sci NS36 (1989), 964-968.

[56] R.E. Carson, M.E. Daube-Witherspoon and M.V. Green, A method for postinjection PET transmission measurements with a rotating source, J Nucl Med 29 (1988), 1558-1567.

[57] P.K. Hooper, S.R. Meikle, S. Eberl and M.J. Fulham, Validation of post injection transmission measurements for attenuation correction in neurologic FDG PET studies, $\mathrm{J}$ Nucl Med 37 (1996), 128-136.

[58] S.R. Meikle, D.L. Bailey, P.K. Hooper, S. Eberl, B.F. Hutton, W.F. Jones, R.R. Fulton and M.J. Fulham, Simultaneous emission and transmission measurements for attenuation correction in whole body PET, J Nucl Med 36 (1995), 1680-1688.

[59] C.J. Thompson, N.T. Ranger and A.C. Evans, Simultaneous transmission and emission scans in positron emission tomography, IEEE Trans Nucl Sci 36(1) (1989), 1011-1016.

[60] J.S. Karp, G. Muehllehner, H. Qu and X.H. Yan, Singles transmission in volume-imaging PET with a ${ }^{137} \mathrm{Cs}$ source, Phys Med Biol 40(5) (1995), 929-944.

[61] H. Anderson, P. Price, M. Blomley, M.O. Leach and P. Workman, Measuring changes in human tumour vasculature in response to therapy using functional imaging techniques, $\mathrm{Br} J$ Cancer 85(8) (2001), 1085-1093.

[62] W.F. Jones, J.C. Moyers, M.E. Casey, C.C. Watson and R. Nutt, Fast-channel LSO detectors and fiber-optic encoding for excellent dual photon transmission measurements in PET, IEEE Trans Nucl Sci 46(4) (1999), 979-984.

[63] C.C. Watson, L. Eriksson, M.E. Casey, W.F. Jones, J.C. Moyers, S. Miller, J. Hamill, A. Van Lingen, B. Bendriem and R. Nutt, Design and performance of collimated coincidence point sources for simultaneous transmission measurements in 3-D PET, IEEE Trans Nucl Sci 48(3) (2001), 673-679.

[64] T. Beyer, D.W. Townsend, T. Brun, P.E. Kinahan, M. Charron, R. Roddy, J. Jerin, J. Young, L. Byars and R. Nutt, A combined PET/CT scanner for clinical oncology, J Nucl Med 41 (2000), 1369-1379. 
[65] P.E. Kinahan, D.W. Townsend, T. Beyer and D. Sashin, Attenuation correction for a combined 3D PET/CT scanner, Med Phys 25 (1998), 2046-2053.

[66] T. Beyer, Design, construction and validation of a combined PET/CT tomograph for clinical oncology, PhD Dissertation, University of Surrey (UK), University of Pittsburgh (USA), 1999.

[67] P.A. Renhowe, Growth factor receptor kinases in cancer, in: Annual Reports in Medicinal Chemistry-36, A.M. Doherty, ed., Academic Press, San Diego, CA, 2001, pp. 109-118.

[68] Y. Yarden, The EGFR family and its ligands in human cancer: signalling mechanisms and the therapeutic opportunities, Eur J Cancer 37 (2001), S3-S8.

[69] A.J. Bridges, The epidermal growth factor receptor family of tyrosine kinasees and cancer: can an atypical exemplar be a sound therapeutic target? Curr Med Chem 3 (1996), 167-194.

[70] Y. Yarden and M.X. Sliwkowski, Untangling the ErbB signalling network, Nat Rev 2 (2001), 127-137.

[71] J. Baselga, D. Tripathy, J. Mendelsohn, S. Baughman, C.C. Benz, L. Dantis, N.T. Sklarin, A.D. Seidman, C.A. Hudis, J. Moore, P.P. Rosen, T. Twaddell, I.C. Henderson and L. Norton, Phase II study of weekly intravenous recombinant humanized anti-p185HER2 monoclonal antibody in patients with HER2/neu-overexpressing metastatic breast cancer, $J$ Clin Oncol 14 (1996), 737-744.

[72] M.A. Cobleigh, C.L. Vogel, D. Tripathy, N.J. Robert, S. Scholl, L. Fehrenbacher, J.M. Wolter, V. Paton, S. Shak and G. Lieberman, Multinational study of the efficacy and safety of humanized anti-HER2 monoclonal antibody in women who have HER2-overexpressing metastatic breast cancer that has progressed after chemotherapy for metastatic disease, $J$ Clin Oncol 17 (1999), 2639-2648.

[73] G. Carpenter, Receptors for epidermal growth factor and other polypeptide mitogens, Annu Rev Biochem 56 (1987), 881-914.

[74] A. Andersson, J. Capala and J. Carlsson, Effects of EGFdextran-tyrosine-131I conjugates on the clonogenic survival of cultured glioma cells, J. Neurooncol 14(3) (1992), 213223.

[75] A. Orlova, A. Bruskin, A. Sjostrom, H. Lundqvist, L. Gedda and V. Tolmachev, Cellular processing of ${ }^{125} \mathrm{I}$ - and ${ }^{111} \mathrm{In}-$ labeled epidermal growth factor (EGF) bound to cultured A431 tumor cells, Nuc Med Biol 27 (2000), 827-835.

[76] R.M. Reilly, R. Kiarash, R.G. Cameron, N. Porlier, J. Sandhu, R.P. Hill, K. Vallis, A. Hendler and J. Gariepy, 111In-labeled EGF is selectively radiotoxic to human breast cancer cells overexpressing EGFR, J Nucl Med 41(3) (2000), 429-438.

[77] S. Remy, R. Reilly, K. Sheldon and J. Gariepy, A new radioligand for the epidermal growth factor receptor: ${ }^{111} \mathrm{In}$ labeled human epidermal growth factor derivitized with a bifunctional metal-chelating peptide, Bioconj Chem 6 (1995), 683-690.

[78] M. Rusckowski, T. Qu, F. Chang and D.J. Hnatowich, Technetium-99m labeled epidermal growth factor-tumor imaging in mice, J Pept Res 50(5) (1997), 393-401.

[79] C. Schatten, N. Patiesky, N. Vavra, P. Ehrenbock, P. Angelberger, G. Sivalopenko and A. Epenetos, Lymphoscintigraphy with 123I-labeled epidermal growth factor, Lancet 337 (1991), 395-396.

[80] S. Scott -Robson, J. Capala, J. Carlsson, P. Malmborg and H. Lundqvist, Distribution and stability in the rat of a ${ }^{76} \mathrm{Br} /{ }^{125} \mathrm{I}-$ labelled polypeptide, epidermal growth factor, Int J Rad Appl Instrum B 18(2) (1991), 241-246.
[81] S. Cammilleri, G. Kaphan, Y. Berthois, S. Siles, F. Khelifa and P. Martin, Biodistribution and imaging studies with radioactively labeled monoclonal antibody anti-epidermal growth factor receptor in athymic mice bearing human mammary tumor, Antibody Immunoconj Radiopharm 4 (1991), 501-506.

[82] C.R. Divgi, S. Welt, M. Kris, F.X. Real, S.D. Yeh, R. Gralla, B. Merchant, S. Schweighart, M. Unger, S.M. Larson et al., Phase I and imaging trial of indium 111-labeled antiepidermal growth factor receptor monoclonal antibody 225 in patients with squamous cell lung carcinoma, J Natl Cancer Inst 83(2) (1991), 97-104.

[83] H. Kalofonos, T. Pawlikowska, A. Hemingway, N. Courtenay-Luck, B. Dhokia, D. Snook, G. Sivolapenko, G. Hooker, C. McKenzie, P. Lavender, D. Thomas and A. Epenetos, Antibody guided diagnoisis and therapy of brain gliomas using radiolabeled monoclonal antibodies against epidermal growth factor receptor and placental alkaline phosphatase, $J$ Nucl Med 20 (1989), 1636-1645.

[84] M. Ramos-Suzarte, N. Rodriguez, J.P. Oliva, N. IznagaEscobar, A. Perera, A. Morales, N. Gonzalez, M. Cordero, L. Torres, G. Pimentel, M. Borron, J. Gonzalez, O. Torres, T. Rodriguez and R. Perez, 99mTc-labeled antihuman epidermal growth factor receptor antibody in patients with tumors of epithelial origin: part III. Clinical trials safety and diagnostic efficacy, J Nucl Med 40(5) (1999), 768-775.

[85] R.M. Reilly, R. Kiarash, J. Sandhu, Y.W. Lee, R.G. Cameron, A. Hendler, K. Vallis and J. Gariepy, A comparison of EGF and MAb 528 labeled with 111In for imaging human breast cancer, J Nucl Med 41(5) (2000), 903-911.

[86] D. Fry, A. Kraker, A. McMichael, L. Ambroso, J. Nelson, W. Leopold, R. Connors and A. Bridges, A specific inhibitor of the epidermal growth factor receptor tyrosine kinase, Science 265 (1994), 1093-1095.

[87] D.W. Fry, A.J. Bridges, W.A. Denny, A. Doherty, K.D. Greis, J.L. Hicks, K.E. Hook, P.R. Keller, W.R. Leopold, J.A. Loo, D.J. McNamara, J.M. Nelson, V. Sherwood, J.B. Smaill, S. Trumpp-Kallmeyer and E.M. Dobrusin, Specific, irreversible inactivation of the epidermal growth factor receptor and erbB2, by a new class of tyrosine kinase inhibitor, Proceedings of the National Academy of Sciences 95(20) (1998), 12022-12027.

[88] A. Gazit, N. Osherov, C. Gilon and A. Levitzki, Tyrphostins. 6. Dimeric benzylidenemalononitrile tyrophostins: potent inhibitors of EGF receptor tyrosine kinase in vitro, $\mathrm{J} \mathrm{Med}$ Chem 39(25) (1996), 4905-4911.

[89] P. Traxler and P. Furet, Strategies toward the design of novel and selective protein tyrosine kinase inhibitors, Pharmacol Ther 82 (1999), 195-206.

[90] P. Traxler and N. Lydon, Recent advances in protein tyrosine kinase inhibitors, Drug Future 20 (1995), 1261-1274.

[91] J.K. Lim, K. Negash, S.M. Hanrahan and H.F. VanBrocklin, Synthesis of 4-(3'-[ ${ }^{125}$ I] iodoanilino-6,7dialkoxyquinazolines: radiolabeled epidermal growth factor tyrosine kinase inhibitors, J Labelled Compd Rad 43 (2000), 1183-1191.

[92] G.K. Mulholland, W. Winkle, B.H. Moch and G. Sledge, Radioiodinated epidermal growth factor receptor ligands as tumor probes, Dramatic potentiation of binding to MDA-486 cancer cells in presence of EGF, $J$ Nucl Med 36 (1995), 71P.

[93] T.A. Bonasera, G. Ortu, Y. Rozen, R. Krais, N.M. Freedman, R. Chisin, A. Gazit, A. Levitzki and E. Mishani, Potential (18)F-labeled biomarkers for epidermal growth factor receptor tyrosine kinase, Nucl Med Biol 28 (2001), 359-374. 
[94] E. Mishani, T.A. Bonasera, Y. Rozen, G. Ortu, A. Gazit and A. Levitzki, Fluorinated EGFR-TK inhibitor-based tracers for PET, J Labelled Compd Rad 42(Suppl 1) (1999), S27S29.

[95] S.E. Snyder, P.S. Sherman and J.B. Blair, 4-(3-chloro-4$\left[{ }^{18} \mathrm{~F}\right]$ fluorophenylamino)-6,7-dimethoxyquinazoline: a radiolabeled EGF receptor inhibitor for imaging tumor biochemistry with PET, J Nucl Med 41(Suppl) (2000), 233.

[96] S.E. Snyder, K.M. Whitmer and C. Brown-Proctor, Synthesis of 3-Chloro-4-[ ${ }^{18}$ F]fluoroaniline as a synthon for epidermal growth factor receptor inhibitors for tumor imaging with PET, J Labelled Compd Rad 42(Suppl 1) (1999), S522-S524.

[97] E.O. Aboagye, A.B. Kelson, M. Tracy and P. Workman, Preclinical development and current status of the fluorinated 2-nitroimidazole hypoxia probe $\mathrm{N}$-(2hydroxy-3,3,3-trifluoropropyl)-2-(2-nitro-1-imidazolyl) acetamide (SR 4554, CRC 94/17): a non-invasive diagnostic probe for the measurement of tumor hypoxia by magnetic resonance spectroscopy and imaging, and by positron emission tomography, Anticancer Drug Des 13(6) (1998), 703-730.

[98] J.K. Lim, D.J. Riese II and H.F. VanBrocklin, Synthesis of 4-(4' $\left[{ }^{18}\right.$ F]fluorobenzylamino)-6,7-diethoxyquinazoline: a positron emitting radioprobe for the epidermal growth factor receptor, J Labelled Compd Rad 42(Suppl 1) (1999), S693S695.

[99] G.K. Mulholland, Q.-H. Zheng, W.L. Winkle and K.A. Carlson, Synthesis and biodistribution of new C-11 and F-18 labeled epidermal growth factor receptor ligands, $\mathrm{J} \mathrm{Nucl} \mathrm{Med}$ 38 (1997), 141.

[100] P. Johnstrom, A. Frediksson, J.-O. Thorell and S. StoneElander, Synthesis of [Methoxy-11C]PD153035, a selective EGF receptor tyrosine kinase inhibitor, J Labelled Compd Rad 41 (1998), 623-629.

[101] A. Frediksson, P. Johnstrom, J.-O. Thorell, G. von Heijne, M. Hassan, S. Eksborg, P. Kogner, P. Borgstrom, M. Ingvar and S. Stone-Elander, In vivo evaluation of the biodistribution of 11C-labeled PD153035 in rats without and with neuroblastoma implants, Life Sci 65 (1999), 165-174.

[102] P. Johnstrom, A. Frediksson, J.-O. Thorell, M. Hassan, P. Kogner, P. Borgstrom, M. Ingvar and S. Stone-Elander, Synthesis and in vivo biodistribution of tyrosine kinase inhibitor, [Methoxy-11C]PD 153035, J Labelled Compd Rad 40 (1997), 377-379.

[103] E. Mishani, I. Ben-David, Y. Rozen, G. Ortu and A. Levitski, Carbon-11 labeled irreversible inhibitors for mapping the epidermal growth factor receptor tyrosine kinase, J Labelled Compd Rad 44(Suppl 1) (2001), S99-S101.

[104] G. Ortu, I. Ben-David, Y. Rozen, A. Levitski and E. Mishani, Biological evaluation of a novel ${ }^{11} \mathrm{C}$ labeled irreversible EGFRTK inhibitor, Q J Nucl Med 45(2) (2001), S-7.

[105] J. Folkman, AntiAngiogenesis: new concept for therapy of solid tumors, Ann Surg 175 (1972), 409-416.

[106] M. Shibuya, Structure and function of VEGF/VEGF-receptor system involved in angiogenesis, Cell Struct Funct $\mathbf{2 6}$ (2001), 25-35.

[107] S. Li, M. Peck-Radosavljevic, E. Koller, F. Koller, K. Kaserer, A. Kreil, S. Kapiotis, A. Hamwi, H.A. Weich, P. Valent, P. Angelberger, R. Dudczak, I. Virgolini and R.G. Cameron, Characterization of $\left(^{123}\right)$ I-vascular endothelial growth factor-binding sites expressed on human tumour cells: possible implication for tumour scintigraphy, Int J Cancer 15 (2001), 789-796.

[108] W.A. Weber, R. Haubner, E. Vabuliene, B. Kuhnast, H.J.
Wester and M. Schwaiger, Tumor angiogenesis targeting using imaging agents, Q J Nucl Med 45 (2001), 179-182.

[109] G. Bold, K.H. Altmann, J. Frei, M. Lang, P.W. Manley, P. Traxler, B. Wietfeld, J. Bruggen, E. Buchdunger, R. Cozens, S. Ferrari, P. Furet, F. Hofmann, G. Martiny-Baron, J. Mestan, J. Rosel, M. Sills, D. Stover, F. Acemoglu, E. Boss, R. Emmenegger, L. Lasser, E. Masso, R. Roth, C. Schlachter and W. Vetterli, New anilinophthalazines as potent and orally well absorbed inhibitors of the VEGF receptor tyrosine kinases useful as antagonists of tumor-driven angiogenesis, $J$ Med Chem 43 (2000), 2310-2323.

[110] L.F. Hennequin, E.S. Stokes, A.P. Thomas, C. Johnstone, P.A. Ple, D.J. Ogilvie, M. Dukes, S.R. Wedge, J. Kendrew and J.O. Curwen, Novel 4-anilinoquinazolines with C-7 basic side chains: design and structure activity relationship of a series of potent, orally active, VEGF receptor tyrosine kinase inhibitors, J Med Chem 45 (2002), 1300-1312.

[111] L.F. Hennequin, A.P. Thomas, C. Johnstone, E.S. Stokes, P.A. Ple, J.J. Lohmann, D.J. Ogilvie, M. Dukes, 1.S.R. Wedge, J.O. Curwen, J. Kendrew and C. Lambert-van der Brempt, Design and structure-activity relationship of a new class of potent VEGF receptor tyrosine kinase inhibitors, J Med Chem 42 (1999), 5369-5389.

[112] S.M. Sebti and A.D. Hamilton, Inhibition of Ras prenylation: a novel approach to cancer chemotherapy, Pharmacol Ther 74(1) (1997), 103-114.

[113] J. Sun, Y. Qian, A.D. Hamilton and S.M. Sebti, Both farnesyltransferase and geranylgeranyltransferase I inhibitors are required for inhibition of oncogenic K-Ras prenylation but each alone is sufficient to suppress human tumor growth in nude mouse xenografts, Oncogene 16(11) (1998), 14671473.

[114] T. Petit, E. Izbicka, R.A. Lawrence, W.R. Bishop, S. Weitman and D.D. Von Hoff, Activity of SCH 66336, a tricyclic farnesyltransferase inhibitor, against human tumor colonyforming units, Ann Oncol 10(4) (1999), 449-453.

[115] G.C. Prendergast and N. Rane, Farnesyltransferase inhibitors: mechanism and applications, Expert Opin Investig Drugs 10(12) (2001), 2105-2116.

[116] S.M. Hahn, E.J. Bernhard, W. Regine, M. Mohiuddin, D.G. Haller, J.P. Stevenson, D. Smith, B. Pramanik, J. Tepper, T.F. DeLaney, K.D. Kiel, B. Morrison, P. Deutsch, R.J. Muschel and W.G. McKenna, A phase I trial of the farnesyltransferase inhibitor L-778,123 and radiotherapy for locally advanced lung and head and neck cancer, Clin Cancer Res 8(5) (2002), 1065-1072.

[117] W.G. McKenna, R.J. Muschel, A.K. Gupta, S.M. Hahn and E.J. Bernhard, Farnesyltransferase inhibitors as radiation sensitizers, Semin Radiat Oncol 12(3 Suppl 2) (2002), 27-32.

[118] J. Ohkanda, D.B. Knowles, M.A. Blaskovich, S.M. Sebti and A.D. Hamilton, Inhibitors of protein farnesyltransferase as novel anticancer agents, Curr Top Med Chem 2(3) (2002), 303-323.

[119] W.T. Purcell and R.C. Donehower, Evolving therapies: farnesyltransferase inhibitors, Curr Oncol Rep 4(1) (2002), 2936.

[120] A. Vogt, J. Sun, Y. Qian, A.D. Hamilton and S.M. Sebti, The geranylgeranyltransferase-I inhibitor GGTI298 arrests human tumor cells in G0/G1 and induces p21(WAF1/CIP1/SDI1) in a p53-independent manner, $J$ Biol Chem 272(43) (1997), 2724-2729.

[121] A. Vogt, Y. Qian, T.F. McGuire, A.D. Hamilton and S.M. Sebti, Protein geranylgeranylation, not farnesylation, is re- 
quired for the $\mathrm{G} 1$ to $\mathrm{S}$ phase transition in mouse fibroblasts, Oncogene 13(9) (1996), 1991-1999.

[122] K. Miquel, A. Pradines, J. Sun, Y. Qian, A.D. Hamilton, S.M. Sebti and G. Favre, GGTI-298 induces G0-G1 block and apoptosis whereas FTI-277 causes G2-M enrichment in A549 cells, Cancer Res 57(10) (1997), 1846-1850.

[123] J.V. Swinnen, T. Roskams, S. Joniau, H. Van Poppel, R. Oyen, L. Baert, W. Heyns and G. Verhoeven, Overexpression of fatty acid synthase is an early and common event in the development of prostate cancer, Int J Cancer 98(1) (2002), 19-22..

[124] P.L. Alo, P. Visca, M.L. Framarino, C. Botti, S. Monaco, V. Sebastiani, D.E. Serpieri and U. Di Tondo, Immunohistochemical study of fatty acid synthase in ovarian neoplasms, Oncol Rep 7(6) (2000), 1383-1388.

[125] T.S. Gansler, W. Hardman 3rd, D.A. Hunt, S. Schaffel and R.A. Hennigar, Increased expression of fatty acid synthase (OA-519) in ovarian neoplasms predicts shorter survival, Hum Pathol 28(6) (1997), 686-692.

[126] P.L. Alo, P. Visca, A. Marci, A. Mangoni, C. Botti and U. Di Tondo, Expression of fatty acid synthase (FAS) as a predictor of recurrence in stage I breast carcinoma patients, Cancer 77(3) (1996), 474-482.

[127] P.L. Alo, P. Visca, G. Trombetta, A. Mangoni, L. Lenti, S. Monaco, C. Botti, D.E. Serpieri and U. Di Tondo, Fatty acid synthase (FAS) predictive strength in poorly differentiated early breast carcinomas, Tumori 85(1) (1999), 35-40.

[128] F.P. Kuhajda, E.S. Pizer, J.N. Li, N.S. Mani, G.L. Frehywot and C.A. Townsend, Synthesis and antitumor activity of an inhibitor of fatty acid synthase, Proc Natl Acad Sci USA 97(7) (2000), 3450-3454.

[129] L.Z. Milgraum, L.A. Witters, G.R. Pasternack and F.P. Kuhajda, Enzymes of the fatty acid synthesis pathway are highly expressed in in situ breast carcinoma, Clin Cancer Res 3(11) (1997), 2115-2120.

[130] E.S. Pizer, C. Jackisch, F.D. Wood, G.R. Pasternack, N.E. Davidson and F.P. Kuhajda, Inhibition of fatty acid synthesis induces programmed cell death in human breast cancer cells, Cancer Res 56(12) (1996), 2745-2747.

[131] E.S. Pizer, F.D. Wood, H.S. Heine, F.E. Romantsev, G.R. Pasternack and F.P. Kuhajda, Inhibition of fatty acid synthesis delays disease progression in a xenograft model of ovarian cancer, Cancer Res 56(6) (1996), 1189-1193.

[132] D.A. Mankoff, F. Dehdasht and A.F. Shields, Characterizing tumors using metabolic imaging: PET imaging of cellular proliferation and steroid receptors, Neoplasia 2(1-2) (2000), 71-88.

[133] D.O. Kiesewetter, M.R. Kilbourn, S.W. Landvatter, D.F. Heiman, J.A. Katzenellenbogen and M.J. Welch, Preparation of four fluorine- 18-labeled estrogens and their selective uptakes in target tissues of immature rats, $J$ Nucl Med $\mathbf{2 5}(11)$ (1984), 1212-1221.

[134] F. Dehdashti, A.H. McGuire, H.F. VanBrocklin, B.A. Siegel, D.P. Andriole, L.K. Griffeth, M.G. Pomper, J.A. Katzenellenbogen and M.J. Welch, Assessment of $21-\left[{ }^{18}\right.$ F]fluoro-16aethyl-19-norprogesterone as a positron-emitting radiopharmaceutical for the detection of progestin receptors in human breast carcinomas, J Nucl Med 32(8) (1991), 1532-1537.

[135] A.H. McGuire, F. Dehdashti, B.A. Siegel, A.P. Lyss, J.W. Brodack, C.J. Mathias, M.A. Minton, J.A. Katzenellenbogen and M.J. Welch, Positron tomographic assessment of 16a$\left[{ }^{18} \mathrm{~F}\right]$ fluoro-17b-estradiol uptake in metastatic breast carcinoma, J Nucl Med 32(8) (1991), 1526-1531.
[136] M.A. Mintun, M.J. Welch, B.A. Siegel, C.J. Mathias, J.W. Brodack, A.H. McGuire and J.A. Katzenellenbogen, Breast cancer: PET imaging of estrogen receptors, Radiology 169(1) (1988), 45-48.

[137] F. Dehdashti, J.E. Mortimer, B.A. Siegele et al., Positron tomographic assessment of estrogen receptors in breast cancer : comparison with FDG-PET and in vitro receptor assays, $J$ Nucl Med 36 (1995), 1766-1774.

[138] J.E. Mortimer, F. Dehdashti, B.A. Siegel et al., Clinical correlation of FDG and FES-PET imaging with estrogen receptors in breast cancer and response to systemic therapy, Clin Cancer Res 2 (1996), 933-939.

[139] F. Dehdashti, F.L. Flanagan, J.E. Mortimer, J.A. Katzenellenbogen, M.J. Welch and B.A. Siegel, Positron emission tomographic assessment of metabolic flare to predict response of metastatic breast cancer to antiestrogen therapy, Eur J Nucl Med 26(1) (1999), 51-56.

[140] J.E. Mortimer, F. Dehdashti, B.A. Siegel, K. Trinkaus, J.A. Katzenellenbogen and M.J. Welch, Metabolic flare: indicator of hormone responsiveness in advanced breast cancer, J Clin Oncol 19(11) (2001), 2797-2803.

[141] S.J. Brandes and J.A. Katzenellenbogen, Fundamental considerations in the design of fluorine-18 labeled progestins and androgens as imaging agents for receptor-positive tumors of the breast and prostate, Nucl Med Biol 15 (1988), 53-67.

[142] K.E. Carlson, S.J. Brandes, M.G. Pomper and J.A. Katzenellenbogen, Uptake of three $[3 \mathrm{H}]$ progestins by target tissues in vivo: implications for the design of diagnostic imaging agents, Int J Rad Appl Instrum B 15(4) (1988), 403-408.

[143] T.J. De Groot, A.H. Braker, P.H. Elsinga, G.M. Visser and W. Vaalburg, Synthesis of 6 alpha- $\left[{ }^{18} \mathrm{~F}\right]$ fluoroprogesterone: a first step towards a potential receptor-ligand for PET, Appl Radiat Isot 45(7) (1994), 811-813.

[144] M.G. Pomper, J.A. Katzenellenbogen, M.J. Welch, J.W. Brodack and C.J. Mathias, 21- $\left[{ }^{18}\right.$ F $]$ fluoro-16a- ethyl-19norprogesterone: synthesis and target tissue selective uptake of a progestin receptor based radiotracer for positron emission tomography, J Med Chem 31 (1988), 1360-1363.

[145] M.H. Al-Qahtani, E.D. Hostetler, T.J. McCarthy and M.J. Welch, Improved labeling procedure of $\left[{ }^{18} \mathrm{~F}\right] \mathrm{FFNP}$ for in vivo imaging of progesterone receptors, J Labelled Compd Rad 44(Suppl 1) (2001), S305-S306.

[146] B.O. Buckman, T.A. Bonasera, K.S. Kirschbaum, M.J. Welch and J.A. Katzenellenbogen, Fluorine-18-labeled progestin 16a,17a-dioxolanes: development of high-affinity ligands for the progesterone receptor with high in vivo target site selectivity, J Med Chem 38 (1995), 328-337.

[147] T.A. Bonasera, J.P. O’ Neil, M. Xu, J.A. Dobkin, P.D. Cutler, L.L. Lich, Y.S. Choe, J.A. Katzenellenbogen and M.J. Welch, Preclinical evaluation of fluorine-18-labeled androgen receptor ligands in baboons, J Nucl Med 37 (1996), 1009-1015.

[148] P.K. Garg, D.C. Labaree, R.M. Hoyte and R.B. Hochberg, [7a-F-18]fluoro-17a-methyl-5a-dihydrotestosterone: a ligand for androgen receptor-mediated imaging of prostate cancer, Nucl Med Biol 28(1) (2001), 85-90.

[149] T.L. Collier, J.C. O'Brien and R.N. Waterhouse, Synthesis of [F-18]-1-(3-fluoropropyl)-4-[(4-cyanophenoxy) methylpiperidine]: a potential sigma-1 receptor radioligand for PET, J Labelled Comp Radiopharm 37 (1996), 785-794.

[150] C.S. Dence, C.S. John, W.D. Bowen and M.J. Welch, Synthesis and evaluation of $\left[{ }^{18} \mathrm{~F}\right]$ labeled benzamides: high affinity sigma receptor ligands for PET imaging, Nucl Med Biol 24(4) (1997), 333-340. 
[151] K. Ishiwata, J. Noguchi, S. Ishii, K. Hatano, K. Ito, T. Nabeshima and M. Senda, Synthesis and preliminary evaluation of $\left[{ }^{11} \mathrm{C}\right] \mathrm{NE}-100$ labeled in two different positions as a PET sigma receptor ligand, Nucl Med Biol 25(3) (1998), 195-202.

[152] Y. Itzhak and I. Stein, Sigma binding sites in the brain; an emerging concept for multiple sites and their relevance for psychiatric disorders, Life Sci 47(13) (1990), 1073-1081.

[153] C.S. John, M.E. Gulden, B.J. Vilner and W.D. Bowen, Synthesis, in vitro validation and in vivo pharmacokinetics of [ $\left.{ }^{125} \mathrm{I}\right] \mathrm{N}$-[2-(4-iodophenyl)ethyl]-N-methyl-2-(1piperidinyl) ethylamine: a high-affinity ligand for imaging sigma receptor positive tumors, Nucl Med Biol 23(6) (1996), 761-766.

[154] A.S. Kimes, A.A. Wilson, U. Scheffel, B.G. Campbell and E.D. London, Radiosynthesis, cerebral distribution, and binding of $\left[{ }^{125} \mathrm{I}\right]-1$-(p-iodophenyl)-3-(1adamantyl)guanidine, a ligand for sigma binding sites, $J$ Med Chem 35(25) (1992), 4683-4689.

[155] G.K. Mulholland, D.M. Wieland, M.R. Kilbourn, K.A. Frey, P.S. Sherman, J.E. Carey and D.E. Kuhl, $\left[{ }^{18} \mathrm{~F}\right]$ fluoroethoxybenzovesamicol, a PET radiotracer for the vesicular acetylcholine transporter and cholinergic synapses, Synapse 30(3) (1998), 263-274.

[156] J.L. Musachio, U. Scheffel, M. Stathis, H.T. Ravert, W.B. Mathews and R.F. Dannals, (+)-[C-11]-cis-N-benzylnormetazocine: a selective ligand for sigma receptors in vivo, Life Sci 55(11) (1994), PL225-232.

[157] C.Y. Shiue, G.G. Shiue, S.X. Zhang, S. Wilder, J.H. Greenberg, F. Benard, J.A. Wortman and A.A. Alavi, N-(Nbenzylpiperidin-4-yl)-2-[ $\left.{ }^{18} \mathrm{~F}\right]$ fluorobenzamide: a potential ligand for PET imaging of sigma receptors, Nucl Med Biol 24(7) (1997), 671-676.

[158] R.N. Waterhouse and T.L. Collier, In vivo evaluation of $\left[{ }^{18} \mathrm{~F}\right] 1$-(3-fluoropropyl)-4-(4-cyanophenoxymethyl) piperidine: a selective sigma-1 receptor radioligand for PET, $\mathrm{Nucl}$ Med Biol 24(2) (1997), 127-134.

[159] R.N. Waterhouse, K. Mardon, K.M. Giles, T.L. Collier and J.C. O'Brien, Halogenated 4-(phenoxymethyl)piperidines as potential radiolabeled probes for sigma-1 receptors: in vivo evaluation of $\left[{ }^{123} \mathrm{I}\right]-1$-(iodopropen-2-yl)-4-[(4cyanophenoxy)methyl]piperidine, $J$ Med Chem 40(11) (1997), 1657-1667.

[160] P.J. Brent and G.T. Pang, Sigma binding site ligands inhibit cell proliferation in mammary and colon carcinoma cell lines and melanoma cells in culture, Eur J Pharmacol 278 (1995), 151-160.

[161] B.J. Vilner, C.S. John and W.D. Bowen, Sigma-1 and sigma2 receptors are expressed in a wide variety of human and rodent tumor cell lines, Cancer Res 55(2) (1995), 408-413.

[162] F.F. Moebius, K. Bermoser, R.J. Reiter, M. Hanner and H. Glossmann, Yeast sterol C8-C7 isomerase: identification and characterization of a high-affinity binding site for enzyme inhibitors, Biochemistry 35(51) (1996), 16871-16878.

[163] F.F. Moebius, R.J. Reiter, M. Hanner and H. Glossmann, High affinity of sigma 1-binding sites for sterol isomerization inhibitors: evidence for a pharmacological relationship with the yeast sterol C8-C7 isomerase, Br J Pharmacol 121(1) (1997), 1-6.

[164] J. Simony-Lafontaine, M. Esslimani, E. Bribes, S. Gourgou, N. Lequeux, R. Lavail, J. Grenier, A. Kramar and P. Casellas, Immunocytochemical assessment of sigma-1 receptor and human sterol isomerase in breast cancer and their relationship with a series of prognostic factors, Br J Cancer 82(12) (2000), 1958-1966.

[165] R.N. Waterhouse, M. Slifstein, P. Talbot, F. Dumont, A. Sultana, Y. Sudo, R. Narenjen, L. Hackett and M. Laruelle, Validation of [F-18]1-(3-fluoropropyl)-4-[(4cyanomethoxy)methyl]piperidine ([F-18]FPS) as an effective PET tracer for measurement of sigma-1 receptors in the primate brain, NeuroImage 16(3) (2002), S6.

[166] R.G. Bristow and R.P. Hill, Molecular and cellular basis of radiotherapy, in: The Basic Science of Oncology, 3rd ed., I.F. Tannock, R.P. Hill, eds, McGraw-Hill, New York, 1987, pp. 295-231.

[167] A. Fornace, Z. Fuks, R.R. Weichselbaum and L. Milas, Radiation therapy, in: The Molecular Basis of Cancer, J. Mendelsohn, P.M. Howley, M.A. Israel and L.A. Liotta, eds., W.B. Saunders Company, Philadelphia, 2001, pp. 423-454.

[168] M. Hockel, K. Schlenger, S. Hockel et al., Association between tumor hypoxia and malignant progression: the clinical evidence in cancer of the uterine cervix, in: Tumour Hypoxia, P. Vaupel and D.K. Kelleher, eds., Wissenschafte Verlagsgesellschaft mbH, Stuttgart, 1999, pp. 65-74.

[169] M. Nordsmark and M. Overgaard, Pretreatment oxygenation predicts radiation response in advanced squamous cell carcinoma of the head and neck, Radiother Oncol 41 (1996), 31-39.

[170] H.B. Stone et al., Oxygen in human tumors: correlations between methods of measurement and response to therapy, Summary of a workshop held November 19-20, 1992, at the National Cancer Institute, Bethesda, MD, Radiat Res (1993), 985-991.

[171] J.S. Rasey, W.J. Koh, M.L. Evans et al., Quantifying regional hypoxia in human tumours with positron emission tomography of (F-18)fluoromisonidazole: a pretherapy study of 37 patients, Int J Radiat Oncol Biol Phys 36 (1996), 417-428.

[172] W.J. Koh, K.S. Bergman, J.S. Rasey et al., Evaluation of oxygenation status during fractionated radiotherapy in human non-small cell lung cancers using (F-18) fluoromisonidazole positron emission tomography, Int J Radiat Oncol Biol Phys 33, (1995), 391-398.

[173] W.J. Koh, J.S. Rasey, M.L. Evans et al., Imaging of hypoxia in human tumors with (F-18)fluoromisonidazole, Int J Radiat Oncol Biol Phys 22 (1992), 199-212.

[174] N. Takahashi, Y. Fujibayashi, Y. Yonekura et al., Evaluation of $\mathrm{Cu}-62$ labeled diacetyl-bis(N-4- methoylthiosemicarbazone) as a hypoxic tissue tracer in patients with lung cancer, Ann Nucl Med 14 (2000), 323-328.

[175] A.K. Buck, H. Schirrmeister and M.e.a. Hetzel, 3-deoxy3-[F-18]fluorothymidine-positron emission tomography for noninvasive assessment of proliferation in pulmonary nodules, Cancer Res 62 (2002), 3331-3334.

[176] P.S. Conti, J. Hilton and D.F. Wong, High-performance liquid-chromatography of C-11 labeled thymidine and its major catabolites for clinical PET studies, Nucl Med Biol 21(8) (1994), 1045-1051.

[177] E.J. Crawford, D. Christman, H. Atkins, M. Friedkin and A. Wolf, Scintigraphy with positron-emitting compounds.1.C11 labeled thymidine and thymidylate, Int J Nucl Med Biol 5 (1978), 61-69.

[178] J. De Reuck, P. Santens and P.e.a. Goethals, [Methyl-C-11] thymidine positron emission tomography in tumoral and nontumoral cerebral lesions, Act Neurol Belg 99(2) (1999), 118125. 
[179] J. Eary, D.A. Mankoff, A.M. Spence et al., 2-[C11]thymidine imaging of malignant brain tumors, Cancer Res 59(3) (1999), 615-621.

[180] M. Edgren, J.E. Westlin, H. Ahlstrom, H. Letocha, P.U. Malmstrom, B. Langstrom and S. Nilsson, Positron emission tomography in the management of metastatic renal cell carcinoma, Antibody Immunoconj 8(4) (1995), 215-226.

[181] P. Goethals, N. Lameire, M. van Eijkeren, D. Kesteloot, H. Thierens and R. Dams, [Methyl-carbon-11]thymidine for in vivo measurement of cell proliferation, J Nucl Med 37 (1996), 1048-1052.

[182] P. Goethals, M. van Eijkeren and I. Lemahieu, In vivo distribution and identification of ${ }^{11} \mathrm{C}$ activity after injection of [Methyl-carbon-11] thymidine in Wistar rats, J Nucl Med 40 (1999), 491-496.

[183] P. Goethals, M. Van Eijkeren, W. Lodewyck and R. Dams, Measurement of [Methyl-carbon-11]thymidine and its metabolites in head and neck tumors, J Nucl Med 36(5) (1995), 880-882.

[184] F. Jamar, N. Leners, D. Labar and A. Ferrant, [2-11C]thymidine Pet scan in Non-Hodgkin's lymphoma, Eur J Nucl Med (1992), 693 (Abstract)

[185] L. Lu, M. Bergström, K.J. Fasth and B. Lângström, Synthesis of $\left[{ }^{76} \mathrm{Br}\right]$ bromofluorodeoxyuridine and its validation with regard to uptake, DNA incorporation, and excretion modulation in rats, $J$ Nucl Med 41 (2000), 1746-4752.

[186] L. Lu, M. Bergstrom, K.J. Fasth, F. Wu, B. Eriksson and B. Lângström, Elimination of nonspecific radioactivity from [Br-76]bromide in PET study with [Br76]bromodeoxyuridine, Nucl Med Biol 26 (1999), 795-802.

[187] D.A. Mankoff, A.F. Shields, J.M. Link, M.M. Graham, M. Muzi, L.M. Peterson, J.F. Eary and K.A. Krohn, Kinetic analysis of 2-[C-11]thymidine PET imaging studies: validation studies, J Nucl Med 40 (1999), 614-624.

[188] W. Mier, U. Haberkorn and M. Eisenhut, $\left[{ }^{18}\right.$ F]FLT; a portrait of a proliferation marker, Eur J Nucl Med 29 (2002), 165169.

[189] M.G. Pomper, C.D. Constantinides, P.B. Barker, A. Bizzi, A.S. Dobgan, F. Yokoi, J.C. McArthur and D.F. Wong, Quantitative MR spectroscopic imaging of brain lesions in patients with AIDS: correlation with [C-11-methyl]thymidine PET and thallium-201 SPECT, Acad Radiol 9 (2002), 4398-4409.

[190] A.F. Shields, J.R. Grierson, B.M. Dohmen et al., Imaging proliferation in vivo with $\left[{ }^{18} \mathrm{~F}\right] \mathrm{FLT}$ and positron emission tomography, Nat Med 4 (1998), 1334-1336.

[191] A.F. Shields, S.M. Larson, Z. Grunbaum and M.M. Graham, Short-term uptake in normal and neoplastic tissues: studies for PET, J Nucl Med 25 (1984), 759-764.

[192] A.F. Shields, K. Lim, J. Grierson, J. Link and K.A. Krohn, Utilization of labeled thymidine in DNA synthesis: studies for PET, J Nucl Med 31 (1990), 337-342.

[193] A.F. Shields, D. Mankoff, M.M. Graham, M. Zheng, S.M. Kozawa, J.M. Link and K.A. Krohn, Analysis of 2-carbon11-thymidine blood metabolites in PET imaging, $\mathrm{J} \mathrm{Nucl} \mathrm{Med}$ 37(2) (1996), 290-296

[194] A.F. Shields, D.A. Mankoff, J.M. Link, M.M. Graham, J.F Eary, S.M. Kozawa, M. Zheng, L.B. et al., Carbon-11thymidine and FDG to measure therapy response, $\mathrm{J}$ Nucl Med 39(10) (1998), 1757-1762.

[195] H. Thierens, M. van Eijkeren and P. Goethals, Biokinetics and dosimetry for [methyl-11C] thymidine, Br J Radiol 67 (1994), 292-295.

[196] M. Van Eijkeren, A. De Schryver, P. Goethals, E. Poupeye, K. Schelstraete, I. Lemahieu and C.R. De Potter, Measurement of short-term 11C-thymidine activity in human head and neck tumours using positron emission tomography, Acta Oncol $\mathbf{3 1}$ (1992), 539-543.

[197] T. Vander Borght, S. Pauwels, L. Lambotte, D. Labar, S. De Maeght, G. Stroobandt and C. Laterre, Brain tumor imaging with PET and 2-[Carbon-11]thymidine, J Nucl Med 35 (1994), 974-982.

[198] H. Young, C. Brock, P. Wells and P. Price, Monitoring response to treatment in the development of anti-cancer drugs using positron emission tomography, Drug Inf J 33(1) (1999), 237-244.

[199] R.S. Brown, J.Y. Leung, S.J. Fisher, K.A. Frey, S.P. Ethier and R.L. Wahl, Intratumoral distribution of tritiated-FDG in breast cancer: correlation between Glut-1 expression and FDG uptake, J Nucl Med 37(6) (1996), 1042-1047.

[200] T. Higashi, N. Tamaki, R. Honda, T. Torizuak, T. Kimura, T. Inokuma, G. Ohshio, R. Hosotonic, H. Imamura and J. Konishi, Expression of glucose transporters in human pancreatic tumors compared with increased FDG accumulation in PET study, J Nucl Med 38 (1997), 1337-1344.

[201] J.P. Vuillez, Fluor-déoxy-D-glucose: biologie, signification, intérêt, Medecine Nucléaire 25 (2001), 507-510.

[202] S. Gambhir, J. Czernin, J. Schwimmer et al., A tabulated summary of the FDG PET literature, J Nucl Med 42 (2001), 2S-8S.

[203] M. Gould, C. Courtney and C.G. MacLean, Accuracy of positron emission tomography for diagnosis of pulmonary nodules and mass lesions; a meta-analysis, JAMA 285(7) (2001), 914-924

[204] J.F. Vansteenkiste, S.G. Stroobants and P.R.e.a. De Leyn, Lymph node staging in non-small-cell lung cancer with FDGPET scan: a prospective study on 690 lymph node stations from 68 patients, J Clin Oncol 16 (1998), 2142-2149.

[205] B.A. Dwamena, S.S. Sonnad, J.O. Angobaldo and R.L. Wahl, Metastases from non-small cell lung cancer: mediastinal staging in the 1990s-meta-analytic comparison of PET and CT, Radiology 213(2) (1999), 530-536.

[206] B.A. Dwamena, C.B. Seema, S.S. Sonnad et al., Metastases from non-small cell lung cancer: mediastinal staging in the 1990s-meta-analytic comparison of PET and CT, Radiology 213 (1999), 530-536.

[207] R. Pieterman, J. van Putten, J. Meuzelaar et al., Preoperative staging of non-small-cell-lung cancer with positron emission tomography, N Engl J Med 27 (2000), 254-261.

[208] E.M. Marom, H.P. McAdams, J.J. Erasmus, P.C. Goodman, D.K. Culhane, R.E. Coleman, J.E. Herndon and E.F. Patz, Staging non-small cell lung cancer with whole-body PET, Radiology 212(3) (1999), 803-809.

[209] R.M. Pieterman, J.W. van Putten, J.J. Meuzelaar, E.L. Mooyaart, W. Vaalburg, G.H. Koeter, V. Fidler, J. Pruim and H.J. Groen, Preoperative staging of non-small-cell lung cancer with positron-emission tomography, $N$ Engl J Med 343(4) (2000), 254-261.

[210] R.M. Glasspool and T.R.J. Evans, Clinical imaging of cancer metastasis, Eur J Cancer 36 (2000), 1661-1670.

[211] E. Bombardieri and F. Crippa, PET imaging in breast cancer, Q J Nucl Med 45 (2001), 245-256.

[212] F.L. Flanagan, F. Dehdashti and B.A. Siegel, PET in breast cance, Sem Nucl Med 28 (1998), 290-302.

[213] D. Gopalan, J.B. Bomanji, D.C. Costa and P.J. Ell, Nuclear medicine in primary breast cancer imaging, Clin Radiology 57(7) (2002), 565-574.

[214] C. Van de Wiele, R.A. Dierckx, F. Scopinaro, R. Waterhouse, A. Annovazzi, A. Kolindou and A. Signore, Nuclear 
medicine for prediction or early assessment of response to chemotherapy in patients suffering from breast carcinoma, Breast Cancer Res Treat 72 (2002), 275-282.

[215] E. Yavin, Regulation of phospholipid metabolism in differentiating cells from rat brain cerebral hemispheres in culture. Patterns of acetylcholine phosphocholine, and choline phosphoglycerides labeling from (methyl- $\left.{ }^{14} \mathrm{C}\right)$ choline, $J$ Biol Chem 251(5) (1976), 1392-1397.

[216] J.R. Alger, J.A. Frank, A. Bizzi, M.J. Fulham, B.X. DeSouza, M.O. Duhaney, S.W. Inscoe, J.L. Black, P.C. van Zijl, C.T. Moonen et al., Metabolism of human gliomas: assessment with H-1 MR spectroscopy and F-18 fluorodeoxyglucose PET [see comments], Radiology 177(3) (1990), 633-641.

[217] M.J. Fulham, A. Bizzi, M.J. Dietz, H.H. Shih, R. Raman, G.S. Sobering, J.A. Frank, A.J. Dwyer, J.R. Alger and G. Di Chiro, Mapping of brain tumor metabolites with proton MR spectroscopic imaging: clinical relevance, Radiology 185 (1992), 675-686.

[218] G. Tedeschi, N. Lundbom, R. Raman, S. Bonavita, J.H. Duyn, J.R. Alger and G. Di Chiro, Increased choline signal coinciding with malignant degeneration of cerebral gliomas: a serial proton magnetic resonance spectroscopy imaging study, J Neurosurg 87(4) (1997), 516-524.

[219] A. Heerschap, G.J. Jager, M. van der Graaf, J.O. Barentsz and S.H. Ruijs, Proton MR spectroscopy of the normal human prostate with an endorectal coil and a double spin-echo pulse sequence, Magn Reson Med 37(2) (1997), 204-213.

[220] J. Kurhanewicz, D.B. Vigneron, H. Hricak, P. Narayan, P. Carroll and S.J. Nelson, Three-dimensional H-1 MR spectroscopic imaging of the in situ human prostate with high (0.24-0.7-cm3) spatial resolution, Radiology 198(3) (1996), 795-805.

[221] R.P. Friedland, C.A. Mathis, T.F. Budinger, B.R. Moyer and M. Rosen, Labeled choline and phosphorylcholine: body distribution and brain autoradiography: concise communication, J Nucl Med 24(9) (1983), 812-815.

[222] M.A. Rosen, R.M. Jones, Y. Yano and T.F. Budinger, Carbon11 choline: synthesis, purification, and brain uptake inhibition by 2-dimethylaminoethanol, J Nucl Med 26 (1985), 1424-1428.

[223] D.R. Haubrich, P.F. Wang and P.W. Wedeking, Distribution and metabolism of intravenously administered choline [methyl- 3-H] and synthesis in vivo of acetylcholine in various tissues of guinea pigs, J Pharmacol Exp Ther 193(1) (1975), 246-255.

[224] T. Hara, N. Kosaka, N. Shinoura and T. Kondo, PET imaging of brain tumor with [methyl- ${ }^{11}$ C]choline, J Nucl Med 38(6) (1997), 842-847.

[225] N. Shinoura, M. Nishijima, T. Hara, T. Haisa, H. Yamamoto, K. Fujii, I. Mitsui, N. Kosaka, T. Kondo and T. Hara, Brain tumors: detection with C-11 choline PET, Radiology 202(2) (1997), 497-503.

[226] T. Hara, N. Kosaka and H. Kishi, PET imaging of prostate cancer using carbon-11-choline, J Nucl Med 39(6) (1998), 990-995.

[227] T. Hara, N. Kosaka, T. Kondo, H. Kishi and O. Kobori, Imaging of brain tumor, lung cancer, esophagus cancer, colon cancer, prostate cancer, and bladder cancer with [C-11]choline, J Nuc Med 38(Suppl 5) (1997), 250.

[228] T.R. DeGrado, S.W. Baldwin, S. Wang, M.D. Orr, R.P. Liao, H.S. Friedman, R. Reiman, D.T. Pric and R.E. Coleman, Synthesis and evaluation of (18)F-labeled choline analogs as oncologic PET tracers, J Nucl Med 42 (2001), 1805-1814.
[229] T. Hara, N. Kosaka and H. Kishi, Development of (18)Ffluoroethylcholine for cancer imaging with PET: synthesis, biochemistry, and prostate cancer imaging, $\mathrm{J} \mathrm{Nucl} \mathrm{Med} \mathbf{4 3}$ (2002), 187-199.

[230] T.R. DeGrado, R.E. Coleman, S. Wang, S.W. Baldwin, M.D. Orr, C.N. Robertson, T.J. Polascik and D.T. Price, Synthesis and evaluation of ${ }^{18} \mathrm{~F}$-labeled choline as an oncologic tracer for positron emission tomography: initial findings in prostate cancer, Cancer Res 61 (2001), 110-117.

[231] O.C. Boerman, H. Rennen, W.J. Oyen and F.H. Corstens, Radiopharmaceuticals to image infection and inflammation, Semin Nucl Med 31(4) (2001), 286-295.

[232] H.J. Rennen, F.H. Corstens, W.J. Oyen and O.C. Boerman, New concepts in infection/inflammation imaging, $Q J$ Nucl Med 45 (2001), 167-173.

[233] A. Signore, A. Annovazzi, M. Chianelli, F. Corsetti, C. Van de Wiele and R.N. Waterhouse, Peptide radiopharmaceuticals for diagnosis and therapy, Eur J Nucl Med 28(10) (2001), $1555-1565$.

[234] A. Signore, A. Annovazzi, F. Corsetti, G. Capriotti, M. Chianelli, F. De Winter and F. Scopinaro, Biological imaging for the diagnosis of inflammatory conditions, Bio Drugs 16(4) (2002), 241-259.

[235] S.M. Okarvi, Recent progress in fluorine-18 labelled peptide radiopharmaceuticals, Eur J Nucl Med 28(7) (2001), 929938.

[236] J.L. Sutcliffe-Goulden, M.J. O'Doherty, P.K. Marsden, I.R. Hart, J.F. Marshall and S.S. Bansal, Rapid solid phase synthesis and biodistribution of (18)F-labelled linear peptides, Eur J Nucl Med Mol Imaging 29(6) (2002), 754-759.

[237] M. Hofmann, H. Maecke, R. Borner, E. Weckesser, P. Schoffski, L. Oei, J. Schumacher, M. Henze, A. Heppeler, J. Meyer and $\mathrm{H}$. Knapp, Biokinetics and imaging with the somatostatin receptor PET radioligand (68)Ga-DOTATOC: preliminary data, Eur J Nucl Med 28(12) (2001), 1751-1757.

[238] O. Ugur, P.J. Kothari, R.D. Finn, P. Zanzonico, S. Ruan, I. Guenther, H.R. Maecke and S.M. Larson, Ga-66 labeled somatostatin analogue DOTA-DPhe1-Tyr3-octreotide as a potential agent for positron emission tomography imaging and receptor mediated internal radiotherapy of somatostatin receptor positive tumors, Nucl Med Biol 29(2) (2002), 147157.

[239] H.J. Wester, J. Brockmann, F. Rosch, W. Wutz, H. Herzog, P. Smith-Jones, B. Stolz, C. Bruns and G. Stocklin, PET-pharmacokinetics of ${ }^{18}$ F-octreotide: a comparison with ${ }^{67}$ Ga-DFO- and 86Y-DTPA-octreotide, Nucl Med Biol 24(4) (1997), 275-286.

[240] R.S. Brown, J.Y. Leung, S.J. Fisher, K.A. Frey, S.P. Ethier and R.L. Wahl, Intratumoral distribution of tritiated fluorodeoxyglucose in breast carcinoma: I. are inflammatory cells important? J Nucl Med 36(10) (1995), 1854-1861.

[241] R. Kubota, S. Yamada, K. Kubota, K. Ishiwata, N. Tamahashi and T. Ido, Intratumoral distribution of fluorine18-fluorodeoxyglucose in vivo: high accumulation in macrophages and granulation tissues studied by microautoradiography, J Nucl Med 33(11) (1992), 1972-1980.

[242] S. Yamada, K. Kubota, R. Kubota, T. Ido and N. Tamahashi, High accumulation of fluorine-18-fluorodeoxyglucose in turpentine-induced inflammatory tissue, J Nucl Med 36(7) (1995), 1301-1306.

[243] Y. Sugawara, T.D. Gutowski, S.J. Fisher, R.S. Brown and R.L. Wahl, Uptake of positron emission tomography tracers in experimental bacterial infections: a comparative biodistribution study of radiolabeled FDG, thymidine, L-methionine, 
${ }^{67}$ Ga-citrate, and ${ }^{125}$ I-HAS, Eur J Nucl Med 26(4) (1999), 333-341.

[244] L.H. Brudin, S.O. Valind, C.G. Rhodes, C.F. Pantin, M. Sweatman, T. Jones and J.M. Hughes, Fluorine-18 deoxyglucose uptake in sarcoidosis measured with positron emission tomography, Eur J Nucl Med 21(4) (1994), 297-305.

[245] A. Guhlmann, D. Brecht-Krauss, G. Suger, G. Glatting, J. Kotzerke, L. Kinzl and S.N. Reske, Fluorine-18-FDG PET and technetium- $99 \mathrm{~m}$ antigranulocyte antibody scintigraphy in chronic osteomyelitis, J Nucl Med 39(12) (1998), 21452152.

[246] Y. Ichiya, Y. Kuwabara, M. Sasaki, T. Yoshida, Y. Akashi, S. Murayama, K. Nakamura, T. Fukumura and K. Masuda, FDG-PET in infectious lesions: the detection and assessment of lesion activity, Ann Nucl Med 10(2) (1996), 185-191.

[247] S.J. Skehan, R. Issenman, J. Mernagh, C. Nahmias and K. Jacobson, 18F-fluorodeoxyglucose positron tomography in diagnosis of paediatric inflammatory bowel disease, Lancet 354(9181) (1999), 836-837.

[248] K.D. Stumpe, H. Dazzi, A. Schaffner and G.K. von Schulthess, Infection imaging using whole-body FDG-PET, Eur J Nucl Med 27 (2000), 822-832.

[249] H. Zhuang and A. Alavi, 18-fluorodeoxyglucose positron emission tomographic imaging in the detection and monitoring of infection and inflammation, Semin Nucl Med 32(1) (2002), 47-59.

[250] F. De Winter, D. Vogelaers, F. Gemmel and R.A. Dierckx, Promising role of 18-F-fluoro-D-deoxyglucose positron emission tomography in clinical infectious diseases, Eur $J$ Clin Microbiol Infect Dis 21(4) (2002), 247-257.

[251] A. Signore, E. Procaccini, A. Annovazzi, M. Chianelli, C. Van der Laken and A. Mire-Sluis, The developing role of cytokines for imaging inflammation and infection, Cytokine 12(10) (2000), 1445-1454.

[252] E. Procaccini, M. Chianelli, P. Pantano and A. Signore, Imaging of autoimmune diseases, $Q$ J Nucl Med 43(1) (1999), $100-112$.

[253] P.M. Murphy, M. Baggiolini, I.F. Charo, C.A. Hebert, R. Horuk, K. Matsushima, L.H. Miller, J.J. Oppenheim and C.A. Power, International union of pharmacology. XXII. Nomenclature for chemokine receptors, Pharmacol Rev 52(1) (2000), 145-176.

[254] P.M. Murphy, Chemokines and the molecular basis of cancer metastasis, $N$ Engl J Med 345(11) (2001), 833-835.

[255] A. Zlotnik and O. Yoshie, Chemokines: a new classification system and their role in immunity, Immunity 12(2) (2000), 121-127.

[256] M. Chianelli, M.G. Parisella, R. Barone, G.P. Nardi, N. Visalli, P. Pozzilli and A. Signore, Imaging of insulitis in newly diagnosed diabetic patients by $99 \mathrm{mTc}$-IL 2 scintigraphy, Eur J Nucl Med 25 (1998), 897.

[257] E. Procaccini, M. Chianelli, M.G. Parisella, R. Barone, G. Di Leve, A. Grossmann and A. Signore, 99mTc-IL2 scintigraphy in autoimmune thyroid diseases, Eur J Nucl Med $\mathbf{2 5}$ (1998), 977.

[258] J. Rendl, R. Guthoff, A. Schirbel, D. Brechtelsbauer, D. Schiller, S. Seybold, P. Schneider, P. Lorenz, W. Lieb and C. Reiners, Iodine-123-interleukin-2 (i-123-il-2) scintigraphy in Graves' ophthalmopathy (go): a new approach to assess disease activity, Endocr J 47 (2000), 0-4.

[259] O. Rolandsson, T. Stigbrand, K. Riklundahlstrom, J. Eary and C. Greenbaum, Accumulation of $\left({ }^{125} \mathrm{I}\right)$ iodine labeled interleukin-2 in the pancreas of NOD mice, J Autoimmun 17(4) (2001), 281-287.
[260] A. Signore, M. Chianelli, A. Annovazzi, E. Bonanno, L.G. Spagnoli, P. Pozzilli, F. Pallone and L. Biancone, ${ }^{123}$ Iinterleukin-2 scintigraphy for in vivo assessment of intestinal mononuclear cell infiltration in Crohn's disease, $\mathrm{J} \mathrm{Nucl} \mathrm{Med}$ 41(2) (2000), 242-249.

[261] A. Signore, M. Chianelli, A. Annovazzi, M. Rossi, L. Maiuri, M. Greco, G. Ronga, K.E. Britton and A. Picarelli, Imaging active lymphocytic infiltration in coeliac disease with iodine123-interleukin-2 and the response to diet, Eur J Nucl Med 27(1) (2000), 18-24.

[262] A. Signore, A. Picarelli, M. Chianelli, L. Biancone, A. Annovazzi, C. Tiberti, E. Anastasi, G. Multari, M. Negri, F. Pallone and P. Pozzilli, I-interleukin-2 scintigraphy: a new approach to assess disease activity in autoimmunity, $J$ Pediatr Endocrinol Metab 9(Suppl 1) (1996), 139-144.

[263] I.C. Abbs, J.R. Pratt, M.J. Dallman and S.H. Sacks, Analysis of activated $\mathrm{T}$ cell infiltrates in rat renal allografts by gamma camera imaging after injection of 123I-iodine-interleukin 2, Transpl Immunol 1 (1993), 45-51.

[264] R. Barone, M. Chianelli, G.P. Nardi, M.G. Parisella, G. Di Leve, A. Mire Sluis and A. Signore, Radiolabelled interleukin-12 p40. A new radiophamaceutical for imaging chronic TH1-mediated inflammation, Q J Nucl Med 42(Suppl 1) (1998), 77.

[265] R. Barone, M. Chianelli, E. Procaccini, A. Annovazzi, U. Bottoni, C. Panetta, D. Innocenzi, S. Calvieri and A. Signore, $99 \mathrm{mTc}$-IL2 scintigraphy in patients with cutaneous melanoma: detection of lymphocytic infiltration, Eur J Nucl Med 25 (1998), 896.

[266] P. Barrera, C.J. van der Laken, O.C. Boerman, W.J. Oyen, M.T. van de Ven, P.L. van Lent, L.B. van de Putte and F.H. Corstens, Radiolabelled interleukin-1 receptor antagonist for detection of synovitis in patients with rheumatoid arthritis, Rheumatology 39(8) (2000), 870-874.

[267] C.J. van der Laken, P. Barrera, O.C. Boerman, W.J.G. Oyen, M.T.P. Van der Ven, J.W.M. van der Meer, L.B.A. van de Putte and F.H.M. Corstens, Radiolabelled interleukin-1 receptor antagonist targets to inflamed joints in patients with active rheumatoid arthritis. A report of preliminary results, Eur $J$ Nucl Med 25 (1998), 897.

[268] C.J. van der Laken, O.C. Boerman, W.J. Oyen, P. Laverman, M.T. van de Ven, F.H. Corstens and J.W. van der Meer, In vivo expression of interleukin-1 receptors during various experimentally induced inflammatory conditions, J Infect Dis 177(5) (1998), 1398-1401.

[269] C.J. van der Laken, O.C. Boerman, W.J. Oyen, M.T. van de Ven, R. Chizzonite, F.H. Corstens and J.W. van der Meer, Preferential localization of systemically administered radiolabeled interleukin-1-alpha in experimental inflammation in mice by binding to the type II receptor, J Clin Invest 100(12) (1997), 2970-2976.

[270] C.J. van der Laken, O.C. Boerman, W.J. Oyen, M.T. van de Ven, R.A. Claessens, J.W. van der Meer and F.H. Corstens, Specific targeting of infectious foci with radioiodinated human recombinant interleukin-1 in an experimental model, Eur J Nucl Med 22(11) (1995), 1249-1255.

[271] C.J. van der Laken, O.C. Boerman, W.J. Oyen, M.T. van de Ven, R.A. Claessens, J.W. van der Meer and F.H. Corstens, Different behaviour of radioiodinated human recombinant interleukin-1 and its receptor antagonist in an animal model of infection, Eur J Nucl Med 23 (1996), 1531-1535.

[272] C.J. van der Laken, O.C. Boerman, W.J.G. Oyen, M.T.P. van de Ven, J.W.M. van der Meer and F.H.M. Corstens, Imaging of infection in rabbits with radioiodinated interleukin-1 (a 
and $\beta$ ), its receptor antagonist and a chemotactic peptide: a comparative study, Eur J Nucl Med 25(4) (1998), 347-352.

[273] F.G. Blankenberg, J.F. Tait, T.A. Blankenberg, A.M. Post and H. William Strauss, Imaging macrophages and the apoptosis of granulocytes in a rodent model of subacute and chronic abscesses with radiolabeled monocyte chemotactic peptide-1 and annexin V, Eur J Nucl Med 28(9) (2001), 1384-1393.

[274] C.J. van der Laken, O.C. Boerman, W.J.G. Oyen, M.P.T. Van de Ven, P. Laverman, J.W.M. van der Meer and F.H.M. Corstens, Targeting inflammation with radiolabeled interleukin-1 and other cytokines in various mouse models, Nucl Med Commun 18 (1997), 478.

[275] S. Gratz, H.J. Rennen, O.C. Boerman, W.J. Oyen and F.H. Corstens, Rapid imaging of experimental colitis with (99m)Tc-interleukin-8 in rabbits, J Nucl Med 42(6) (2001), 917-923.

[276] S. Gratz, H.J.J.M. Rennen, O.C. Boerman, W.J.G. Oyen, P. Burma and F.H.M. Corstens, 99mTc-Interleukin-8 for imaging acute osteomyelitis, J Nucl Med 42 (2001), 1257-1264.

[277] M.D. Gross, B. Shapiro, L.M. Fig, R. Steventon, R.W.S. Skinner and R.V. Hay, Imaging of human infection with 131Ilabeled recombinant human interleukin-8, J Nucl Med 42(11) (2001), 1656-1659.

[278] R.V. Hay, R.S. Skinner, O.C. Newman, S.L. Kunkel, L.R. Lyle, B. Shapiro and M.D. Gross, Scintigraphy of acute inflammatory lesions in rats with radiolabelled recombinant human interleukin-8, Nucl Med Commun 18(4) (1997), 367378.

[279] H.J. Rennen, O.C. Boerman, W.J. Oyen, J.W. Van der Meer and F.H. Orstens, Specific and rapid scintigraphic detection of infection with 99mTc-labeled interleukin-8, J Nucl Med 42(1) (2001), 117-123.

[280] H.J. Rennen, J.E. van Eerd, W.J. Oyen, F.H. Corstens, D.S. Edwards and O.C. Boerman, Effects of coligand variation on the in vivo characteristics of Tc-99m-labeled interleukin8 in detection of infection, Bioconjug Chem 13(2) (2002), 370-377.

[281] C.J. van der Laken, O.C. Boerman, W.J.G. Oyen, M.T.P. van de Ven, J.W.M. van der Meer and F.H.M. Corstens, Radiolabeled interleukin-8: specific scintigraphic detection of infection within a few hours, J Nucl Med 41 (2000), 463-469.

[282] F. Berger and S.S. Gambhir, Recent advances in imaging endogenous or transferred gene expression utilizing radionuclide technologies in living subjects: applications to breast cancer, Breast Cancer Res 3(1) (2001), 28-35.

[283] R. Blasberg, Imaging gene expression and endogenous molecular processes: molecular imaging, J Cereb Blood Flow Metab 22(10) (2002), 1157-1164.

[284] R. Blasberg, PET imaging of gene expression, Eur J Cancer 38(16) (2002), 2137.

[285] S.S. Gambhir, H.R. Herschman, S.R. Cherry, J.R. Barrio, N. Satyamurthy, T. Toyokuni, M.E. Phelps, S.M. Larson, J. Balatoni, R. Finn, M. Sadelain, J. Tjuvajev and R. Blasberg, Imaging transgene expression with radionuclide imaging technologies, Neoplasia 2(1-2) (2000), 118-138.

[286] D.C. MacLaren, T. Toyokuni, S.R. Cherry, J.R. Barrio, M.E. Phelps, H.R. Herschman and S.S. Gambhir, PET imaging of transgene expression, Biol Psychiatry 48(5) (2000), 337348.

[287] M.E. Phelps, PET: the merging of biology and imaging into molecular imaging, J Nucl Med 41 (2000), 661-681.

[288] V. Sharma, G.D. Luker and D. Piwnica_Worms, Molecular imaging of gene expression and protein function in vivo with
PET and SPECT, J Magn Reson Imaging 16(4) (2002), 336351.

[289] J.G. Tjuvajev, N. Avril, T. Oku, T. Sasajima, T. Miyagawa, R. Joshi, M. Safer, B. Beattie, G. DiResta, F. Daghighian, F. Augensen, J. Koutcher, J. Zweit, J. Humm, S.M. Larson, R. Finn and R. Blasberg, Imaging herpes virus thymidine kinase gene transfer and expression by positron emission tomography, Cancer Res 58(19) (1998), 4333-4341.

[290] R.G. Blasberg and J.G. Tjuvajev, Herpes simplex virus thymidine kinase as a marker/reporter gene for PET imaging of gene therapy, Q J Nucl Med 43(2) (1999), 163-169.

[291] L.I. Wiebe and E.E. Knaus, Enzyme-targeted, nucleosidebased radiopharmaceuticals for scintigraphic monitoring of gene transfer and expression, Curr Pharm Des 7(18) (2001), 1893-1906.

[292] S.S. Gambhir, J.R. Barrio, H.R. Herschman and M.E. Phelps, Assays for noninvasive imaging of reporter gene expression, Nucl Med Biol 26(5) (1999), 481-490.

[293] D.E. Reichert, J.S. Lewis and C.J. Anderson, Metal complexes as dagnostic tools, Coordination Chem Rev 184 (1999), 3-66.

[294] J.S. Lewis and M.J. Welch, Copper chemistry related to radiopharmaceutical production, in: Technetium, Rhenium and Other Metals in Chemistry and Nuclear Medicine, M. Nicoline and U. Mazzi, eds, SGEditoriali, Padova, 2002, pp. 2333.

[295] L.J. Ashfield, C. Clarke, A.R. Cowley, J.R. Dilworth, P.S. Donnelly and J.M. Heslop, Towards new copper and rhenium based radiopharmaceticals, in: Technetium, Rhenium and Other Metals in Chemistry and Nuclear Medicine, $\mathrm{M}$. Nicoline and U. Mazzi, eds, SGEditoriali, Padova, 2002, pp. 91-96.

[296] M.A. Flower, J. Zweit, A.D. Hall, D. Burke, M.M. Davies, M.J. Dworkin, H.E. Young, J. Mundy, R.J. Ott, V.R. McCready, P. Carnochan and T.G. Allen Mersh, 62Cu-PTSM and PET used for the assessment of angiotensin II-induced blood flow changes in patients with colorectal liver metastases, Eur J Nucl Med 28(1) (2001), 99-103.

[297] K.S. Chao, W.R. Bosch, S. Mutic, J.S. Lewis, F. Dehdashti, M.A. Mintun, J.F. Dempsey, C.A. Perez, J.A. Purdy and M.J. Welch, A novel approach to overcome hypoxic tumor resistance: $\mathrm{Cu}$-ATSM-guided intensity-modulated radiation therapy, Int J Radiat Oncol Biol Phys 49(4) (2001), 11711182 .

[298] J.S. Lewis, A. Srinivasan, M.A. Schmidt and C.J. Anderson, In vitro and in vivo evaluation of ${ }^{64} \mathrm{Cu}$-TETA-Tyr3octreotate, A new somatostatin analog with improved target tissue uptake, Nucl Med Biol 26(3) (1999), 267-273.

[299] A.L. Vevere, J.S. Lewis and M.J. Welch, Imaging of antiangiogenic treatments: microPET as a surrogate marker for tumor response, in: Technetium, Rhenium and Other Metals in Chemistry and Nuclear Medicine, M. Nicoline and U. Mazzi, eds, SGEditoriali, Padova, 2002, pp. 101-105.

[300] V. Sharma, A. Beatty, S.P. Wey, J. Dahlheimer, C.M. Pica, C.L. Crankshaw, L. Bass, M.A. Green, M.J. Welch and D. Piwnica-Worms, Novel gallium(III) complexes transported by MDR1 P-glycoprotein: potential PET imaging agents for probing P-glycoprotein-mediated transport activity in vivo, Chem Biol 7(5) (2000), 335-343.

[301] E. Dadachova, C. Park, N. Eberly, D. Ma, C.H. Paik and M.W. Brechbiel, In vitro and in vivo characterization of ${ }^{67} \mathrm{Ga}(3+)$ complexes with cis,cis-1,3,5-triaminocyclohexane-N,N',N"-triacetic acid derivatives, Nucl Med Biol 28(6) (2001), 695-701. 
[302] J. Schuhmacher, G. Klivenyi, S. Kaul, M. Henze, R. Matys, H. Hauser and J. Clorius, Pretargeting of human mammary carcinoma xenografts with bispecific anti-MUC1/antiGa chelate antibodies and immunoscintigraphy with PET, Nucl Med Biol 28(7) (2001), 821-828.

[303] H.M. Bigott and M.J. Welch, Technetium-94m-sestamibi: preparation and quality control for human use, in: Technectium, Rhenium and Other Metals in Chemistry and Nuclear Medicine, M. Nicoline and U. Mazzi, eds., SGEditoriali, Padova, 2002, pp. 559-561.

[304] G.L. Griffiths, D.M. Goldenberg, F. Roesch and H.J. Hansen, Radiolabeling of an anti-carcinoembryonic antigen antibody Fab' fragment (CEA-Scan) with the positron-emitting radionuclide Tc-94m, Clin Cancer Res 5(Suppl 10) (1999), $3001 \mathrm{~s}-3003 \mathrm{~s}$

[305] S.K. Zeisler and D.W. Becker, A new method for PET imaging of tumors: human serum albumin labeled with the longlived Nd-140/Pr-140 in vivo radionuclide generator, Clin Positron Imaging 2 (1999), 324

[306] F. Brady, S.K. Luthra, G.D. Brown, S. Osman, E. Aboagye, A. Saleem and P.M. Price, Radiolabelled tracers and anticancer drugs for assessment of therapeutic efficacy using PET, Curr Pharm Des 7 (2001), 1863-1892.

[307] H.D. Burns, T.G. Hamill, W.S. Eng, B. Francis, C. Fioravanti and R.E. Gibson, Positron emission tomography neuroreceptor imaging as a tool in drug discovery, research and development, Curr Opin Chem Biol 3(4) (1999), 388-394.

[308] S.R. Cherry, Fundamentals of positron emission tomography and applications in preclinical drug development, J Clin Pharmacol 41(5) (2001), 482-491.

[309] R.E. Gibson, H.D. Burns, T.G. Hamill, W.S. Eng, B.E. Francis and C. Ryan, Non-invasive radiotracer imaging as a tool for drug development, Curr Pharm Des 6(10) (2000), 973989.

[310] N. Gupta, P.M. Price and E.O. Aboagye, PET for in vivo pharmacokinetic and pharmacodynamic measurements, Eur J Cancer 38(16) (2002), 2094.

[311] J. Hietala, Ligand-receptor interactions as studied by PET: implications for drug development, Ann Med 31(6) (1999), 438-443.

[312] A.M. Paans and W. Vaalburg, Positron emission tomography in drug development and drug evaluation, Curr Pharm Des 6(16) (2000), 1583-1591.

[313] P. Price, Monitoring response to treatment in the development of anticancer drugs using PET, Nucl Med Biol 27(7) (2000), 691.

[314] A. Saleem, E.O. Aboagye and P.M. Price, In vivo monitoring of drugs using radiotracer techniques, J. Nucl Med 41 (2000), 21-39.

[315] W. Vaalburg, N.H. Hendrikse and E.F. de_Vries, Drug development, radiolabelled drugs and PET, Ann Med 31(6) (1999), 432-437.

[316] H. Anderson and P. Price, Clinical measurement of blood flow in tumours using positron emission tomography: a review, Nucl Med Commun 23(2) (2002), 131-138.

[317] D.R. Collingridge, V.A. Carroll, M. Glaser, E.O. Aboagye, S. Osman, O.C. Hutchinson, H. Barthel, S.K. Luthra, F. Brady, R. Bicknell, P. Price and A.L. Harris, The development of $\left[{ }^{124}\right.$ I]iodinated-VG76e: a novel tracer for imaging vascular endothelial growth factor in vivo using positron emission tomography, Cancer Res 62(20) (2002), 5912-5919.

[318] P. Price and T. Jones, Molecular imaging: what picture does it paint for future oncology? Drug Discov Today 7(14) (2002), 741-743.
[319] A. Saleem, J. Yap, S. Osman, F. Brady, B. Suttle, S.V. Lucas, T. Jones, P.M. Price and E.O. Aboagye, Modulation of fluorouracil tissue pharmacokinetics by eniluracil: in-vivo imaging of drug action, Lancet 355(9221) (2000), 2125-2131.

[320] G.C. Jayson, J. Zweit, A. Jackson, C. Mulatero, P. Julyan, M. Ranson, L. Broughton, J. Wagstaff, L. Hakannson, G. Groenewegen, J. Bailey, N. Smith, D. Hastings, J. Lawrance, H. Haroon, T. Ward, A.T. McGown, M. Tang, D. Levitt, S. Marreaud, F.F. Lehmann, M. Herold and H. Zwierzina, Molecular imaging and biological evaluation of HuMV833 anti-VEGF antibody: implications for trial design of antiangiogenic antibodies, J Natl Cancer Inst 94(19) (2002), 14841493

[321] A.D. Van den Abbeele, R.D. Badawi, J.-P. Cliche, M.J. Janicek, R. Tetrault, T. Spangler, A. Potter, P. Merriam, S. Silberman, S. Dimitrijevic and G.D. Demetri, ${ }^{18}$ F-FDG-PET predicts response to imatinib mesylate (Gleevec) in patients with advanced gastrointestinal stromal tumors (GIST), Proceedings of the American Society of Clinical Oncology 21 (2002), Abstract Number 1610.

[322] C.H. Kao, J.F. Hsieh, S.C. Tsai, Y.J. Ho and J.K. Lee, Quickly predicting chemotherapy response to paclitaxel-based therapy in non-small cell lung cancer by early technetium99m methoxyisobutylisonitrile chest single-photon-emission computed tomography, Clin Cancer Res 6(3) (2000), 820824.

[323] P. Price and T. Jones, Can positron emission tomography (PET) be used to detect subclinical response to cancer therapy? The EC PET Oncology Concerted Action and the EORTC PET Study Group, Eur J Cancer 31A(12) (1995), 1924-1927.

[324] A. Saleem, R.J. Harte, J.C. Matthews, S. Osman, F. Brady, S.K. Luthra, G.D. Brown, N. Bleehen, T. Connors, T. Jones, P.M. Price and E.O. Aboagye, Pharmacokinetic evaluation of $\mathrm{N}$-[2-(dimethylamino)ethyl]acridine-4-carboxamide in patients by positron emission tomography, J Clin Oncol 19(5) (2001), 1421-1429.

[325] K. Spaepen, S. Stroobants, P. Dupont, S. Van Steenweghen, J. Thomas, P. Vandenberghe, L. Vanuytsel, G. Bormans, J. Balzarini, C. De Wolf Peeters, L. Mortelmans and G. Verhoef, Prognostic value of positron emission tomography (PET) with fluorine-18 fluorodeoxyglucose ( $\left.\left[{ }^{18} \mathrm{~F}\right] \mathrm{FDG}\right)$ after first-line chemotherapy in non-Hodgkin's lymphoma: is $\left[{ }^{18} \mathrm{~F}\right] \mathrm{FDG}-\mathrm{PET}$ a valid alternative to conventional diagnostic methods? J Clin Oncol 19 (2001), 414-419.

[326] P. Tsatalpas, B. Beuthien-Baumann, J. Kropp, A. Manseck, C. Tiepolt, O.W. Hakenberg, W. Burchert, W.G. Franke and M.P. Wirth, Diagnostic value of 18F-FDG positron emission tomography for detection and treatment control of malignant germ cell tumors, Urol Int 68(3) (2002), 157-163.

[327] A.T. van Oosterom, I. Judson, J. Verweij, S. Stroobants, E. Donato di Paola, S. Dimitrijevic, M. Martens, A. Webb, R. Sciot, M. Van Glabbeke, S. Silberman and O.S. Nielsen, Safety and efficacy of imatinib (STI571) in metastatic gastrointestinal stromal tumours: a phase I study, Lancet 358(9291) (2001), 1421-1423.

[328] A.G. Vlassenko, B. Thiessen, B.J. Beattie, M.G. Malkin and R.G. Blasberg, Evaluation of early response to SU101 targetbased therapy in patients with recurrent supratentorial malignant gliomas using FDG PET and Gd-DTPA MRI, $\mathrm{J} \mathrm{Neu-}$ rooncol 46(3) (2000), 249-259.

[329] A. Dirlik, Z. Burak, T. Goksel, R. Erinc, H. Karakus, Z. Ozcan, A. Veral and M. Ozhan, The role of Tc-99m sestamibi 
imaging in predicting clinical response to chemotherapy in lung cancer, Ann Nucl Med 16(2) (2002), 103-108.

[330] A. Kao, S.C. Shiun, N.Y. Hsu, S.S. Sun, C.C. Lee and C.C. Lin, Technetium-99m methoxyisobutylisonitrile chest imaging for small-cell lung cancer. Relationship to chemotherapy response (six courses of combination of cisplatin and etoposide) and p-glycoprotein or multidrug resistance related protein expression, Ann Oncol 12(11) (2001), 1561-1566.

[331] C.H. Kao, Y.J. Ho, Y.Y. Shen and J.K. Lee, Evaluation of chemotherapy response in patients with small cell lung cancer using technetium-99m-tetrofosmin, Anticancer Res 19(3B), 2311-2315.

[332] L. Kostakoglu, Noninvasive detection of multidrug resistance in patients with hematological malignancies: are we there yet? Nucl Med Commun 2(4) (2002), 242-248.

[333] Y.C. Shiau, S.C. Tsai, J.J. Wang, Y.J. Ho, S.T. Ho and C.H. Kao, To predict chemotherapy response using technetium$99 \mathrm{~m}$ tetrofosmin and compare with p-glycoprotein and multidrug resistance related protein-1 expression in patients with untreated small cell lung cancer, Cancer Lett 169(2) (2001), 181-188.

[334] P.H. Elsinga, E.J. Franssen, N.H. Hendrikse, L. Fluks,
A.M. Weemaes, W.T. van der Graaf, E.G. de Vries, G.M Visser and W. Vaalburg, Carbon-11-labeled daunorubicin and verapamil for probing P-glycoprotein in tumors with PET, $J$ Nucl Med 37 (1996), 1571-1575.

[335] E. Eriks Fluks, P.H. Elsinga, N.H. Hendrikse, E.J. Franssen and W. Vaalburg, Enzymatic synthesis of [4-methoxy11C]daunorubicin for functional imaging of P-glycoprotein with PET, Appl Radiat Isot 49 (1998), 811-813.

[336] A.B. Packard, J.F. Kronauge, E. Barbarics, S. Kiani and S.T. Treves, Synthesis and biodistribution of a lipophilic ${ }^{64} \mathrm{Cu}-$ labeled monocationic copper(II) complex, Nucl Med Biol 29(3) (2002), 289-294.

[337] N. Hendrikse and W. Vaalburg, Dynamics of multidrug resistance: P-glycoprotein analyses with positron emission tomography, Methods 27(3) (2002), 228.

[338] N.H. Hendrikse, Monitoring interactions at ATP-dependent drug efflux pumps, Curr Pharm Des 6(16) (2000), 16531668.

[339] N.H. Hendrikse, E.J. Franssen, W.T. van der Graaf, W. Vaalburg and E.G. de Vries, Visualization of multidrug resistance in vivo, Eur J Nucl Med 26(3) (1999), 283-293. 


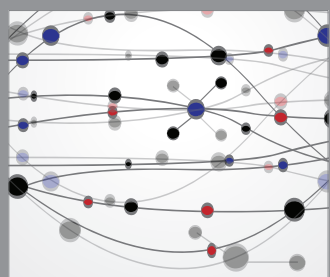

The Scientific World Journal
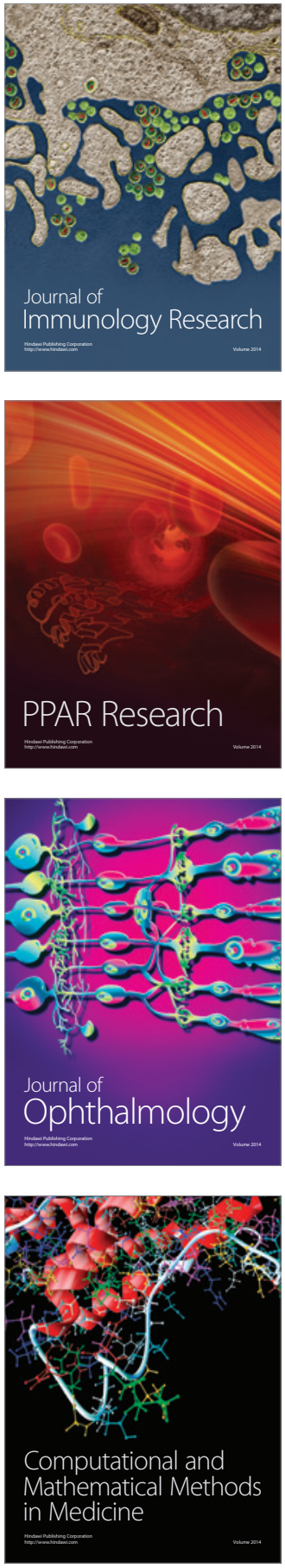

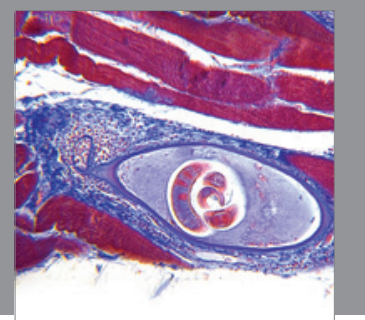

Gastroenterology

Research and Practice
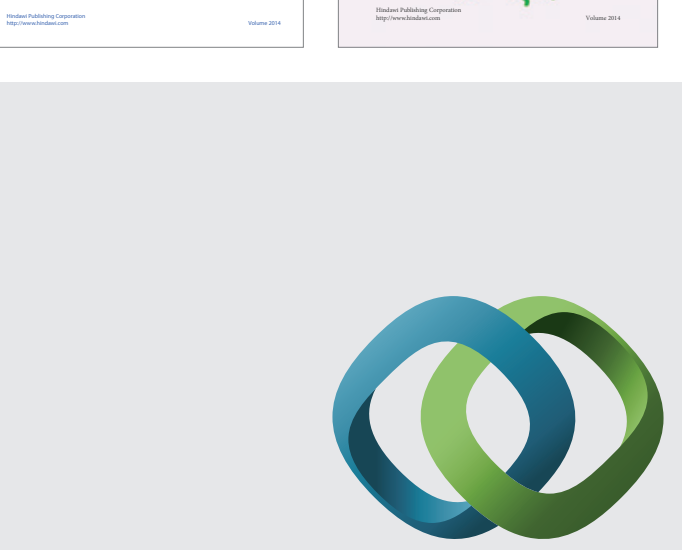

\section{Hindawi}

Submit your manuscripts at

http://www.hindawi.com
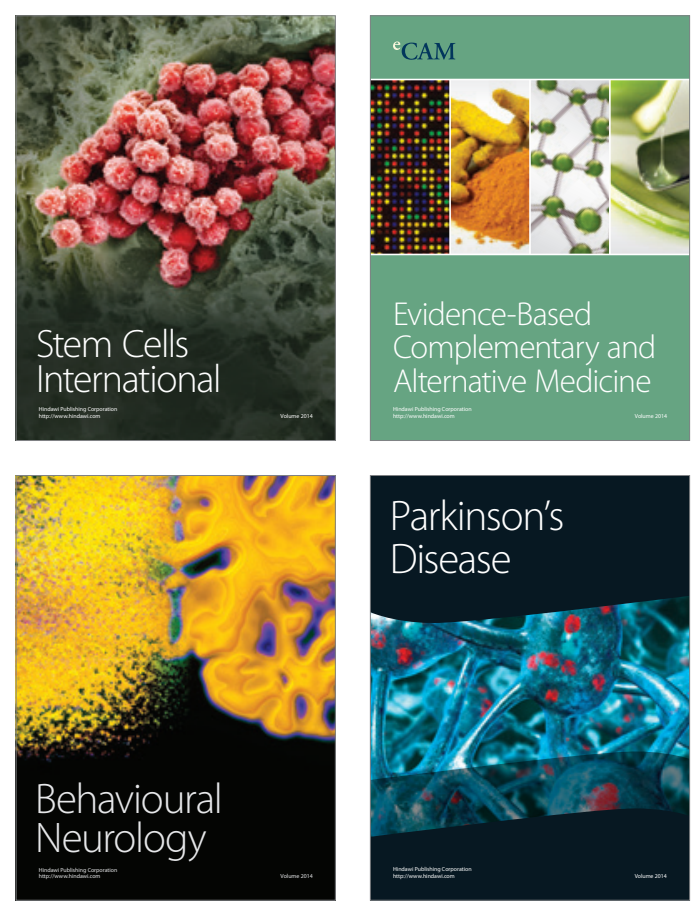

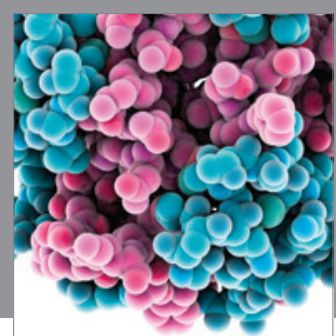

Journal of
Diabetes Research

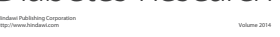

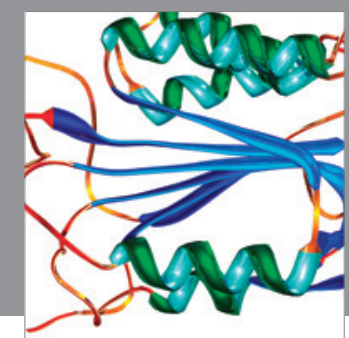

Disease Markers
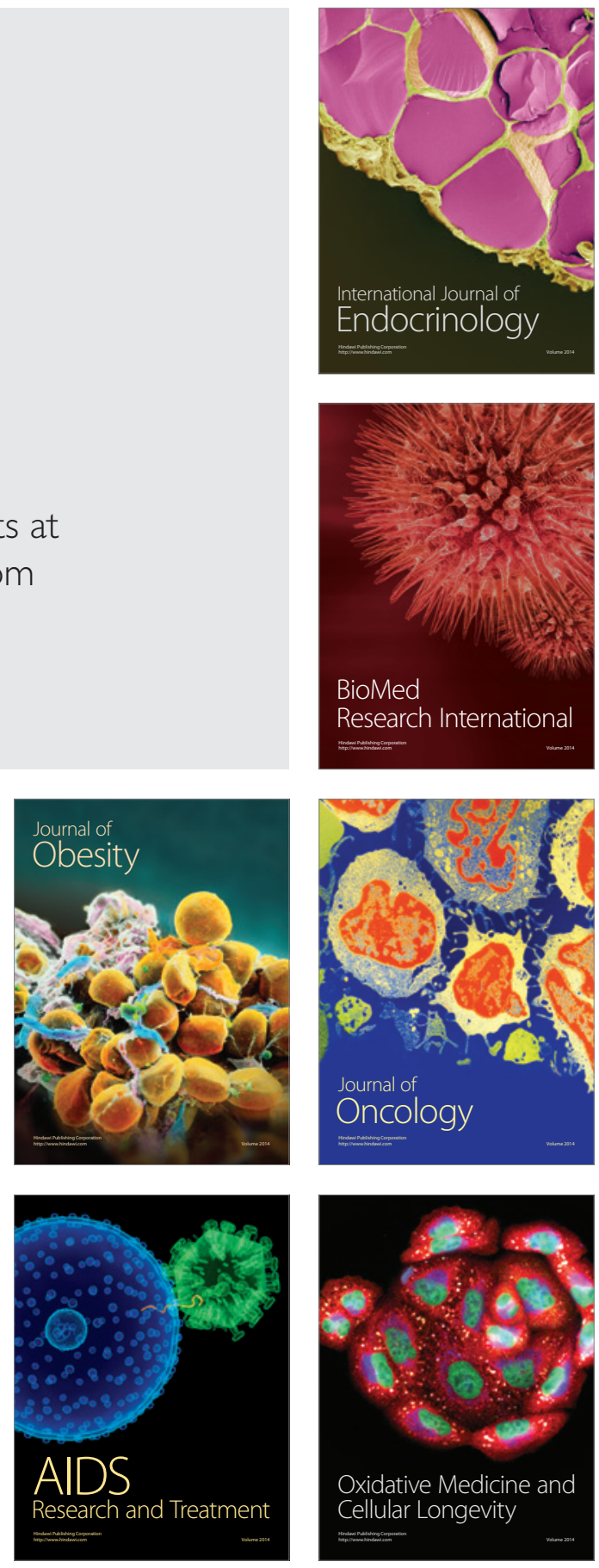